\title{
Simulação Social
}

Helder Coelho

MAS BioISI, Colégio Doutoral Mente-Cérebro, Universidade de Lisboa

hmcoelho@ciencias.ulisboa.pt

\section{CITAÇÃO \\ Coelho, H. (2018) \\ Simulação Social, \\ Rev. Ciência Elem., V6 (04):076. \\ doi.org/10.24927/rce2018.076}

\section{EDITOR}

José Ferreira Gomes,

Universidade do Porto

\section{EDITOR CONVIDADO}

Jorge Manuel Canhoto,

Universidade de Coimbra

\section{RECEBIDO EM}

22 de outubro de 2018

\section{ACEITE EM}

02 de novembro de 2018

\section{PUBLICADO EM}

04 de dezembro de 2018

\section{COPYRIGHT}

(C) Casa das Ciências 2018.

Este artigo é de acesso livre, distribuído sob licença Creative Commons com a designação CC-BY-NC-SA 4.0, que permite a utilização e a partilha para fins não comerciais, desde que citado o autor e a fonte original do artigo.

rce.casadasciencias.org

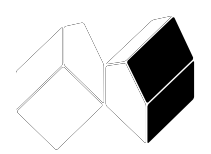

A Simulação Social refere-se ao uso de métodos computacionais e analíticos, baseados na Ciência da Complexidade e na Ciência dos Dados e, ainda, no rigor matemático para melhorar a compreensão dos sistemas sociais (por exemplo, alguns problemas nacionais, como a mobilidade urbana e os transportes, a crise financeira global, a saúde pública, ou a educação). Nalguns casos, recorre-se à interseção de disciplinas, como a Ciência da Computação, Inteligência Artificial, Sociologia, Filosofia, Física Aplicada, Investigação Operacional e Estatística. A inter e multidisciplinaridade é frequente e isso impõe uma flexibilidade mental muito apreciada para cruzar saberes e descobrir soluções.

Quando se fala em complexidade queremos dizer que estes problemas nascem associados a múltiplos aspetos e componentes, e a inúmeras relações e interações. Por exemplo, as eleições num país são hoje objeto da exploração de redes sociais (e do aplicativo WhatsApp) via Internet, do recurso a notícias falsas, além da atividade habitual dos media correntes (jornais, rádio, televisão). Daqui resultam padrões de comportamentos humanos coletivos em grande escala e com uma relevância política assinalável.

Peguemos no caso das manifestações de rua, que por vezes envolvem a violência, e que são habituais em muitos países (França, Ucrânia, Reino Unido, Espanha, Itália, Egito). Na última década, as do Cairo ficaram famosas por estarem associadas à chamada Primavera Árabe, num conjunto de países do norte de África (Tunísia, Argélia e Marrocos). Em geral, recorre-se às reportagens em vídeo (televisão e rádio), às entrevistas, ou aos inquéritos de rua. Podemos também estudar estes conflitos sociais, graças à simulação social e às redes, os quais são confrontações entre atores públicos, um tipo de lutas pelo poder e a agência numa sociedade.

No caso do recurso à simulação social, baseada em computador, e quando existe complexidade, podemos recorrer à modelação baseada em agentes inteligentes (vulgo Agent Based Modeling ou ABM), um tópico da Inteligência Artificial, e a ferramentas computacionais simples, como o NetLogo (disponíveis livremente na Internet). Um agente é qualquer entidade que percebe o ambiente envolvente (através de sensores) e que age através de atuadores. Deve ser autónomo, isto é, decidir por si próprio (em função dos estímulos recebidos da envolvente) de forma a alcançar os seus objetivos, e possuir algum mecanismo de cognição. Isso permitirá a construção rápida de demonstrações e protótipos, a visualização das interações e o controlo de vários parâmetros num cenário simples. A dinâmica dos padrões ajuda a pensar e sugere ainda várias outras experiências que se podem depois fazer. 0 modelo de agentes escolhido consagra o círculo virtuoso de observar-planear-comportar, com estados internos e decisão.

A Simulação é uma área popular neste momento em muitas conferências científicas, ao longo do ano, inclusive em Portugal, com uma comunidade científica muito ativa em vários 
pontos do país.

Quando se enfrenta um conflito social, seja ele uma simples rixa de rua ou um violento confronto numa escadaria, a complexidade surge para nos alertar sobre os modos como a natureza humana se revela através de sentimentos. Sabemos que nem sempre os estados mentais são triviais, os dos seres humanos e os dos agentes artificiais, e que existe sempre uma complicação que emerge dos comportamentos por causa de emoções descontroladas, quase sempre por causas difíceis de explicar.

Se saltarmos da vida humana para os mundos virtuais e artificiais, os agentes podem não ter corpo e muitas vezes não necessitam mesmo de caraterísticas sociais e emocionais (caso de se adotarem modelos só com dois estados mentais, crenças e objetivos). Esta simplificação pode condicionar as atividades de pensar, refletir e antever as correntes de causalidade, de gerar os efeitos e do que virá a seguir no futuro. E isso pode constituir um enorme desafio e, por vezes, opta-se por amplificar essas habilidades, obtendo-se uma ajuda para a meditação da complexidade.

A plataforma ProtestLab é uma instalação laboratorial realizada em NetLogo, usando várias janelas de observação (variáveis) e contagem de aspetos, que permite realizar experiências sociais e complexas (em 2D e 3D). Os agentes não são sofisticados e não necessitam de modelos pesados (tipo Beliefs-Desires-Intentions ou Agent_Zero), respondendo bem a um leque de perguntas sofisticadas ( 0 que engendrou a violência e porquê? Como e porquê se agruparam os agentes para atacarem os outros?).

Podemos ter pelo menos 1000 agentes, com tipos e personalidades diferentes (jornalistas de televisão para obter imagens de choques, polícias de motim, comando policial e manifestantes variados, desde os passivos até aos mais ativos e conflituosos) e uma condição humana variada (líderes, seguidores), num cenário pré-determinado em Lisboa (manifestação pela rua de São Bento abaixo, desde o Largo do Rato até às escadas da Assembleia da República (AR)), com saídas para a calçada da Estrela, avenida de D. Carlos I e rua de São Bento. 0 cenário de violência poderá surgir ao longo do trajeto da manifestação, entre os assistentes colocados nos passeios e o grosso dos manifestantes e na escadaria quando alguns participantes pretenderem subir as escadas, à força, e invadir a AR.

0 realismo poderá ser restringido pelo número total de agentes envolvidos. 0 escalonamento até $2000,3000,5000$ ou 10000 indivíduos poderá ser difícil num computador portátil (mas não num supercomputador), considerando a sua capacidade normal de armazenamento de dados e mesmo o seu poder de processamento. Esta atualização da dimensão da massa de manifestantes evoca a questão central do realismo e é material para uma avaliação mais ponderada sobre a verosimilhança dos resulatados obtidos. 0 recurso a imagens de outras manifestações (Madrid, Kiev, Londres, Cairo) permitirá um julgamento mais rigoroso, sobretudo se o contexto dos embates estiver acessível.

A ausência de agentes mais sofisticados (sem pulsões e laços sociais) também reduzirá o realismo da experimentação, embora se possa optar por 3 dimensões, melhorando a qualidade dos choques, o efeito visual mais espetacular e a natureza social do sistema. No entanto, a expressão de toda a paleta emocional de criaturas não será completamente revelada nos agentes artificiais e em escala microscópica. De igual modo, o efeito macro não será totalmente atingido, embora não seja pobre, e obter-se-á algo francamente interessante para 
refletir com o tempo e no espaço. Nomeadamente, os fenómenos complexos serão captados e compreender-se-á que estamos perante algo sofisticado do ponto de vista de um sistema social dinâmico e adaptativo. A temporalidade deverá ser analisada com algum cuidado, pois o efeito tempo poderá tornar a análise dos eventos mais acessível. Se optar por recorrer a um mecanismo de previsão do futuro (com aprendizagem e redes neuronais convolutas), o comando da polícia de choque reagirá com melhores estratégias para atrasar o progresso dos invasores, e, eventualmente, desviar parte dos manifestantes para as saídas.

Simulation AR5
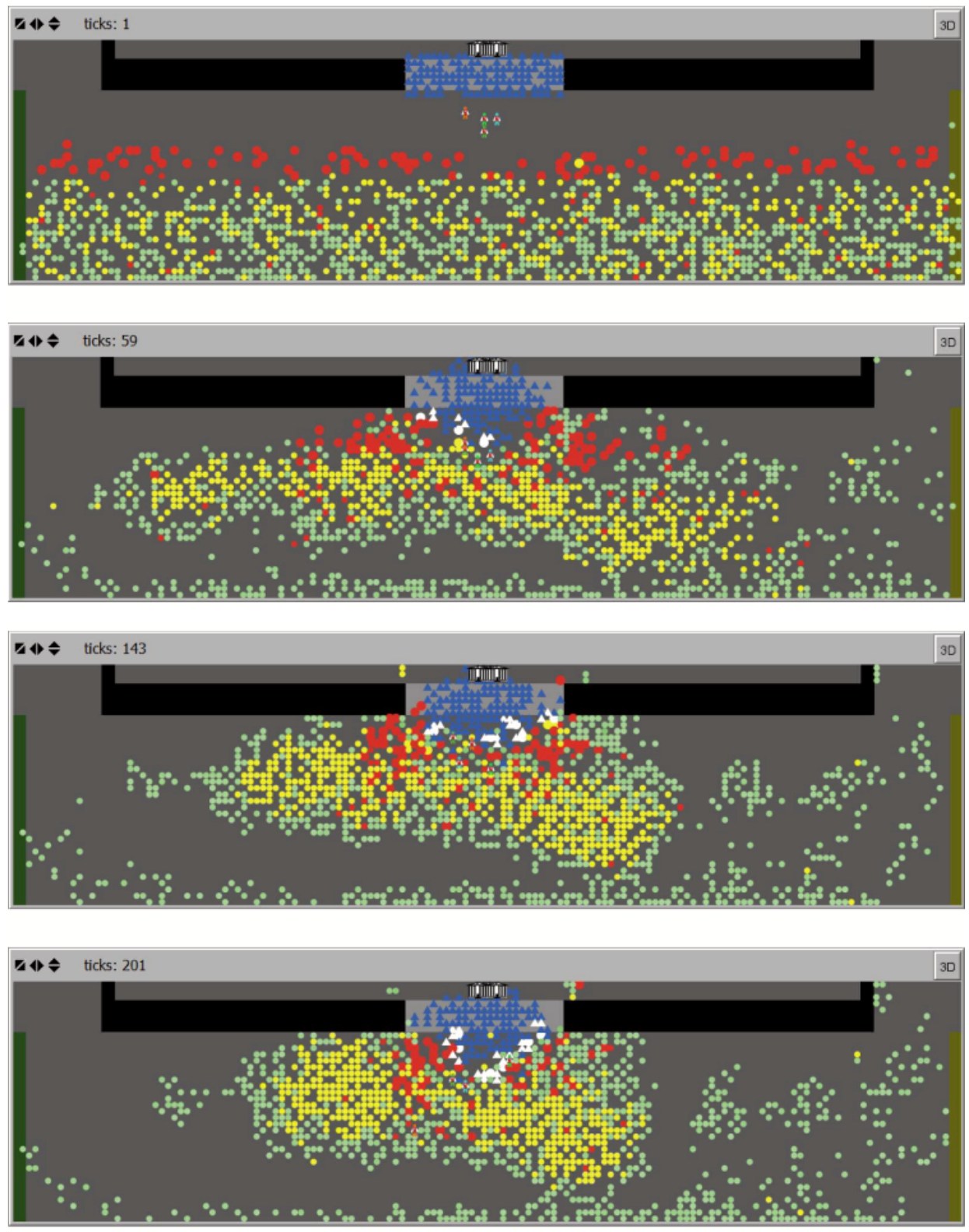

FIGURA 1. Protestos na rua: representação em 2D dos manifestantes, polícias e jornalistas junto às escadarias da Assembleia da República, em Lisboa. (Polícias a azul, manifestantes violentos a vermelho, manifestantes em luta a branco, manifestantes ativos a amarelo, manifestantes normais a verde, jornalistas (TV) figuras). Apresentam-se 4 instantâneos da simulação, o ponto de partida e o resultado depois de 59, 143 e 201 passos. Pode observar-se a dinâmica dos vários tipos de agentes considerados na simulação. 
A construção e montagem artificial permitirá deixar antever um estado natural, submetido a normas e restrições, onde uma lógica de ações e reações ao longo do tempo será visível. As circunstâncias marcadas pela simulação poderão aproximar-se do realismo, possibilitando o acompanhamento das dinâmicas dos grupos, das adaptações e da evolução dos choques. As relações de coordenação e colaboração ajudarão a isolar as multitudes e a focar os agrupamentos. A transparência das escalas é razoável, com destaque para a atuação das lideranças das duas principais frentes (polícias versus protestantes) e com o acompanhamento dos media. 0 recurso a redes sociais e a notícias falsas também são vulgares e devem ser consideradas (transversalidade), com algum cuidado, pois provocam situações inesperadas (veja-se o caso do Brasil em 2018).

A ilusão da profundidade está também presente e acompanha o desenrolar dos acontecimentos, cuja imbricação pode ser horizontal ou vertical, em camadas. Sobretudo, a transparência das contas a ajustar é visível e não há desencanto, o que garante um efeito voyeur de quem acompanha de fora o desenlace final. Será interessante sublinhar como as organizações de dependência (em coletivos) poderão se comportar e que consequências provocarão no desenrolar de outros eventos.

A falta de corpos, nos agentes, não impede a abstração da dança entre os intervenientes, embora a falta de paixões não permita qualquer tipo de empatia ou agudização da cólera e da raiva (procura de possíveis vítimas tipo bodes expiatórios). E, a curiosidade mantém-se durante todo o tempo, não afastando o efeito imaginário de quem se envolve ou já participou em demonstrações de repúdio.

Quem assiste às sessões de demonstração do ProtestLab completa os detalhes do mundo físico através da sua própria imaginação e experiência, e não se ofende com a simplicidade das mentes das personagens criadas. Nestas experiências (em ciências sociais e políticas, nas Forças Armadas, GNR ou na PSP) são os padrões a terem uma grande capacidade de interrogar os observadores. E com a acessibilidade ao mecanismo do reconhecimento de padrões criam-se possíveis complicações.

A validação dos modelos baseados em agentes em simulação social depende muito das coleções de dados disponíveis (data sets), em particular a partir dos levantamentos (fotográficos, vídeos, filmes de televisão, entrevistas, ou inquéritos no local) realizados durante as próprias manifestações e ainda dos comportamentos dos agentes artificiais. Deste modo, podem-se comparar os padrões, entre os produzidos pelos modelos para a simulação e os reais vividos nos locais onde se realizaram as demonstrações. Um tal tipo de comparação exige muito trabalho complementar, sobretudo ao nível sociológico. A sofisticação do caráter dos agentes sugerirá o envolvimento da análise psicológica e sociológica.

A validação pode ser quantitativa (número de manifestantes muito ativos, aprisionados, ou capazes de atrair os media) e qualitativa (orientada pelos movimentos dos padrões, níveis de violência, e recurso a armas), e, assim, cobrir vários aspetos, dimensões e escalas. Nalguns casos, é admitido ser impossível qualquer validação dos modelos, ou dos mecanismos subjacentes. Além dos ABMs focados nos participantes, podem também existir outros modelos exploratórios e auxiliares, por exemplo focados em previsões, que poderão ajudar a esclarecer outros tipos de situações.

Interessa ainda lembrar que a instalação do ProtestLab se destina também a ajudar a 
ação reflexiva, recriando simulacros (ilusões) e libertando um tipo de narrativa ficcional (como nos jogos de computador, onde se confunde amiúde o real e o imaginário, de maneira a interrogar ambas as possibilidades e a alcançar alvos possíveis).

Finalmente, hoje em dia, para os investigadores de comunicação social (media sobre eleições, referendos) interessa explicar os fenómenos emergentes e os coletivos, como a dinâmica da opinião pública, a atenção coletiva e a ação coletiva. Isto implica aceder a níveis de análise, das ações individuais para as interações de grupo e as dinâmicas de agregados. Muitas das teorias de comunicação mais antigas, como a da espiral do silêncio ou da cultivação (efeitos de longo prazo da televisão), oferecem intuições sobre como estes níveis de análise podem ser integrados, embora sejam difíceis de testar empiricamente.

\section{REFERÊNCIAS}

${ }^{1}$ EDMONDS, B., Different Modelling Purposes, in Simulating Social Complexity: A Handbook, Bruce Edmonds e Ruth Meyer (Eds.), pp. 39-58, Springer International Publishing, 2017.

${ }^{2}$ COELHO, H., Living with Digital Worlds: A Personal View of Artificial Intelligence, Chapter 2 of Current and Future Developments in Artificial Intelligence, Vol. 1, pp. 60-93, Faria Nassiri-Mofakham, F. (Ed.), 9781681085029-17-1401, e-Book, Bentham, 2017.

${ }^{3}$ HASSAN, S. et al., Asking the Oracle: Introducing Forecasting Principles into Agent-Based Modelling, Journal of Artificial Societies and Social Simulation 16 (3), 2013.

${ }^{4}$ LEMOS, C. M., On Agent-Based Modelling of Large Scale Conflict Against a Central Authority: from Mechanisms to Complex Behaviour, Tese de Doutoramento, FCUL e ISCTE, Dezembro, 2016.

${ }^{5}$ LEMOS, C. M., et al., ProtestLab - A Computational Laboratory for Studying Street Protests, in Nemiche, M. and Essaaidi, M. (Eds.), Advances in Complex Societal, Environmental and Engineered Systems, Non Linear Systems and Complexity Series, pp. 3-29, Springer, 2017.

${ }^{6}$ LOPES, F. \& COELHO, H., (Eds.) Electricity Markets with Increasing Levels of Renewable Generation: Structure, Operation, Agent-based Simulation and Emerging Designs, Springer, Series Studies in Systems, Decision and Control, Volume 86359367, Março, 2018.

${ }^{7}$ WOOLDRIDGE, M., Artificial Intelligence: Everything you need to know about the coming AI, Ladybird Expert Series, Michael Joseph, 2018 


\section{CITAÇÃo}

Duarte, L.V. (2018)

Tesouros Geológicos da Jordânia,

Rev. Ciência Elem., V6 (04):078.

doi.org/10.24927/rce2018.078

\section{EDITOR}

José Ferreira Gomes,

Universidade do Porto

\section{EDITOR CONVIDADO}

Jorge Manuel Canhoto,

Universidade de Coimbra

\section{RECEBIDO EM}

15 de março de 2018

\section{ACEITE EM}

15 de março de 2018

\section{PUBLICADO EM}

04 de dezembro de 2018

\section{COPYRIGHT}

(C) Casa das Ciências 2018.

Este artigo é de acesso livre, distribuído sob licença Creative Commons com a designação CC-BY-NC-SA 4.0, que permite a utilização e a partilha para fins não comerciais, desde que citado o autor e a fonte original do artigo.

rce.casadasciencias.org

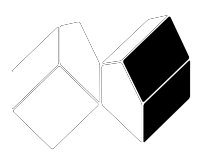

\section{$-$ \\ Tesouros Geológicos da Jordânia}

\author{
Luís Vítor Duarte \\ MARE- Departamento de Ciências da Terra da Universidade de Coimbra \\ lduarte@dct.uc.pt
}

A Jordânia é um território com uma história e um património construído riquíssimos, e onde o termo "tesouro" faz todo o sentido. Mesmo em termos geológicos. Para ganhar um "apetite" adicional, houve a necessidade de rever a longa-metragem Lawrence da Arábia, que sustenta este novo percurso por mais um território despido de vegetação. 0 terceiro capítulo da série Indiana Jones, A Última Cruzada, estreado em 1989, também nos ajuda a orientar naquele território, preparando os nossos olhos para o imenso património histórico e geológico da Jordânia, que só resta ser contemplado in situ. Nesta viagem, a fasquia é bem alta, e fica difícil optar por onde começar: Wadi Rum e Petra, dois sítios classificados internacionalmente pela UNESCO. E dois espaços de água salgada: o Golfo de Aqaba e o Mar Morto! Paisagens com rochas muito antigas e exemplos de fenómenos geológicos que nos contam a história mais recente do nosso planeta.

Começamos pelo Wadi Rum, o extenso e inigualável deserto de cor vermelha, com os seus penhascos rochosos, aqui e ali esculpidos com a imagem do oficial britânico E.T. Lawrence, o Lawrence da Revolta Árabe, o grande mote cinematográfico desta viagem e intensamente filmado neste local. Quase no limite com a Arábia Saudita, na extremidade sul da Jordânia, abundam neste ambiente desértico sedimentos de cor avermelhada, moldados pelos agentes eólicos, de onde sobressaem inselbergues ${ }^{1}$ (conceito que abrange, por exemplo, o Pão de Açucar no Rio de Janeiro, ou o castelo e grande parte da vila que viu nascer Pedro Álvares Cabral), geralmente compostos na sua base por rochas granitoides do designado Complexo de Aqaba do Proterozoico Superior ${ }^{2}$. Assente sobre esta unidade, em inconformidade, ocorre uma sucessão estratigráfica siliciclástica, o Grupo Ram (decomposto em várias formações), composta por arenitos e siltitos, sendo a base localmente mais conglomerática e de cor avermelhada (FIGURA 1). Dominando grande parte das referidas morfologias, estes sedimentos de origem essencialmente fluvial, onde não se descarta alguma influência marinha, são datados do Paleozoico, concretamente dos seus dois primeiros períodos, Câmbrico e Ordovícico ${ }^{3}$. Algumas rochas mostram uma particular abundância em feldspatos (arcoses), o que sugere que este território, nos primórdios do Fanerozoico, há cerca de 500 milhões de anos, era algo diferente do atual, onde a água doce não faltava, com a sedimentação a ocorrer muito próxima da área mãe dos referidos sedimentos ${ }^{3}$. 


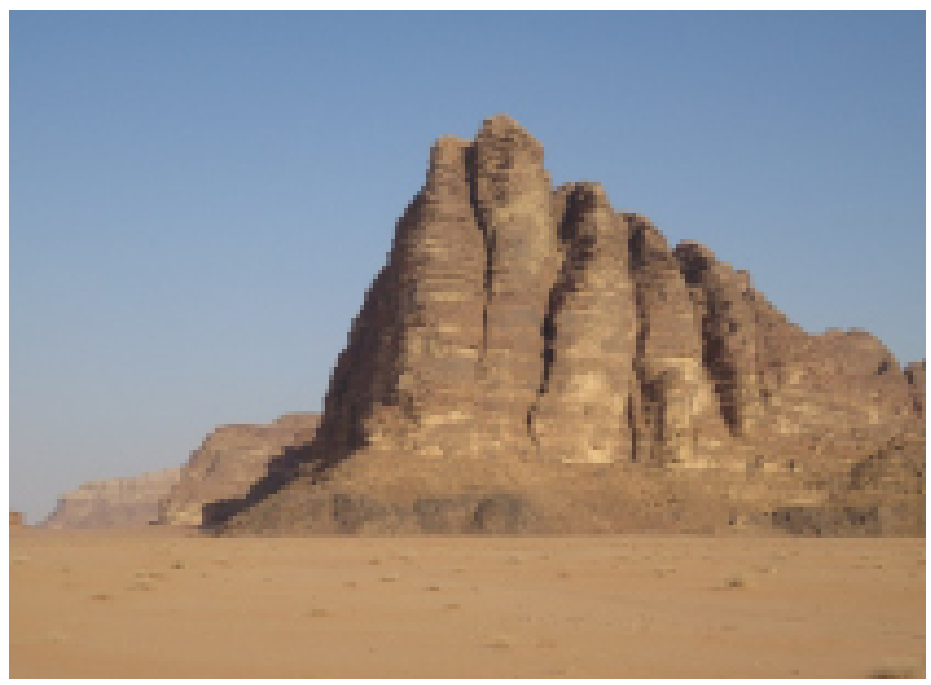

FIGURA 1. A imagem de entrada em Wadi Rum, a seguir ao Centro de Visitantes: as "seven pillars of wisdom". Onde se nota muito bem a inconformidade entre as rochas ígneas proterozoicas do Complexo de Aqaba (na base; aqui com uma cor escura intensa devido à ocorrência de rochas básicas) com rochas arenosas, estratificadas, do Paleozoico Inferior (Grupo Ram).

Distanciada cerca de 100 quilómetros de Wadi Rum, mas algo idêntica quanto ao seu contexto geológico, litologica e temporalmente falando, deparamo-nos com aquela que é considerada a segunda das novas Sete Maravilhas do Mundo: a cidade nabateia de Petra. Um hino à arte e arquitetura! Com afloramentos de arenitos e rochas afins, do Paleozoico Inferior, intensamente esculpidas no mais ínfimo pormenor estético, desde o desfiladeiro, estreito, longo e sinuoso (Siq), que conflui no símbolo mais globalizado de Petra, o Al-Khazneh ("tesouro") (FIGURA 2), até às múltiplas fachadas que compõem este síto arqueológico, interminável e diverso, capaz de nos deixar completamente rendidos. 0 enquadramento ideal para Harrison Ford (o Indiana Jones) e o seu fictício pai, Sean Connery, protagonizarem a alucinante busca do Cálice Sagrado. Do ponto de vista geomorfológico, é particularmente interessante uma visão aérea deste espaço, que nos permite perceber melhor o lado escondido onde se instalou esta cidade e que se aproveitou dos intensos fenómenos de erosão ocorridos ao longo dos últimos milénios. Curiosamente, uma cidade instalada nas mesmas unidades que afloram em Wadi Rum. No caso, com arenitos mais quartzosos, com belíssimas estruturas entrecruzadas (FIGURA 3), a testemunharem uma continuidade da ação fluvial então reinante nesta porção do atual Médio Oriente, embora com maior influência marinha relativamente aos registos no "deserto vermelho" 3 .

De repente, vem à memória os Dez Mandamentos de Cecil de Mille, de Moisés, e da "abertura" do Mar Vermelho. Ao que se saiba, não filmado na Jordânia. É que muito próximo de Wadi Rum surge o Golfo de Aqaba, a "ramificação" direita do Mar Vermelho, separada do Golfo do Suez pelo "bíblico" Monte Sinai. Seguramente, um dos recortes morfológicos da Terra visto do Espaço que chama particular atenção. E que tem a necessária explicação geológica. Basta centrar-nos no Ciclo de Wilson que, associado à teoria da tectónica de placas, exemplifica a génese, evolução e morte de um oceano. 


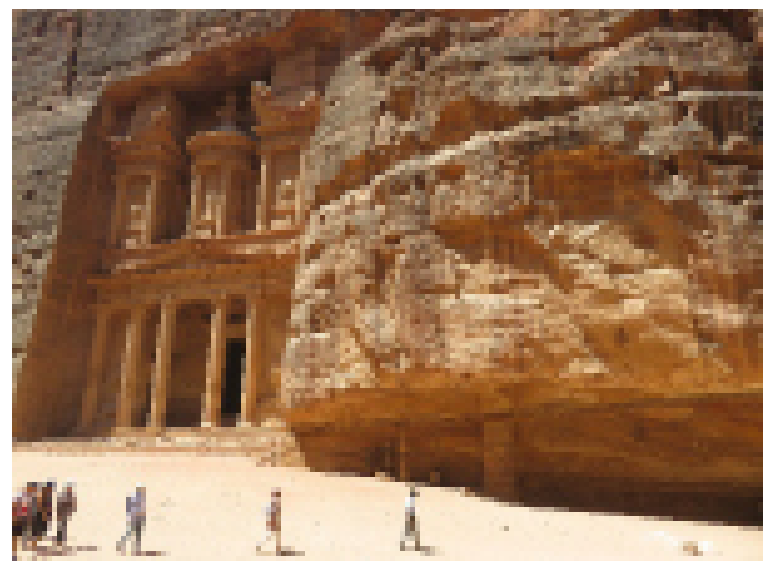

FIGURA 2. O Al-Khazneh, o grande ícone de Petra, esculpido em rochas arenosas do Paleozoico Inferior (Grupo Ram). Lateralmente à fachada nota-se claramente a estratificação das rochas.

Tendo sempre por base o princípio do Uniformitarismo, neste ciclo, o Mar Vermelho exemplifica precisamente a fase embrionária de um oceano (a "Fase Mar Vermelho"), com direito a rifte médio oceânico, de natureza basáltica. Uma história complexa de atividade magmática recorrente e diferenciada ${ }^{4}$ e que separa hoje as placas arábica e africana. Neste contexto, o Golfo de Aqaba não é mais do que o efeito de uma falha transformante, prolongando-se para norte, pelo Mar Morto e pelo não menos bíblico vale do rio Jordão.

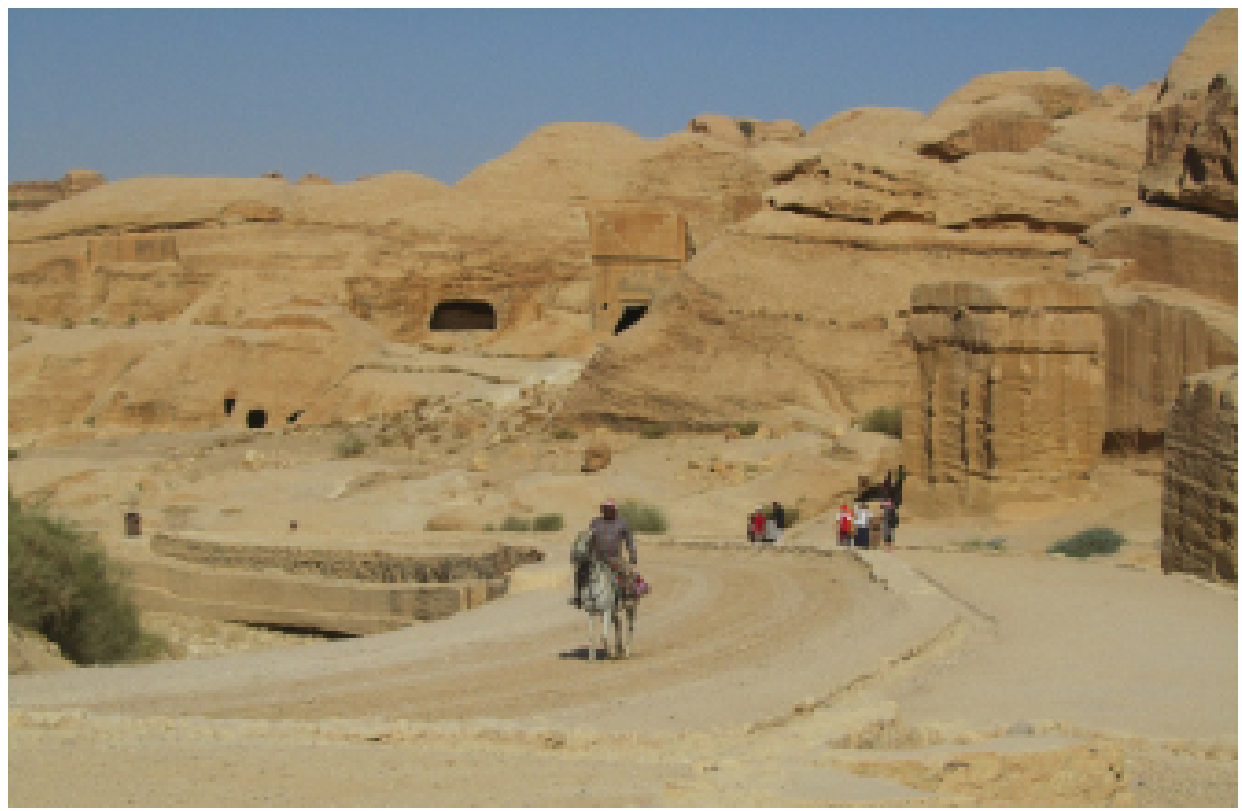

FIGURA 3. Corpos sedimentares da unidade Disi Sandstone (uma das formações do Grupo Ram que mostra a transição do Câmbrico ao Ordovícico) aflorante em Petra, nas imediações do Túmulo do Obelisco. Entre as diversas esculturas exibidas em arenitos de cor cinzenta-esbranquiçada abundam estruturas entrecruzadas, resultantes de ação fluvial ao tempo da sua génese.

Independentemente deste enquadramento, a viagem de Wadi Rum para Aqaba é um dos melhores espetáculos que se podem vivenciar em termos geológicos. Aqui, as rochas 
granitoides, proterozoicas, do Complexo de Aqaba, o tal que aflora na base rochosa de Wadi Rum, encontram-se intensamente recortadas por diques magmáticos de diversas composições mineralógicas e geoquímicas ${ }^{2}$ (FIGURA 4). Apesar de ser extremamente fácil identificar algumas das múltiplas paisagens de Wadi Rum (inselbergues, dunas, estratos erodidos, etc...) no Lawrence da Arábia de David Lean, o mesmo não acontece com a passagem cinematográfica da chegada - e consequente conquista aos turcos - a Aqaba. As pretensas montanhas de Aqaba estão lá, no filme, mas falta a espetacularidade dos diques magmáticos. Certamente, um dos melhores "livros" abertos, com este tipo de corpos de natureza ígnea.

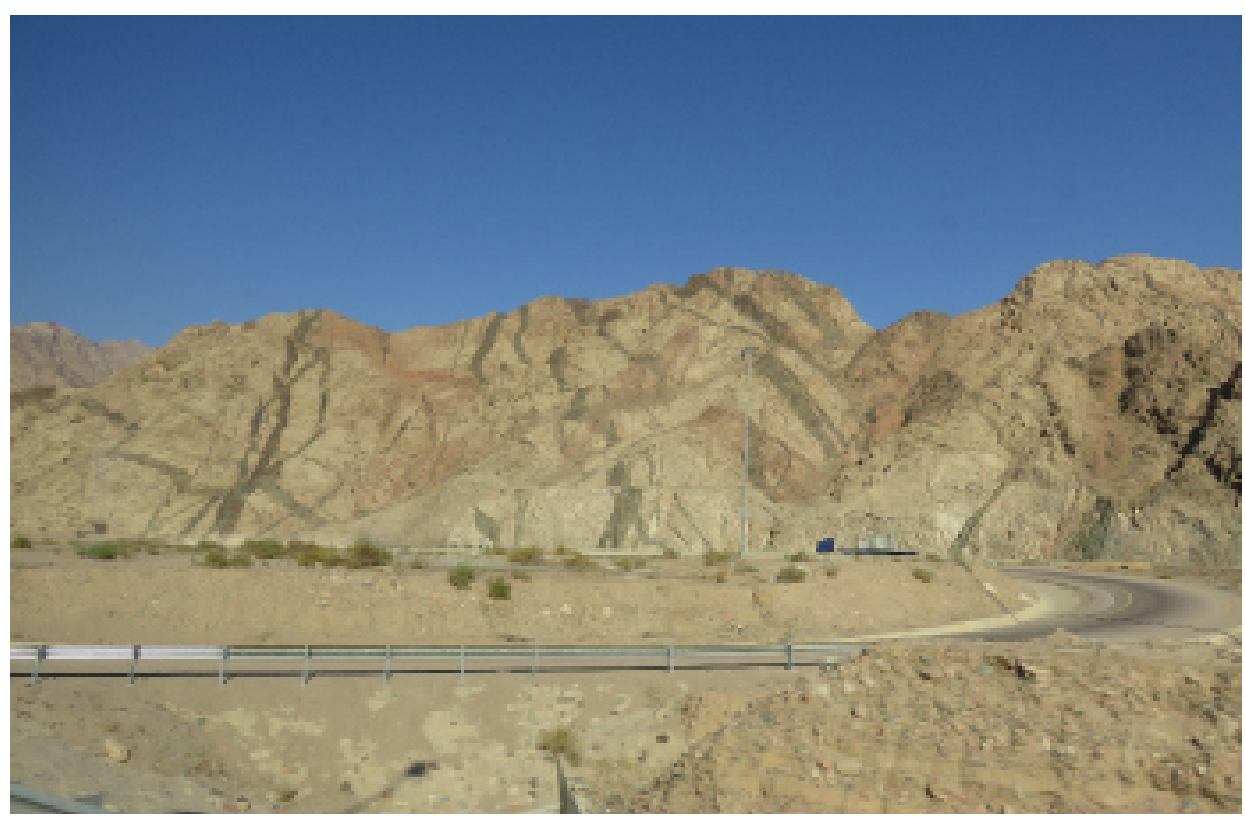

FIGURA 4. Rochas granitoides do Complexo de Aqaba densamente recortadas por filões de rocha básica. Estrada no 80, perto de Aqaba.

0 percurso ao longo do Wadi Araba, para norte de Aqaba, onde se desenha uma das mais problemáticas fronteiras políticas do mundo atual, permite-nos assomar ao mítico Mar Morto. Que, inevitavelmente, teria de ser o último sítio geológico selecionado. Por duas razões: a primeira delas, por uma questão de história geológica. Dos quatro lugares visitados, este é o que ilustra a evolução geológica mais recente, enquadrada por rochas do Cenozoico e testemunhada pela diminuição anual, gritante, do seu nível de água. A segunda, porque é o sítio ideal para culminar esta visita, experimentando os efeitos da elevada densidade da água deste cada vez mais reduzido lago hipersalino (cerca de $28 \%$ de sal dissolvido, perto de 7 vezes superior à concentração média dos oceanos) ${ }^{5}$, cuja temperatura dá a sensação de um "caldo". Resultante do clima tórrido e árido, da quase ausência de água doce que anteriormente provinha do rio Jordão, o fenómeno de evaporação é máximo. Estamos só no ponto da superfície terrestre mais baixo do Planeta, num plano inferior ao nível do mar nos oceanos, com mais de 400 metros! Onde, contrariamente à lei da física vigente em qualquer ambiente marinho de salinidade dita normal, nunca iremos submergir (FIGURA 


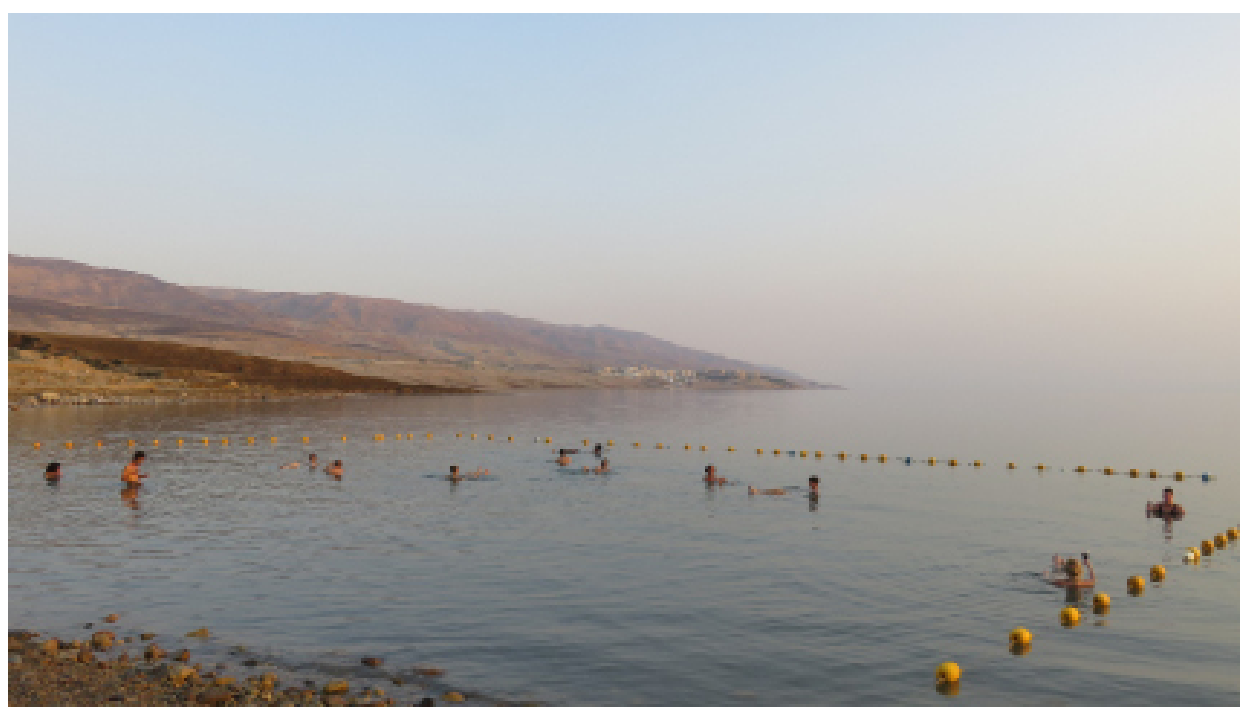

FIGURA 5. O Mar Morto na sua extremidade mais setentrional: a imagem clássica dos corpos humanos a flutuar numa massa de água com uma concentração de sais cerca de dez vezes superior à dos oceanos.

\section{REFERÊNCIAS}

${ }^{1}$ OSBORN, G. \& DUFORD, J. M., Geomorphological processes in the inselberg region of South-Western Jordan. Palestine Exploration Quarterly, 1-17, 1981.

2 JARRAR, G. H. et al, A hybrid composite dike suite from the northern Arabian Nubian Shield, southwest Jordan: Implications for magma mixing and partial melting of granite by mafic magma. Journal of Volcanology and Geothermal Research 254, 80-93, 2013.

${ }^{3}$ POWELL, J. H. et al, Cambrian stratigraphy of Jordan. GeoArabia 19 (3), 81-134, 2014.

${ }^{4}$ BOSWORTH, W., et al, The Red Sea and Gulf of Aden Basins. Journal of African Earth Sciences 43, 334-378, 2005.

${ }^{5}$ LENSKY, N. G. et al, Water, salt, and energy balances of the Dead Sea. Water Resources Research 41, W12418, 2005. 


\section{CITAÇÃO}

Canhoto, J. M. (2018)

A árvore de Natal na perspetiva de um biólogo,

Rev. Ciência Elem., V6 (04):079.

doi.org/10.24927/rce2018.079

\section{EDITOR}

José Ferreira Gomes,

Universidade do Porto

\section{EDITOR CONVIDADO}

Jorge Manuel Canhoto,

Universidade de Coimbra

\section{RECEBIDO EM}

23 de novembro de 2018

\section{ACEITE EM}

24 de novembro de 2018

\section{PUBLICADO EM}

04 de dezembro de 2018

\section{COPYRIGHT}

(C) Casa das Ciências 2018.

Este artigo é de acesso livre, distribuído sob licença Creative Commons com a designação CC-BY-NC-SA 4.0, que permite a utilização e a partilha para fins não comerciais, desde que citado o autor e a fonte original do artigo.

rce.casadasciencias.org

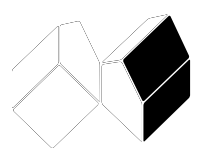

\section{A árvore de Natal na perspetiva de um biólogo}

Jorge M. Canhoto

CEF/ Universidade de Coimbra

jorgecan@uc.pt

Estamos a poucos dias do Natal. O Natal é no inverno, mas é no outono que começa a cheirar a Natal. É a época dos frutos e também da mudança de cor das árvores, que passam do verde a uma paleta de cores, que vão do amarelo ao castanho, que tornam os jardins e as florestas locais apetecíveis para longos passeios. Mas é também quando apetece estar em casa, fazer uma lareira e comer umas castanhas acompanhadas pela tradicional jeropiga ou por um dos muitos e bons tintos das nossas variadas regiões vitivinícolas. O São Martinho (11 de novembro) marca as castanhas com o vinho novo!

É também quando se começa a pensar em "fazer" a árvore de Natal. Atualmente muitas pessoas optam por uma árvore de Natal artificial, havendo uma enorme variedade destas disponíveis no mercado. No entanto, nada se compara a uma verdadeira árvore de Natal, que pode ser mesmo uma árvore jovem ou um ramo de uma árvore adulta. As árvores artificiais foram apresentadas como alternativa ambiental, para evitar que muitas árvores sejam cortadas. No entanto, existem atualmente viveiristas que possuem árvores de Natal disponíveis para venda e que podem ser usadas durante alguns anos. Pode ser mais caro, mas uma árvore verdadeira é sem dúvida mais apelativa que uma qualquer boa cópia. Muitos municípios têm procedimentos de recolha das árvores/ramos após a época natalícia, pelo que a opção por uma árvore natural não tem atualmente impacto ambiental e não vai sobrecarregar o sistema de reciclagem de mais material plástico.

Pensa-se que em Portugal, o costume da árvore de Natal terá sido iniciado no século XVIII, por D. Fernando, marido da rainha D. Maria II, a educadora. De origem alemã, terá importado para Portugal uma tradição alemão que se crê ser devida a Martinho de Lutero, mais conhecido pelo seu envolvimento na reforma protestante. Numa noite de céu estrelado, Lutero ter-se-á apercebido da extrema beleza das árvores envolvidas pelo brilho das estrelas, tendo replicado esse cenário enfeitando um ramo na sua própria casa, por altura do Natal. Nos países bálticos acredita-se que a tradição da árvore de Natal se iniciou em Riga, no início do século XVI. A aparente origem luterana atrasou a incorporação da árvore de Natal nos rituais que comemoram o nascimento de Cristo nos países de tradição católica do sul da Europa. 
Em praticamente todo o mundo, mesmo nos países tropicais em que se celebra o Natal, a árvore de Natal é uma gimnospérmica, mais concretamente uma conífera. Deixando um pouco de lado a magia do Natal e entrando no mundo da botânica, importa referir que as coníferas constituem uma divisão das plantas chamada Pinophyta. São normalmente árvores (FIGURA 1) que possuem como estruturas reprodutoras cones ou pinhas (também conhecidos por estróbilos) e que são típicas das extensas florestas do Norte da Europa, Ásia e América, bem como das regiões de altitude elevada (e.g., Alpes, Pirinéus, Montanhas Rochosas). A figura da capa desta revista mostra uma pinha feminina. Para além da sua beleza, a disposição das escamas ao redor do eixo da pinha tem apaixonado matemáticos devido aos padrões a que obedece e, numa perspetiva mais prosaica, são excelentes para acender lareiras devido ao seu teor em resinas. As coníferas não produzem frutos, uma vez que não têm flores, mas as sementes de algumas destas espécies são muito apreciadas, como acontece com as sementes de pinheiro-manso, em Portugal. Os pinheiros, as epícias, os abetos, os cedros, os ciprestes, os zimbros e os teixos são exemplos de coníferas.

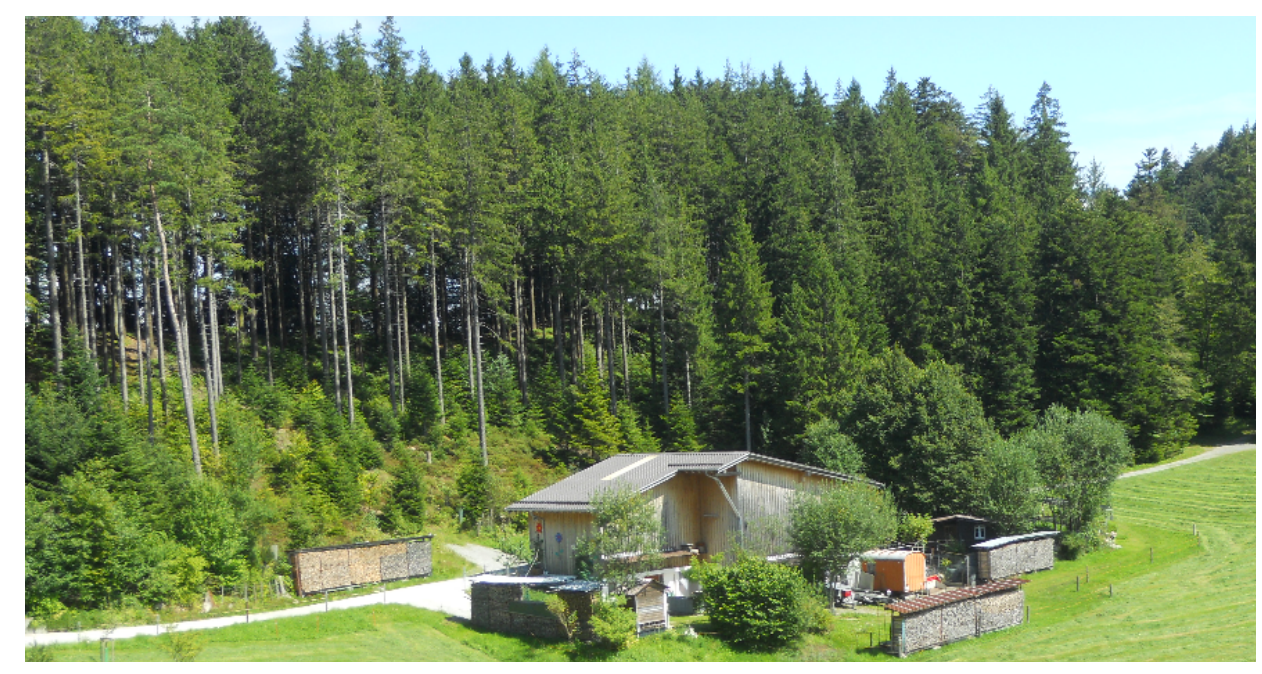

FIGURA 1. Pequena quinta nos Alpes Suíços, no maciço montanhoso de Pilatos, cerca de Lucerna, rodeada por uma floresta de coníferas.

Embora quase sempre coníferas, as árvores de Natal pertencem a espécies muito diferentes consoante as coníferas que estão disponíveis em cada país, quase se podendo dizer que a árvore de Natal é a conífera que estiver mais à mão. Por exemplo, em Portugal, a espécie mais utilizada é o pinheiro-bravo (Pinus pinaster) que forma extensas manchas florestais na zona centro. 0 pinheiro-manso (Pinus pinea) é também usado. Outros pinheiros que existem em Portugal, embora com áreas de distribuição muito mais reduzidas, como o pinheiro-silvestre (Pinus sylvestris) ou o pinheiro-do-Alepo são pouco comuns como árvores de Natal. Muitos viveiristas vendem como árvore de Natal o pinheiro-de-Douglas ou abeto-de-Douglas (Pseusotsuga menziesii), uma árvore nativa da América do Norte. Em França são muito comuns, como árvores de Natal, o abeto branco (Abies alba) e a epícia vermelha (Picea abies), pertencentes a dois géneros diferentes.

0 comércio de árvores de Natal naturais é um mercado em franca expansão e, em alguns países, como nos Estados Unidos, existem as chamadas "quintas de árvores de Natal" que se dedicam exclusivamente à propagação destas árvores. Estima-se que neste país, 
$98 \%$ das árvores de Natal naturais sejam compradas e apenas $2 \%$ cortadas de árvores adultas a crescer no campo. 0 preço médio de uma árvore de Natal vendida nos Estados Unidos ronda os 41 dólares e o mercado movimenta anualmente mais de dez mil milhões de dólares. Trata-se de uma cultura que requer uma logística complexa, uma vez que as árvores devem ser colhidas e colocadas à venda num curto período de tempo. Em termos globais, estima-se que as espécies mais utilizadas como árvores de Natal sejam 4 espécies de abeto Abies fraseri, Abies balsamea, Abies alba e Abies nordmanniana, e o já referido abeto-de-Douglas, que é uma pseudotsuga. Nenhuma destas espécies é muito conhecida em Portugal.

Para além das coníferas, existem outras espécies de plantas que são associadas às decorações natalícias. São normalmente espécies que produzem frutos vermelhos, como o azevinho (Ilex aquifolium) ou a gilbardeira (Ruscus aculeatus) ou sementes como o teixo (Taxus bacatta). Destas, só o último é uma conífera, sendo as outras angiospérmicas. Esta associação do vermelho ao Natal não é uma novidade com raízes no pai natal da coca-cola, mas antes uma tradição que parece remontar à comemoração do solstício de inverno por povos celtas, que utilizavam nessa comemoração o azevinho. Deve referir-se que todas as espécies acima referidas estão ameaçadas, pelo que a sua colheita no campo não é permitida, mas é hoje fácil de cultivar e assim alimentar o mercado. Do ponto de vista botânico, importa ainda referir que uma apelativa árvore de Natal requer um presépio coberto de musgo, uma designação que engloba um conjunto de plantas muito importantes do ponto de vista evolutivo, pois foram as primeiras a conquistar ambientes terrestres, as briófitas.

Em alguns países do hemisfério Sul a designação árvore de Natal é atribuída a plantas que nada têm a ver com as coníferas. Na Nova Zelândia, trata-se da espécie Metrosideros excelsa, uma planta da família do eucalipto (Myrtaceae) que floresce abundantemente na altura do Natal, o mesmo se passa na Austrália com a espécie Nuytsia floribunda, uma espécie semiparasítica.

Já sabíamos, relembrando Ary dos Santos, que o Natal é em dezembro/Mas em maio pode ser/Natal é em setembro/É quando um homem quiser. 0 mesmo se pode aplicar à árvore de Natal. Artificial ou natural, pinheiro ou abeto, árvore de Natal é tudo o que um Homem quiser. 


\section{Professor do Ano 2018}

\section{CITAÇÃo}

Professor do Ano 2018,

Rev. Ciência Elem., V6 (04):082.

doi.org/10.24927/rce2018.082

\section{EDITOR}

José Ferreira Gomes,

Universidade do Porto

\section{EDITOR CONVIDADO}

Jorge Manuel Canhoto,

Universidade de Coimbra

\section{COPYRIGHT}

(C) Casa das Ciências 2018.

Este artigo é de acesso livre, distribuído sob licença Creative Commons com a designação CC-BY-NC-SA 4.0, que permite a utilização e a partilha para fins não comerciais, desde que citado o autor e a fonte original do artigo.

\section{casadasciencias.org}

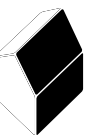

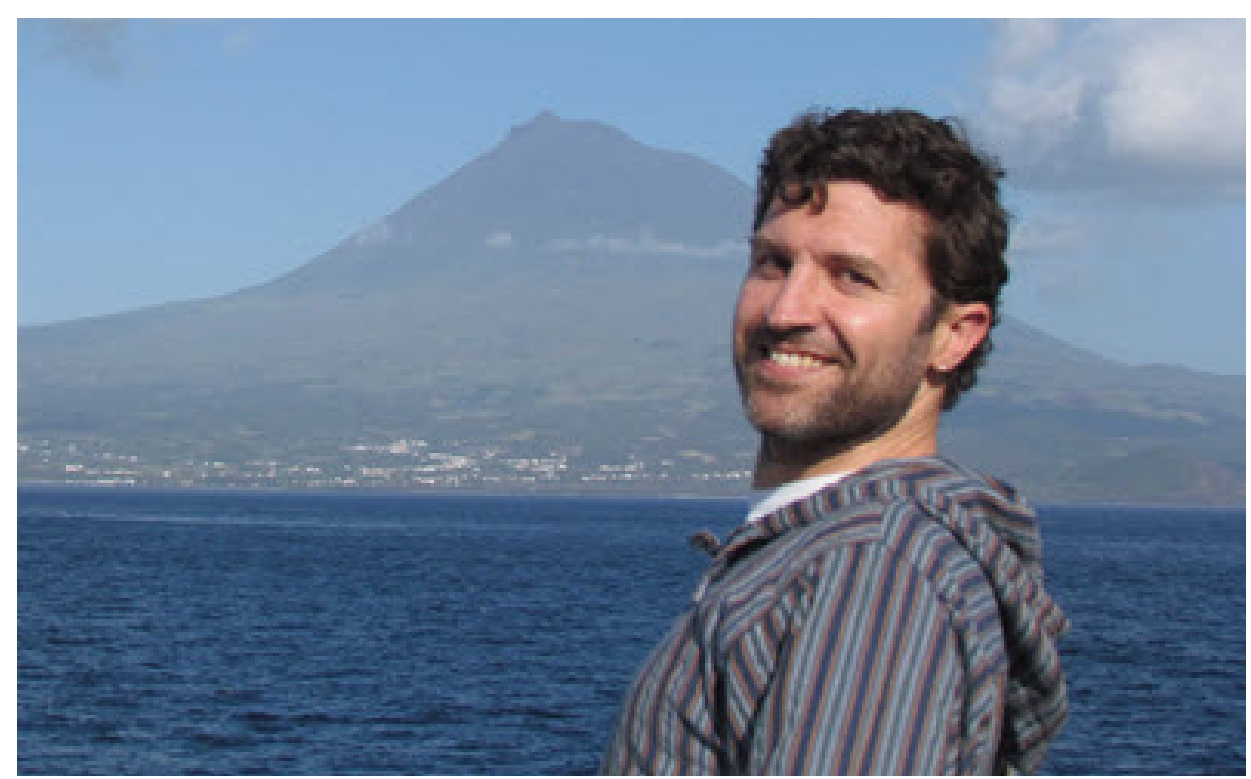

Hélder José Rodrigues Pereira

É natural de Lisboa, onde nasceu em 1974. Fixou-se no Algarve, em 1992, onde concluiu a licenciatura em Ensino de Biologia e Geologia e o mestrado em Gestão e Conservação da Natureza (especialização em Património Geológico) na Universidade do Algarve, respetivamente em 1997 e 2004.

É professor de Biologia e Geologia na Escola Secundária de Loulé, desde 2003, onde coordena e dinamiza as atividades do Clube das Ciências da Terra e do Espaço. Tem participado com os seus alunos em diversos concursos, congressos e feiras de ciência, tanto a nível nacional como internacional, tendo os trabalhos apresentados sido galardoados com vários prémios. Em 2005, foi um dos membros fundadores da Associação para a Defesa e Divulgação do Património Geológico do Alentejo e do Algarve.

Entre 2008 e 2013 participou, como educador e comunicador de ciência, em várias missões oceanográficas, tanto a nível nacional como internacional. De entre estas missões, destaca-se o período de dois meses passados a bordo do navio JOIDES Resolution quando serviu como Education Officer, durante a Expedição 339 do Integrated Ocean Drilling Program (IODP).

É autor e coautor de vários artigos científicos publicados em várias revistas nacionais e internacionais, sendo de destacar o trabalho 'Onset of Mediterranean outflow into the North 
Atlantic' publicado, em 2014, na prestigiada revista Science. É ainda autor e coautor de vários trabalhos na área do ensino, da divulgação e da promoção das ciências, destacando-se o livro "Histórias gravadas nas rochas - Guia de campo: à descoberta das rochas e fósseis em Loulé".

Com o objetivo de promover o ensino experimental das ciências tem, desde o ano 2000 , dinamizado ações de formação para professores e desenvolvido diversos materiais didáticos (alguns dos quais partilhados através da "Casa das Ciências"), baseados na utilização de dados científicos reais na sala de aula. Enquanto docente da Escola Secundária de Loulé, tem ainda participado e coordenado diversos projetos nacionais e internacionais (Comenius, Erasmus+, Ciência Viva no Verão, entre outros). É o coordenador do projeto UNESCO na Escola Secundária de Loulé desde setembro de 2018. É membro do Committee on Education da European Geosciences Union (EGU) desde outubro de 2018.

Foi com o Hélder que aprendi que "ter sorte, dá um trabalho que nem queiras saber!", mas no fundo, isso é o que dá sabor a cada momento...

Tiago Mendes (ex-aluno)

Vi muitos alunos do ensino secundário, sob a sua orientação, desenvolver trabalhos de investigação científica que orgulhariam qualquer instituição universitária... Em articulação, estiveram sempre presentes os conteúdos a ser lecionados, com efeitos no desempenho desses alunos nos momentos de avaliação escolar.

Alexandre Costa (Professor de Física e Química,

Presidente da Associação Europeia para o Ensino da Astronomia)

"Professor do Ano" é a distinção atribuída anualmente pela Comissão Editorial da Casa das Ciências a um professor em reconhecimento do seu mérito como docente do ensino básico ou secundário e da sua disponibilidade de partilhar a sua experiência com os colegas. 


\section{CITAÇÃO}

Tomé, D., Caeiro, A., Castro, F.,

Neto, C., Santos, T., Lopes, P. (2018)

Efeitos do ruído na audição,

Rev. Ciência Elem., V6(04):083.

doi.org/10.24927/rce2018.083

\section{EDITOR}

José Ferreira Gomes,

Universidade do Porto

\section{EDITOR CONVIDADO}

Jorge Manuel Canhoto,

Universidade de Coimbra

\section{RECEBIDO EM}

20 de junho de 2018

\section{ACEITE EM}

22 de outubro de 2018

\section{PUBLICADO EM}

04 de dezembro de 2018

\section{COPYRIGHT}

(C) Casa das Ciências 2018.

Este artigo é de acesso livre, distribuído sob licença Creative Commons com a designação CC-BY-NC-SA 4.0, que permite a utilização e a partilha para fins não comerciais, desde que citado o autor e a fonte original do artigo.

rce.casadasciencias.org

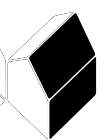

\section{Efeitos do ruído na audição}

\section{Literacia em saúde na era digital}

\author{
David Tomé ${ }^{* \neq}+$ Alberto Caeiro ${ }^{+}$, Fátima Castro ${ }^{+}$, Catarina Neto ${ }^{\dagger}$, \\ Tiago Santos' ${ }^{\dagger}$ Paula Lopes ${ }^{\dagger \#}$ \\ ‘Departamento de Audiologia, Escola Superior de Saúde, Politécnico do Porto (ESS-P.Porto) \\ ${ }_{\ddagger}$ Neurocognition Group, Laboratory of Psychossocial Rehabilitation, ESS-P.Porto, Portugal \\ +Departamento de Ciências Experimentais, Escola Secundária Dr. Manuel Gomes de Almeida, Espinho \\ \#Universidade Aberta - doutoramento em Relações Interculturais (doutoranda) \\ *dts@ess.ipp.pt
}

Com a evolução da tecnologia, os jovens utilizam cada vez mais dispositivos portáteis para entretenimento, aprendizagem e como forma de comunicação. A maioria da utilização destes dispositivos envolve uma exposição excessiva e desnecessária ao ruído e/ou a sons de elevada intensidade, que podem provocar perda auditiva. 0 setor educacional, pela sua abrangência, é um parceiro importante para a concretização de sensibilizações e ações promotoras da saúde individual e de grupo tendo como objetivo o bem-estar de toda a comunidade escolar. Assim, as escolas serão o local de eleição na preservação auditiva e na sua promoção.

Com a evolução da tecnologia, atualmente os jovens utilizam cada vez mais dispositivos portáteis para entretenimento, aprendizagem e como forma de comunicação ${ }^{1}$. Devido à popularidade que estes equipamentos obtiveram ao longo dos anos, estima-se que $90 \%$ dos estudantes universitários possuam algum tipo destes dispositivos pessoais de escuta $(\mathrm{DPE})^{2}$.

A sua utilização, envolve muitas vezes uma exposição excessiva e desnecessária ao ruído e/ou a sons de elevada intensidade, que podem provocar perda auditiva, sendo atualmente a exposição prolongada a elevados níveis de ruído considerada uma questão de saúde pública, tendo sido historicamente elaborada legislação em 2006 com o Decreto-Lei $182 / 2006$, de 6 de setembro ${ }^{3,4}$. Para além disto, verifica-se ainda um aumento da poluição sonora nas cidades ou mesmo perto dos locais que estes jovens costumam frequentar, o que poderá contribuir ainda mais para o risco de perda auditiva e/ou sintomas otológicos associados no âmbito das suas atividades de lazer, para além de outros problemas de saúde que se fazem sentir a curto médio ou longo prazo, com grande impacto na sua qualidade de vida.

A exposição contínua ao ruído e a sons de elevada intensidade, pode resultar na pro- 
gressiva morte ou lesão, lenta mas irreversível, das células ciliadas do ouvido interno e órgão de Corti (cóclea; FIGURA 1) ${ }^{5,6}$. Esta perda celular é sensorioneural e irreversível, não tendo as células ciliadas capacidade de regeneração. Poderá também despoletar outros sintomas como por exemplo zumbidos, fadiga, diminuição da eficiência no trabalho, alterações do ritmo cardíaco, do sono e da tensão arterial e, por último, stress ${ }^{7}$. Sendo que estes problemas variam de acordo com a tolerância e suscetibilidade de cada indivíduo ${ }^{8}$.
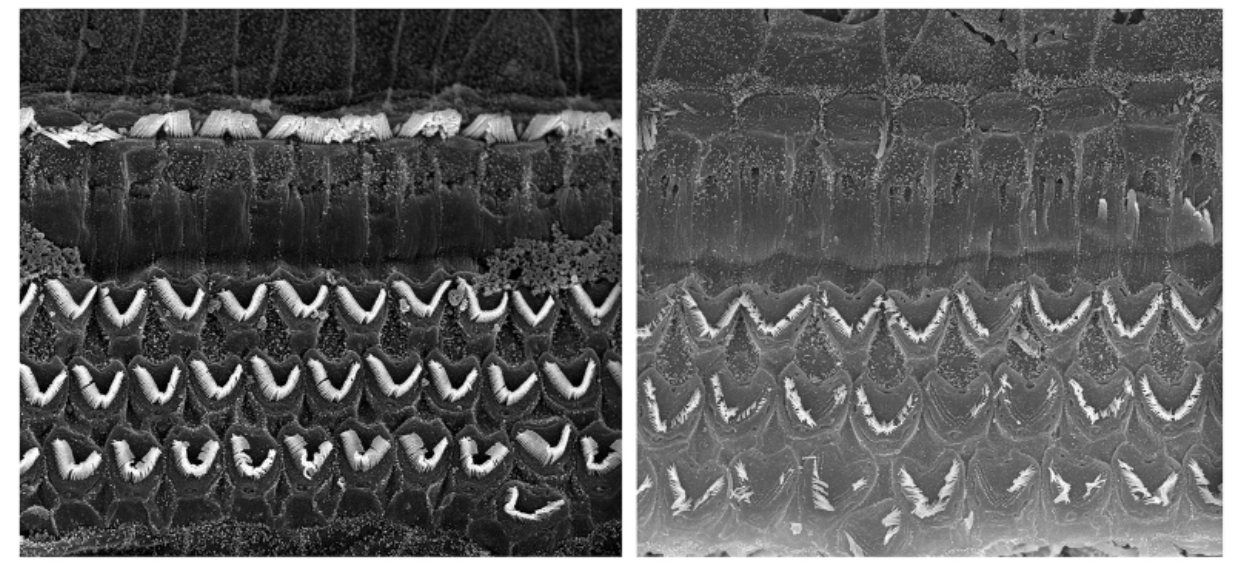

FIGURA 1. Imagem das células ciliadas no órgão de Corti ao Microscópio Eletrónico de Varrimento (MEV) antes (à esquerda) e após (à direita) exposição ao ruído num porquinho-da-índia. É possível observar que nas células ciliadas danificadas, muitos estereocílios são interrompidos ou ausentes. Este tipo de danos levam a uma perda auditiva sensorioneural irreversível. Modificado de Chen et al, doi: 10.1371/journal.pone.0100774 (cortesia).

Existe hoje em dia uma grande preocupação por parte dos profissionais de saúde pelas perdas de audição provocadas pela exposição ao ruído (PAIR - perda auditiva induzida pelo ruído), não só devido aos DPEs (smartphones, iPod, leitores de mp3, etc.), como também à frequência de ginásios ou discotecas, onde os níveis sonoros são de grande intensidade, sendo possível que os equipamentos utilizados nem sempre estejam de acordo com a legislação vigente. Além disso, o tempo de exposição por parte dos utilizadores poder ser excessivo, muito por falta de informação ou sensibilização para comportamentos de risco. Relativamente aos DPEs, dependendo do tipo de auscultador utilizado, a saída máxima tem uma variância de nível sonoro máximo entre 83,4 e $107,3 \mathrm{~dB}(\mathrm{~A})^{9}$. Tendo em conta que por regra geral não deveriam exceder os $85 \mathrm{~dB}(\mathrm{~A})$, os dispositivos digitais representam um perigo para o sistema auditivo $0^{9,10}$. Alguns dispositivos alertam quando se atinge um nível de volume prejudicial para a audição, não significando que as normas do fabricante estejam de acordo com a legislação de cada país. Os impactos dos comportamentos de risco atrás mencionados, no sistema auditivo, são semelhantes aos sofridos pelos trabalhadores expostos ao ruído ${ }^{11}$ : A mudança temporária do limiar auditivo (fenómeno de fadiga auditiva, observada quando o indivíduo é exposto a níveis de pressão sonora elevados, leva a um aumento dos limiares auditivos, mas normaliza após um repouso de cerca de 14 horas a 3 dias); a PAIR (quando não há recuperação dos limiares auditivos, sendo caracterizada como uma perda auditiva do tipo sensorioneural irreversível, gradual, muitas vezes bilateral, provocada pela exposição continuada a elevados níveis de pressão sonora, não dolorosa nem relacionada a desconforto auditivo); e o traumatismo acústico (quando 
a configuração audiométrica da PAIR tem um escotoma ou queda numa determinada frequência, habitualmente os 4000 ou os $2000 \mathrm{~Hz}$, devido a uma maior vulnerabilidade destas frequências à onda hidromecânica que percorre a cóclea). Assim, exposição ao ruído ou sons de elevada intensidade provocam uma excessiva estimulação coclear, originando que as células ciliadas (auditivas) presentes na cóclea (órgão de Corti) libertem uma grande quantidade do neurotransmissor glutamato, provocando um edema e rebentamento do botão sináptico (excitotoxicidade) e consequente morte celular.

A PAIR pode causar nos jovens graves problemas nas dimensões do aproveitamento escolar, convívio social e futuramente nas suas vidas profissionais. Promover a saúde auditiva dos adolescentes, que serão futuros adultos e cidadãos promotores de saúde, é eficaz pelo esclarecimento e consciencialização da adoção de um estilo de vida saudável e de um bem-estar harmonioso ${ }^{12}$. Tendo Portugal, no ano de 2015, 1450134 estudantes matriculados no ensino básico, secundário ou CET, esta população constituir-se-á como alvo de atenção primordial neste estudo uma vez que são os adolescentes, o grupo mais propenso à adesão de forma mais fácil a estilos de vida saudáveis, nomeadamente no que respeita à saúde auditiva.

De forma a proteger e preservar a saúde auditiva das gerações mais novas, é necessária a existência de programas de sensibilização que possam explicar de forma adequada às diferentes faixas etárias, quais os comportamentos de risco, as suas consequências e também formas de proteção e reabilitação. Promovendo também a literacia em saúde, que se define pela "capacidade de tomar decisões fundamentadas, no decurso da vida do dia-a-dia, em casa, na comunidade, no local de trabalho, na utilização de serviços de saúde (...) aumentando o controlo das pessoas sobre a sua saúde, a capacidade para procurar informação e assumir responsabilidades" ${ }^{13}$. Existe uma relação entre o nível de literacia e o estado de saúde da pessoa. Sabe-se hoje em dia que um nível inadequado de literacia em saúde acarreta muitos custos para o sistema, nas mais variadas áreas da saúde.

Esta adoção de comportamentos de saúde positivos tem impactos que incluem ${ }^{14}$ : melhor estado e redução de custo em saúde, aumento dos conhecimentos em saúde e utilização menos frequente dos cuidados/serviços de saúde. A par desta intervenção pedagógica, é relevante implementar medidas e ações de saúde escolar à semelhança de outros países europeus, como a realização na mudança de ciclo de rastreios auditivos escolares por profissionais especializados (p.e.: audiologistas) e formações/sessões de esclarecimento e sensibilização sobre o funcionamento do sistema auditivo, os efeitos da exposição sonora na audição, os comportamentos de risco, tipos de protetores auditivos e como preservar a saúde auditiva consoante a situação.

\section{Considerações finais}

O setor educacional, pela sua abrangência, é um parceiro importante para a concretização de sensibilizações e ações promotoras da saúde individual e de grupo tendo como objetivo o bem-estar de toda a comunidade escolar. Assim, as escolas serão o local de eleição destinados às áreas da preservação auditiva e à sua promoção. Sugere-se um plano de promoção de saúde auditiva, promovendo assim hábitos de escuta seguros e sensibilizando os jovens para os efeitos nefastos da exposição prolongada e contínua a sons com intensidades elevadas. Para além disto, a integração destes dados num futuro plano de saúde auditiva a nível na- 
cional é algo vantajoso pois seria possível realizar campanhas e palestras de sensibilização, com o intuito de modificar hábitos precocemente, bem como a realização de rastreios auditivos para que seja possível uma detecção e intervenção atempadas.

Um dos objetivos da ESS-P.Porto, é que os estudantes de licenciatura desenvolvam a promoção da reflexividade, análise crítica e o desenvolvimento de respostas criativas ajustadas às particularidades dos contextos. Neste sentido, esta é uma iniciativa de inovação pedagógica que permite, em particular aos estudantes de Audiologia, a aquisição de competências na prevenção e comunicação em cuidados de saúde primários, em contexto escolar (não hospitalar) num trabalho presencial e de proximidade.

\section{REFERÊNCIAS}

${ }^{1}$ FEARN, R. \& HANSON, D., Hearing level of young subjects exposed to amplified music. Journal of Sound Vibration, 128(3), 509-512, 1989.

${ }^{2}$ TORRE, P., Young adults' use and output level settings of personal music systems. Ear and hearing, 29, 791-799, 2008. ${ }^{3}$ ABREU, S., Estudo da influência da proteção auditiva na perceção de sinais de alerta na presença de ruído de fundo. Tese de Mestrado, Universidade do Minho, 2012.

${ }^{4}$ Decreto-lei no 182/2006, Diário da República, 1aㅡ série - №172 de 6 de setembro, Prescrições mínimas de segurança e saúde em matéria de exposição dos trabalhadores aos riscos devido ao ruído.

${ }^{5}$ KATZ, J., Tratado de Audiologia Clínica. 4a Edição, 1999. São Paulo. Editora Manole.

${ }^{6}$ CHEN, L. et al, Hydrogen-Saturated Saline Protects Intensive Narrow Band Noise-Induced Hearing Loss in Guinea Pigs through an Antioxidant Effect. PLoS ONE, 9(6): e100774, 2014.

${ }^{7}$ NIOSH. Criteria for a recommended standard: occupational noise exposure. Publication 98 - 126, 1998.

8 MOHAMMADI, G., Hearing conservation programs in selected metal fabrication industries. Applied Acoustics, 69(4), 287-292, 2008.

${ }_{9} \mathrm{KEITH}$, S. et al, Evaluating the maximum playback sound levels from portable digital audio players. Journal of Acoustical Society of America, 123, 4227 - 4237, 2008.

${ }^{10}$ LEVEY, S. et al, Noise exposure estimates of urban MP3 player users. Journal of Speech, Language, and Hearing Research, 54(1), 263-277, 2011.

${ }^{11}$ KIRCHNER, D.B. et al, Occupational Noise-Induced Hearing Loss. Journal of Occupational and Environmental Medicine, 54(1): 106-108, 2012.

12 ZHAO, Y.M. et al, Application of the kurtosis statistic to the evaluation of the risk of hearing loss in workers exposed to high-level complex noise. Ear and Hearing, 31:527-532, 2010.

${ }^{13} \mathrm{KICKBUSCH}$, I. et al, Navigating health: The role of health literacy. London: Alliance for Health and the Future. International Longevity Centre-UK, 2005.

${ }^{14}$ PEDRO, A.R. et al, Literacia em saúde, dos dados à ação: tradução, validação e aplicação do European Health Literacy Survey em Portugal. Revista Portuguesa de Saúde Pública, 34 (3): 259-275, 2016. 


\section{CITAÇÃO}

Lage, E. (2018)

Mecânica dos Fluidos

Rev. Ciência Elem., V6 (04):084.

doi.org/10.24927/rce2018.084

\section{EDITOR}

José Ferreira Gomes,

Universidade do Porto

\section{EDITOR CONVIDADO}

Jorge Manuel Canhoto,

Universidade de Coimbra

\section{RECEBIDO EM}

7 de fevereiro de 2018

\section{ACEITE EM}

15 de fevereiro de 2018

\section{PUBLICADO EM}

15 de janeiro de 2019

\section{COPYRIGHT}

(C) Casa das Ciências 2018.

Este artigo é de acesso livre, distribuído sob licença Creative Commons com a designação CC-BY-NC-SA 4.0, que permite a utilização e a partilha para fins não comerciais, desde que citado o autor e a fonte original do artigo.

rce.casadasciencias.org

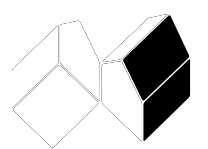

\section{- \\ Mecânica dos Fluidos}

\author{
Eduardo Lage \\ Universidade do Porto \\ ejslage@gmail.com
}

Perante a enorme variedade e natureza dos fluidos e o vasto e diverso tipo de comportamentos que apresentam, podíamos ser levados a pensar que não haveria uma descrição universal da sua mecânica. Contudo, não é assim: as leis que regem a dinâmica de qualquer fluido são bem conhecidas e derivam de princípios universais. Sendo assim, onde está a dificuldade em descrevermos quantitativamente o escoamento de um fluido nas suas múltiplas manifestações?

A resposta pode ser já adiantada, embora só mais adiante se perceberá cabalmente a sua essência: as equações básicas são altamente não lineares, um capítulo da matemática ainda por desenvolver completamente. Mesmo a simulação numérica destas equações apresenta, muitas vezes, o fenómeno de caos onde a evolução, para os mesmos dados, da dinâmica de um fluido, embora inteiramente determinista, acaba por originar soluções que divergem exponencialmente ao longo do tempo quer porque a introdução dos dados num computador necessariamente introduz arredondamentos, quer porque as próprias equações têm que ser discretizadas originando uma dependência na "finura" da malha utilizada. É devido ao caos que previsões meteorológicas só são fiáveis para poucos dias, mesmo quando se recorre aos computadores mais avançados. Perante isto, percebe-se que soluções analíticas daquelas equações não são frequentes, mas existem e são de grande importância porque têm um grande domínio de aplicações e porque permitem aferir o grau de fiabilidade de soluções numéricas. Compreende-se, também, que, na prática, aquelas equações fundamentais sejam objeto de aproximações determinadas por números adimensionais (Mach, Taylor, Froude, Prandtl, Rayleigh, Reynolds, etc.), os quais medem a importância relativa de vários termos nas equações, justificando a aproximação utilizada e o âmbito da sua aplicação. Mais abaixo, ver-se-á um exemplo.

Genericamente, um fluido em movimento é descrito por vários campos ${ }^{1}$ que mutuamente se influenciam.

a) Em primeiro lugar, temos, evidentemente, o campo (vetorial) de velocidades $\vec{v}(\vec{r}, t)$ ele indica, em cada ponto, a velocidade da pequena porção de fluido aí localizada, em cada instante. Uma linha de corrente é, em cada instante, tangente, em cada ponto, à velocidade 
naquele ponto e instante; em geral, não coincide com a trajetória de qualquer pequena massa, como se pode observar, com bastante atenção, no movimento de um ribeiro. Só no caso do movimento permanente (i.e. nada depende explicitamente do tempo) uma linha de corrente coincide com a trajetória das partículas que nela se localizem A partir do campo de velocidades, constrói-se o campo (vetorial) de acelerações $\vec{a}(\vec{r}, t)$ - é a aceleração a que está submetida a pequena massa naquele ponto e naquele instante. Esta descrição é conhecida por formulação de Euler mas, apesar da sua simplicidade, esconde uma relação nada trivial entre os dois campos considerados. Com efeito, para obter a aceleração da pequena massa temos de comparar a sua velocidade inicial com a velocidade que tem noutro instante: ora, durante este pequeno intervalo de tempo, a pequena massa deslocou-se da primeira para a segunda posição, isto é:

$$
\vec{a}(\vec{r}, t)=\frac{1}{\delta t}[\vec{v}(\vec{r}+\vec{v} \delta t, t+\delta t)-\vec{v}(\vec{r}, t)]=\frac{\partial \vec{v}}{\partial t}+\vec{v} . \nabla \vec{v} \equiv \frac{d \vec{v}}{d t}
$$

Introduzimos, aqui, o operador $\frac{d}{d t} \equiv \frac{\partial}{\partial t}+\vec{v}$. $\nabla$ designado por derivada hidrodinâmica: ele determina, para qualquer grandeza, a taxa de evolução temporal dessa grandeza quando acompanhamos uma pequena massa.

b) Em segundo lugar, surge o campo (escalar) da massa específica $\rho(\vec{r}, t)$, a massa por unidade de volume. Se não existirem reações químicas ou nucleares, a massa de qualquer pequena porção do fluido conserva-se, evidentemente, mas irá, em geral, ocupar diferentes volumes ao longo do tempo e, portanto haverá alterações locais da massa específica. Deixamos, aqui, registada a equação a que tem de obedecer a massa específica, conhecida por equação da continuidade, remetendo para outro lugar a sua dedução:

$$
\frac{\partial \rho}{\partial t}+\nabla \cdot(\rho \vec{v})=0 \quad \leftrightarrow \quad \frac{\partial \rho}{\partial t}+\vec{v} \cdot \nabla \rho+\rho \nabla \vec{v} \equiv \frac{d \rho}{d t}+\rho \nabla \vec{v}=0
$$

Podemos dar uma outra forma a esta equação de maneira a torna-la mais transparente. Designemos por $v$ o volume ocupado pela unidade de massa (não confundir o símbolo $v$ com o símbolo da velocidade). É óbvio que $v=\frac{1}{\rho}$. Então:

$$
\frac{d v}{d t}=-\frac{1}{\rho^{2}} \frac{d \rho}{d t}=\frac{1}{\rho} \nabla \cdot \vec{v}=v \nabla \cdot \vec{v}
$$

Isto é, a taxa de variação percentual do volume por unidade de massa, $\frac{1}{v} \frac{d v}{d t}$, é simplesmente determinada pela divergência do campo de velocidades: $\frac{1}{v} \frac{d v}{d t}=\nabla \cdot \vec{v}$. Então, se pudermos considerar o fluido como incompressível, i.e., a mesma massa ocupa sempre o mesmo volume, o campo de velocidades tem divergência nula, resultado de grande importância em várias aplicações. 


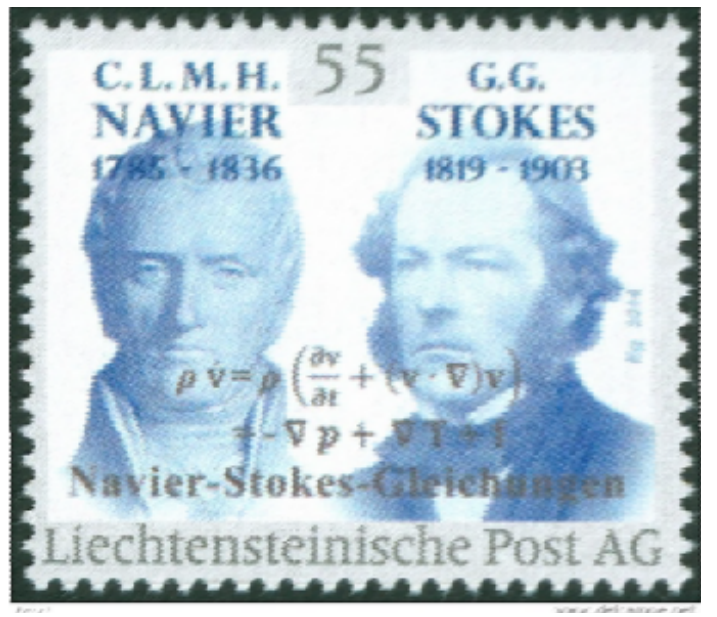

FIGURA 1. Evocação, em selo, de Charles Navier e George Stokes, e da equação que leva os seus nomes.

c) Em terceiro lugar, temos de considerar os campos de forças que atuam sobre o fluido. Desde logo, o peso que origina a densidade volúmica $\rho \vec{g}$, mas para várias situações, sobretudo em meteorologia ou geofísica, também a força de Coriolis ${ }^{2}$ devida à rotação da Terra. 0 campo de pressões determina outra importante força: se a pequena massa está submetida a uma pressão não uniforme, surgirá uma força que aponta da maior para a menor pressão, i.e., oposta ao gradiente de pressões, originando a densidade volumíca $-\nabla p$. Em fluidos viscosos há, também que incluir as tensões viscosas; no caso de fluidos newtonianos $^{3} \mathrm{e}$ isotrópicos, a tensão é proporcional o gradiente da velocidade, daqui resultando a densidade volumíca ${ }^{4} \eta \vec{v}+\left(\frac{\eta}{3}+\zeta\right) \nabla(\nabla . \vec{v})$ onde $\eta$ é o coeficiente de viscosidade dinâmica e $\zeta$ é o coeficiente de viscosidade volúmica, ambos, aqui supostos constantes. Note-se que o último termo da expressão anterior, desaparece para fluidos incompressíveis; em qualquer caso, ele será ignorado no que se segue (tal termo, porque proporcional a um gradiente, pode ser adicionado ao termo de pressão, redefinindo, assim, este último campo).

Com estes resultados, a equação fundamental da dinâmica escreve-se:

$$
\rho \vec{a}=\rho \vec{g}-\nabla p+\eta \Delta \vec{v}
$$

É a equação de Navier-Stokes, a equação fundamental para fluidos viscosos ${ }^{5}$. Ela tem de ser completada com as condições fronteira: perfeita aderência a corpos sólidos (i.e., as velocidades do fluido e do sólido são iguais nos pontos de contacto) ou na superfície que separa dois fluidos viscosos e imiscíveis.

Como aplicação, considere-se o escoamento entre dois planos horizontais, estando fixo o de baixo e movendo-se o de cima com velocidade uniforme U (ver FIGURA 1 em "Viscosidade"). 0 escoamento é suposto permanente e o fluido é considerado incompressível. Tomemos o eixo $x$ no plano horizontal, alinhado com a direção do movimento do fluido, e o

2 Ver "Força".

"Ver "Fluidos".

${ }^{4} O$ símbolo $\Delta$ representa o laplaciano: $\Delta=\frac{\partial^{2}}{\partial x^{2}}+\frac{\partial^{2}}{\partial y^{2}}+\frac{\partial^{2}}{\partial z^{2}}$

${ }^{5} \mathrm{~A}$ existência e unicidade de solução desta equação para condições gerais, é um dos problemas do Prémio Milénio ainda sem solução. 
eixo $y$ na vertical; o terceiro eixo $z$, normal aos anteriores, não desempenha, aqui qualquer papel. É óbvio que as linhas de corrente são horizontais, coincidindo com as trajetórias das pequenas massas. 0 campo de velocidades reduz-se à componente $v_{\mathrm{x}}$ que não pode depender do tempo (movimento permanente), nem da coordenada $x$ (fluido incompressível), nem da coordenada $z$ (por simetria). Assim, $v_{\mathrm{x}}(\mathrm{y})$, apenas. Então, a velocidade de qualquer pequena massa permanece constante ao longo da linha de corrente, i.e., é nula a sua aceleração. Projetando a equação de Navier-Stokes segundo o eixo $y$, obtemos o campo de pressões que se reduz, afinal, à pressão hidrostática. Projetando segundo o eixo $x$, obtemos $\frac{d^{2}}{d y^{2}} v_{x}=0$, que se integra facilmente com as condições de aderência aos dois planos: $v_{x}=\frac{U}{h} y$, onde h é a distância entre os planos. Assim, o caudal (em volume), por unidade de comprimento transversal (i.e., segundo $z$ ) é $Q=\int_{0}^{h} d y v_{x}=\frac{U h}{2}$. 0 plano superior exerce a tensão tangencial $\tau=\eta\left(\frac{d v_{x}}{d y}\right)_{y=h}=\eta \frac{U}{h}$, mas move-se uniformemente pelo que a potência das forças que temos de aplicar para manter o seu movimento é $\eta \frac{U^{2}}{h}$ dissipada sob a forma de calor no seio do fluido.

d) 0 exemplo atrás elaborado mostra que, em fluidos viscosos, deve, também, ser considerado o campo (escalar) da temperatura, o qual se revela responsável por dois efeitos importantes: por um lado, os coeficientes de viscosidade variam fortemente com a temperatura ${ }^{6}$ e, portanto, não poderão, em geral, ser considerados constantes; por outro lado, se a temperatura não for uniforme, haverá propagação de calor por condução ou por convexão, surgindo esta última pela dilatação térmica do fluido. Não prosseguiremos aqui estes importantes tópicos, mas a que retornaremos noutras publicações.

e) Por último, temos de analisar o campo de pressões. Cada pequena massa deve ser encarada como um sistema termodinâmico, o que pressupõe ser formada por um número de átomos ou moléculas da ordem do número de Avogadro. Além disso, admitimos que tal pequena massa está em equilíbrio termodinâmico, obedecendo a uma equação de estado que relaciona a pressão, temperatura e massa específica. Por exemplo, para um gás ideal é $p=\frac{R}{M} \rho T$, onde $M$ é a massa molecular, $R$ a constante dos gases perfeitos e $T$ a temperatura absoluta. Este equilíbrio é designado por equilíbrio local porque assumido para qualquer pequena massa, embora possa não haver, e geralmente não há, equilíbrio global de todo o fluido como se depreende da existência de um campo de temperaturas, em geral não uniforme.

Os considerandos anteriores servem, essencialmente, para fazer intuír que o escoamento de um fluido apresenta um enorme desafio matemático que só em casos relativamente simples, embora importantes, é suscetível de solução analítica. Um dos principais recursos utilizados em muitas aplicações, consiste em tornar adimensional a equação de Navier-Stokes como, a seguir, ilustraremos com um exemplo simples. Imaginemos um fluido viscoso e incompressível mover-se através de uma configuração geométrica caracterizada por um comprimento $L$ típico, por exemplo o diâmetro de uma esfera ou de um cilindro imóveis

${ }^{6}$ Ver "Viscosidade". 
no seio do fluido obrigado, assim, a escoar-se em torno destas figuras. Designemos por $V$ uma velocidade típica do fluido, por exemplo a velocidade em regiões afastadas daquelas figuras ou determinado pelo caudal. Podemos, agora, mudar para variáveis adimensionais, notadas por uma plica, definidas como segue: $\vec{r}^{\prime}=\frac{\vec{r}}{L}, t^{\prime}=\frac{V}{L} t, p^{\prime}=\frac{p}{\rho V^{2}}, \vec{g}^{\prime}=\frac{L \vec{g}}{V^{2}}$. Substituindo na equação, obtém-se:

$$
\frac{d \vec{v}^{\prime}}{d t^{\prime}}=-\nabla^{\prime} p^{\prime}+\frac{1}{R e} \Delta^{\prime} v^{\prime}+\vec{g}^{\prime}
$$

onde $\operatorname{Re}=\frac{\rho L V}{\eta}$ é o número de Reynolds (adimensional). Daqui decorre que, se dois fluidos, em geometrias semelhantes, obedecem a esta mesma equação adimensional, então o comportamento dos dois fluidos é idêntico, apenas tendo que se mudar as escalas. É assim que aviões e automóveis são "experimentados" em túneis de vento, bastando efetuar as experiências com miniaturas geometricamente semelhantes, desde que se garanta que objeto e miniatura estão submetidos ao mesmo número de Reynolds. 0 ponto mais interessante destas leis de escala é não ser necessário resolver qualquer equação para se conseguir obter respostas adequadas para o sistema de interesse. Por exemplo, a tensão viscosa $\eta \frac{d v}{d x}=\frac{\eta V}{L} \frac{d v^{\prime}}{d x^{\prime}}$ quando integrada sobre a superfície do sólido em contacto com o fluido, origina uma força $A \eta V L$, onde $A$ é um número adimensional que dependerá do número de Reynolds; do mesmo modo, a pressão, integrada sobre a mesma superfície determina uma resultante $B \rho V^{2} L^{2}$, onde $B$ é outra constante adimensional que também depende do número de Reynolds. Estas constantes $A$ e $B$ podem ser medidas experimentalmente, daqui resultando que a força exercida pelo fluido sobre o sólido tem a forma $A \eta V L+B \rho V^{2} L^{2}=\eta V L(A+B R e)$.

Voltando à equação anterior, vemos que para grandes números de Reynolds, poderemos, como primeira aproximação, ignorar o termo da viscosidade, simplificando a equação fundamental da dinâmica para a seguinte forma:

$$
\rho \vec{a}=\rho \vec{g}-\nabla p
$$

Esta é a equação de Euler que rege a mecânica de fluidos perfeitos, i.e., sem viscosidade. Embora de forma aproximada, esta equação descreve um inúmero conjunto de aplicações, como se verá noutras publicações. Aqui, importa realçar que uma solução da equação de Euler como aproximação para um fluido viscoso, falha nas proximidades de corpos sólidos ou nas interfaces entre líquidos. Tal acontece devido às diferentes condições fronteira que fluidos viscosos e perfeitos apresentam naquelas circunstâncias. 

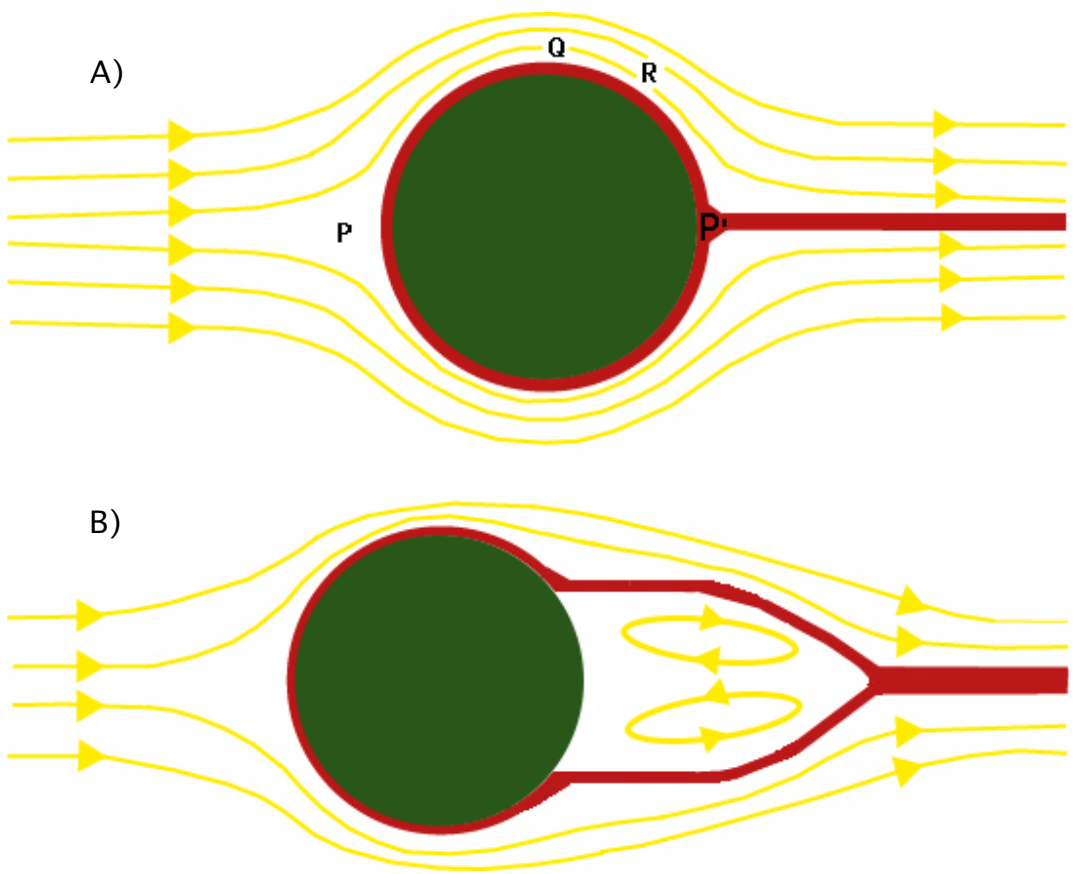

FIGURA 2. Escoamento de um fluido viscoso em torno de uma esfera. A camada limite está marcada a vermelho, separando-se da esfera para maior número de Reynolds, aparecendo, neste caso, vórtices no seu interior. 0 fluído é livre de vorticidade fora da camada limite, representada pelo sombreado. Em A) a camada limite ainda está ligada à esfera, apesar de continuar para além dela. Em B) o fluido separou-se, formando vortices por trás da esfera.

Um fluido viscoso adere ao sólido enquanto que um fluido perfeito apenas satisfaz a condição de não entrar nem sair do sólido. Deste modo, um fluido viscoso comportar-se-á como perfeito até uma certa distância do corpo sólido ou da interface com outro fluido. Define-se, assim, a camada limite, a região dentro da qual a diferença relativa entre os campos de velocidade de um fluido viscoso e de um fluido perfeito é superior a, por exemplo, 10\%. No exterior dessa camada limite, a equação de Euler constituirá uma excelente aproximação da equação de Navier-Stokes.

\section{REFERÊNCIAS}

${ }^{1}$ MASSEY, B. S., WARD-SMITH, A. J., Mechanics of Fluids (9th ed.). London \& New York: Spon Press, 2011. ISBN 978-0-415-60259-4. OCLC 690084654

2 TRITTON, D.J., Physical fluids dynamics. New York: Van Nostrand-Reinhold, 1977.

3 J.F. DOUGLAS, J.M. GASIOREK, J.A. SWAFFIELD, Fluid Mechanics, Longman Scientific \& Technical, Essex, 1995.

${ }^{4}$ LAMB, W. Hydrodynamics.

${ }^{5}$ LAI, W. M. et al., Introduction to continuum mechanics. Butterworth-Heinemann, 2009.

${ }^{6}$ PRANDTL, L., \& TIETJENS, O. G., Applied Hydrodynamics.

${ }^{7}$ CURLE, N., DAVIES, H. J., Modern fluid dynamics, 1968.

${ }^{8}$ FETTER, A. L., \& WALECKA, J. D., Theoretical mechanics of particles and continua. Courier Corporation, 2003. 


\section{CITAÇÃO}

Azevedo, E., Barata, M. (2018)

Diversidade no reino Fungi e

aplicações à Indústria,

Rev. Ciência Elem., V6(04):077.

doi.org/10.24927/rce2018.077

\section{EDITOR}

José Ferreira Gomes,

Universidade do Porto

\section{EDITOR CONVIDADO}

Jorge Manuel Canhoto,

Universidade de Coimbra

\section{RECEBIDO EM}

22 de janeiro de 2018

\section{ACEITE EM}

15 de abril de 2018

\section{PUBLICADO EM}

04 de outubro de 2018

\section{COPYRIGHT}

(C) Casa das Ciências 2018.

Este artigo é de acesso livre, distribuído sob licença Creative Commons com a designação CC-BY-NC-SA 4.0, que permite a utilização e a partilha para fins não comerciais, desde que citado o autor e a fonte original do artigo.

rce.casadasciencias.org

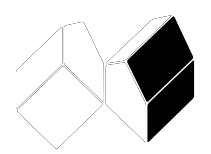

\section{$-$ \\ Diversidade no reino Fungi e aplicações à Indústria}

\author{
Egídia Azevedo ${ }^{*}$, Margarida Barata ${ }^{\dagger}$ \\ ${ }^{*}$ Ce3C/CESAM/Universidade de Lisboa \\ ${ }^{\dagger} \mathrm{Ce} 3 \mathrm{C} /$ Universidade de Lisboa \\ gigiazd@gmail.com
}

Os fungos são organismos que podem ser encontrados em quase todos os ambientes (terrestres e aquáticos) a colonizar uma grande variedade de substratos (solo, água, plantas, detritos orgânicos). 0 número estimado de espécies de fungos é de 2,2 a 3,8 milhões em oposição a cerca das 120000 descritas. No que diz respeito à classificação dos organismos vivos, os fungos pertencem ao Domínio Eucarya e estão mais próximos dos animais do que das plantas, compartilhando o ancestral com os animais. Os fungos pertencem ao Reino Fungi e estão distribuídos por 6 filos e 4 sub-filos. Podem ser definidos, com base nas características morfológicas e fisiológicas, como organismos eucariontes, na maioria com soma filamentoso (micélio), heterotróficos com uma nutrição osmotrófica ou por absorção, diferente da dos restantes eucariontes. Propagam-se por esporos formados por meiose no processo de reprodução (meiósporos) e por esporos de propagação vegetativa formados por mitose (mitósporos). Como resultado do seu metabolismo os fungos podem ser prejudiciais (por exemplo devido à produção de micotoxinas) no entanto muitos são benéficos para o homem, sendo utilizados em várias indústrias nomeadamente na farmacêutica e na alimentar.

Os fungos ocorrem numa grande diversidade de ambientes: terrestre, marinho, dulçaquícola e aéreo, com uma distribuição global, das regiões temperadas às polares. Apresentam grande diversidade de formas, de ciclos de vida e de modo de vida. Os fungos na sua maioria são sapróbios, mas também existem fungos parasitas (de animais, de plantas e de outros fungos), simbiontes mutualistas (como líquenes, micorrizas e ainda associações com insetos e outros animais) e predadores de animais microscópicos.

Em 1991, foi apresentada uma estimativa conservadora para a biodiversidade fúngica de 1,5 milhões de espécies ${ }^{1}$. Os cálculos basearam-se no número de plantas vasculares e de fungos descritos para a Grã-Bretanha e na constatação que existi- 
riam 6 espécies fúngicas para cada uma das plantas vasculares.

Em 2011, Blackwel, baseado em dados moleculares, apresenta uma nova estimativa de 5,1 milhões de espécies fúngicas ${ }^{2}$. Recentemente, em 2017, foram estimados novos números de espécies para a biodiversidade fúngica global: 2,2 a 3,8 milhões $^{3}$. Nesta estimativa foram consideradas: as espécies crípticas, os dados de sequenciação das amostras ambientais, a comparação entre dados moleculares e dados morfológicos, as novas extrapolações da proporção fungo por planta, os hot spots de biodiversidade, os ambientes pouco inventariados e os materiais de coleção em estudo. 0 número de espécies fúngicas descritas é 120 000, que é cerca de 3 a $8 \%$ do número estimado de espécies ${ }^{3}$.

Até à primeira metade do século $X X$, os fungos integraram o Reino Plantae, na subdivisão Thallophyta. Em 1969, Whittaker ${ }^{4}$ criou o Reino Fungi estabelecendo a sua separação dos restantes Reinos (Animalia, Plantae, Monera e Protista). Woese et al. (1990), com base na análise de sequências de rRNA, apresentaram um sistema de classificação dos organismos vivos em 3 domínios: Eucarya (eucariontes); Bacteria (eubactéria) e Archae (bactérias termófilas extremas, metanogénicas e halofitas extremas), estabelecendo a origem comum para os seres vivos.

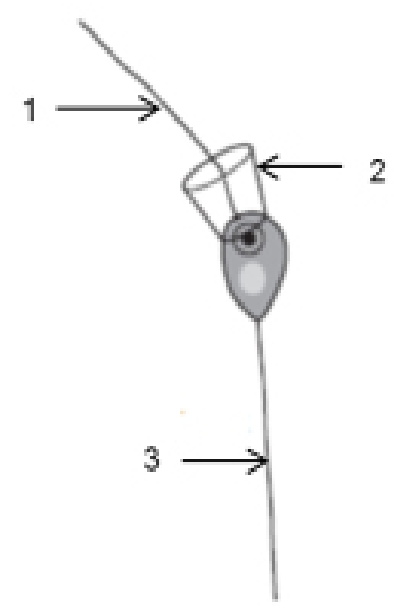

FIGURA 1. Codosiga gracilis. 1 - Flagelo; 2 - Colar; 3 - Pedúnculo.

Codosiga gracilis membro dos coanoflagelados, organismo com um flagelo e um colar, é considerado o ancestral dos fungos e dos animais ${ }^{6}$ (FIGURA 1). Os fungos flagelados Olpidium brassicae e Rozella sp. com posição filogenética incerta, são endoparasitas e apresentam um soma reduzido a um corpo esférico, o qual absorve os nutrientes do citoplasma circundante do hospedeiro. Microsporidia são parasitas intracelulares (principalmente de animais) sem mitocôndrias e com quitina e trealose na parede celular dos esporos (como os fungos). Os estudos moleculares realizados não suportam uma posição filogenética dentro do reino fungi ${ }^{7}$ (FIGURA 2). 


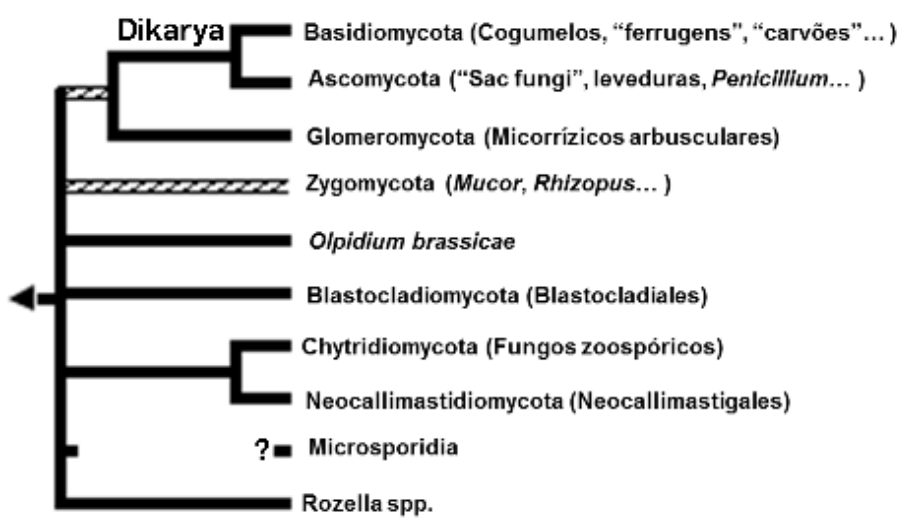

FIGURA 2. Árvore filogenética para o Reino Fungi (adaptada daTree of Life Web project).

Os fungos sensu stricto são organismos eucariontes, heterotróficos, unicelulares (leveduras) ou constituídos por um sistema de filamentos ramificados (as hifas), maioritariamente aeróbios, obtém os seus nutrientes por absorção. Neste processo ocorre a produção e excreção de enzimas que decompõem as moléculas complexas presentes nos substratos, em moléculas mais simples e solúveis em água, sendo estas posteriormente absorvidas para o interior do soma através da parede celular e da membrana citoplasmática. A parede celular é constituida por polissacarídeos principalmente por quitina, glucanas, galactomananas e proteínas são os compostos mais frequentes, embora a quantidade varie entre as diferentes espécies de fungos. 0 principal esterol das membranas é o ergosterol.

A maioria apresenta no seu ciclo de vida duas fases de reprodução que culminam com a produção de esporos, nomeadamente uma fase sexuada com produção de meiósporos e uma fase assexuada com produção de mitósporos.

0 crescimento dos fungos é influenciado por factores abióticos (temperatura, humidade, concentração de oxigénio e de dióxido de carbono e $\mathrm{pH}$ ) e substâncias químicas (nutrientes, vitaminas, fatores de crescimento) ${ }^{8}$.

Para os fungos dimórficos a variação de alguns fatores abióticos e químicos (temperatura, teor de oxigénio, $\mathrm{pH}$ e nutrientes no meio) funciona como interruptor de alternância entre os somas leveduriforme e filamentoso (exemplos: Candida albicans, Cryptococcus neoformans, Fusarium oxyporum, Mucor rouxii, Beauveria bassiana).

A identificação dos fungos baseia-se essencialmente na observação e caraterização morfológica (macroscópica e microscópica) das estruturas vegetativas e reprodutoras produzidas durantes os vários estádios de maturação, com posterior utilização de chaves dicotómicas, sendo atualmente complementada com os dados provenientes da biologia molecular (análises de sequencias de DNA, RNA e de proteínas).

A formação de esporos por mitose, por conseguinte esporos de propagação vegetativa e por isso denominados mitósporos, pode ocorrer dentro de estruturas simples (exemplos: zoósporos e esporangiósporos) dando origem a endósporos ou externamente a partir do soma fúngico dando origem a exósporos (exemplo: conídios). A reprodução sexuada implica a ocorrência de plasmogamia, cariogamia e posterior 
meiose que culmina na produção de meiósporos. Os meiósporos denominam-se: zigósporos - quando se formam por meiose do zigoto, a única estrutura diplóide no ciclo de vida de alguns fungos; ascósporos - os que se formam por meiose em ascos e basidiósporos - os que se formam por meiose em basídios (FIGURA 3A e 3B).
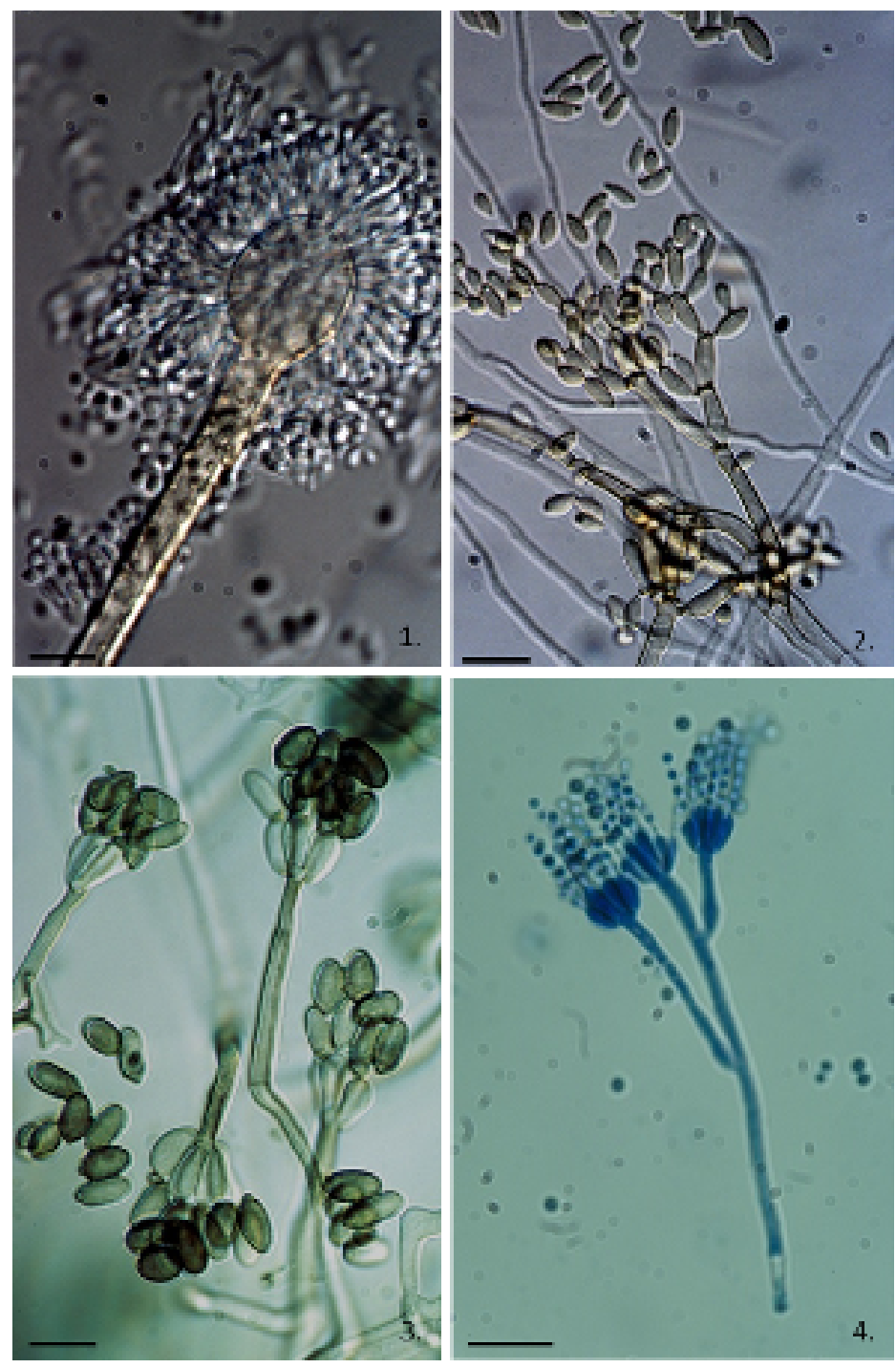

FIGURA 3A. Fase assexuada de 4 fungos filamentosos.1 - Aspergillus sp. Conidióforo com vesícula terminal e conídios. 2 - Cladosporium sp. Conidióforo com conídios. 3 - Stachybotrys sp. Conidióforos com fiálides e conídios. 4 - Penicillium sp. Conidióforos monoverticilados com cadeias basípetas de conídios (Barras das figuras: $1=50 \mathrm{~m} ; 2=15 \mathrm{~m} ; 3=16 \mathrm{~m} ; 4=50 \mathrm{~m} ; 5=25 \mathrm{~m}$ ). (Fotografias de Azevedo, E.). 

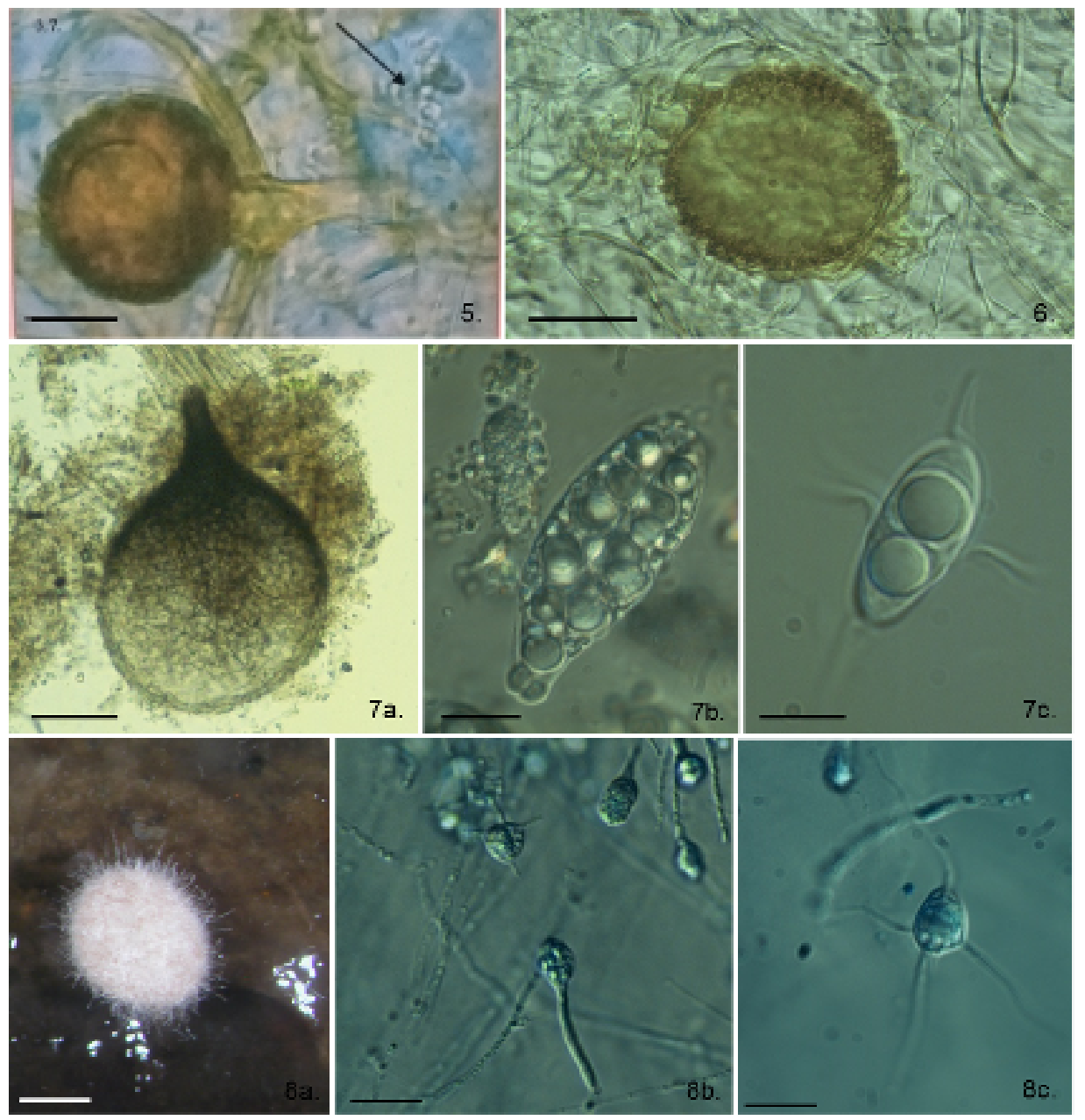

FIGURA 3B. Fase sexuada de 4 fungos filamentosos. 5 - Absidia sp. Zigósporo maduro com apêndices. 6 - Mucor hiemalis Wehmer (1903). Zigósporo maduro. 7 - Halosphaeria apendiculata Linder (1944). a) Peritécio. b) Asco unitunicato imaturo. c) Ascósporo com apêndices mucilaginosos. 8 - Nia vibrissa R. T. Moore \& Meyers (1961) a) Basidiocarpo de cor branca com pêlos peridiais. b) Basídios imaturos. c) Basidiósporo com apêndices mucilaginosos. (Barras das figuras: 5 e $6=50 \mathrm{~m} ; 7 \mathrm{a}=100 \mathrm{~m} ; 7 \mathrm{~b}=15 \mathrm{~m} ; 7 \mathrm{c}=10 \mathrm{~m} ; 8 \mathrm{a}=1 \mathrm{~mm} ; 8 \mathrm{~b}=20 \mathrm{~m}$; $8 \mathrm{c}=10 \mathrm{~m})$. (Fotografias de Azevedo, E.).

A importância económica dos fungos é muito vasta. São importantes produtores de ácidos orgânicos como o ácido cítrico, fumárico e glutâmico e também produtores de metabolitos secundários e enzimas com diferentes aplicações ${ }^{6}$ (QUADRO 1).

Os fungos também são responsáveis pela produção de muitos dos nossos alimentos. A levedura Saccharomyces cerevisiae, com soma unicelular e conhecida pelo nome vulgar de levedura do padeiro, é o microrganismo usado no fabrico do pão. As leveduras com o metabolismo fermentativo, no qual utilizam a glucose produzindo etanol e dióxido de carbono, são também utilizadas na produção de bebidas alcoólicas como o saké Japonês, a cerveja e o vinho.

As espécies Penicillium camemberti, $P$. roquefortii e $P$. caseiolum são responsáveis respetivamente pela produção dos queijos Camembert, Roquefort e Brie, conferindo distintos sabores, texturas e aromas a estes queijos. 
QUADRO 1. Exemplos de metabolitos secundários e de enzimas produzidos comercialmente a partir de fungos e respetivas aplicações (adaptado de Deacon, 2006).

\begin{tabular}{|c|c|c|}
\hline Metabolito & Fungo & Aplicação \\
\hline Penicilinas & Penicillium chrysogenum & Antibacteriano \\
\hline Cefalosporinas & Acremonium chrysogenum & Antibacteriano \\
\hline Griseofulvinas & Penicillium griseofulvum & Antifúngico \\
\hline Ciclosporinas & Tolypocladium spp. & Imunosupressor \\
\hline Giberelinas & Giberella fujikuroi & Hormona de plantas \\
\hline Ergotinas & Claviceps purpurea & $\begin{array}{l}\text { Muitos efeitos incluindo: } \\
\text { tratamento de enxaquecas; } \\
\text { vasoconstritor; vasodilatador; } \\
\text { anti-Parkinson; anti- } \\
\text { hipertensão e distúrbios } \\
\text { psiquiátricos }\end{array}$ \\
\hline \multicolumn{3}{|l|}{ Enzima } \\
\hline$\alpha$-amilase & Aspergillus niger, A. oryzae & Hidrólise do amido \\
\hline Protease & Aspergillus spp. & $\begin{array}{l}\text { Hidrólise de proteinas } \\
\text { (panificação) }\end{array}$ \\
\hline Pectinase & Aspergillus, Rhizopus & Clarificação de sumos de fruta \\
\hline Lipase & Mucor, Aspergillus, Penicillium & Lacticínios e detergentes \\
\hline Renina & Mucor spp. & Coagulação do leite \\
\hline Celulase & Trichoderma reesei & Indústria alimentar \\
\hline Lactase & Aspergillus niger & Indústria alimentar \\
\hline
\end{tabular}

Muitos dos cogumelos silvestres são comestíveis e por isso são colhidos no campo e comercializados em mercados, entre os mais apreciados estão as trufas (Tuber melanosporum e Tuber magnatum), pertencentes ao filo Ascomycota, cujos ascocarpos lembram tubérculos, com odor caraterístico e que são diferenciados debaixo do solo (hipógeos). As trufas formam micorrizas com as raízes de árvores como os carvalhos.

Nos últimos anos registou-se um aumento considerável das atividades económicas relacionadas com a exploração dos cogumelos silvestres. Várias associações micológicas promovem festivais de míscaros (Amanita ponderosa, Lactarius deliciosus), associando a colheita deste recurso à prova gastronómica das espécies encontradas.

Algumas espécies de fungos pertencentes ao filo Basidiomycota já são cultivadas em estufas e os seus corpos frutíferos - basidiocarpos - são comercializados em supermercados. Em Portugal, os principais cogumelos comercializados são: Agaricus bisporus ("champignon de Paris"), Pleurotus ostreatus (cogumelo ostra), Lentinula edodes ("shiitake") e Lactarius deliciosus (míscaro, sancha). Como curiosidade, os fungos conhecidos pelo nome vulgar de "champignon de Paris" são muito apreciados e utilizados em receitas culinárias como strogonoff, risotos e pizas. São ricos em proteínas, em vitaminas do complexo $\mathrm{B}$ e em sais minerais, como o $\mathrm{Ca}, \mathrm{K}, \mathrm{P}$, e Mg.

Considerando o elevado número estimado de espécies fúngicas ainda por identificar é de prever que num futuro próximo, com os avanços científico-tecnológicos, seja possí- 
vel obter novos produtos (como novos medicamentos, bioferilizantes, novos alimentos) a partir destes organismos, aumentando deste modo o sucesso da aplicação dos fungos em benefício do homem e do ambiente.

\section{REFERÊNCIAS}

${ }^{1}$ HAWKSWORTH, D. L., The fungal dimension of biodiversity: magnitude, significance and conservation. Mycological Research, 95: 641-655, 1991.

${ }^{2}$ BLACKWELL, M., The fungi: 1, 2, 3... 5.1. million species?, American Journal of Botany, 98: 426-438, 2001.

${ }^{3}$ HAWKSWORTH, D. L., LÜCKING R., Fungal Diversity Revisited: 2.2 to 3.8 Million Species. Microbiology Spectrum, 5: 1-2, 2017.

${ }^{4}$ WHITTAKER, R. H., New concepts of kingdoms of organisms. Science, 163: 150-160, 1969.

${ }^{5}$ WOESE, C., et al., Towards a natural system of organisms: Proposal for the domains Archaea, Bacteria, and Eucarya. Proceedings of the National Academy of Sciences of the United States, 87: 4576-4579, 1990.

${ }^{6}$ DEACON, J., Fungal Biology. Blackwell publishing. 4th edition, 2006.

${ }^{7}$ HIBBETT, D.S., et al., A higher-level phylogenetic classification of the Fungi. Mycological Research, 111: 509-547, 2007.

${ }^{8}$ ALCÂNTARA, F., et al., Microbiologia Práticas Laboratoriais. Universidade de Aveiro. 1a edição, 1996. 


\section{CITAÇÃO}

Lage, E. (2018)

Viscosidade,

Rev. Ciência Elem., V6(04):085.

doi.org/10.24927/rce2018.085

\section{EDITOR}

José Ferreira Gomes,

Universidade do Porto

\section{EDITOR CONVIDADO}

Jorge Manuel Canhoto,

Universidade de Coimbra

\section{RECEBIDO EM}

7 de fevereiro de 2018

\section{ACEITE EM}

15 de fevereiro de 2018

\section{PUBLICADO EM}

15 de janeiro de 2019

\section{COPYRIGHT}

(C) Casa das Ciências 2018.

Este artigo é de acesso livre, distribuído sob licença Creative Commons com a designação CC-BY-NC-SA 4.0, que permite a utilização e a partilha para fins não comerciais, desde que citado o autor e a fonte original do artigo.

\section{rce.casadasciencias.org}

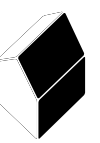

\section{Viscosidade}

\author{
Eduardo Lage \\ Universidade do Porto \\ ejslage@gmail.com
}

Uma propriedade universal dos fluidos e que se manifesta como uma força de atrito.

Qual a origem microscópica da viscosidade ${ }^{1}$ ? Recordemos a sua definição fenomenológica: para manter um fluido (gás ou liquido) em escoamento permanente entre dois planos (FIGURA 1), estando fixo um deles e movendo-se uniformemente o outro, é necessário aplicar uma tensão tangencial $\tau$ neste outro, originando-se, desta forma, um gradiente da velocidade $v_{x}(y)$ o qual satisfaz à lei de Newton: $\tau=\eta \frac{d v_{x}}{d y}$, onde $\eta$ é o coeficiente de viscosidade do fluido. Somos, então, obrigados a concluir que esta é a tensão que se exerce em cada plano, paralelo aos anteriores, situado no interior do fluido, caracterizando a força tangencial, por unidade de área, que a parte do fluido acima do plano exerce sobre a parte abaixo do plano.

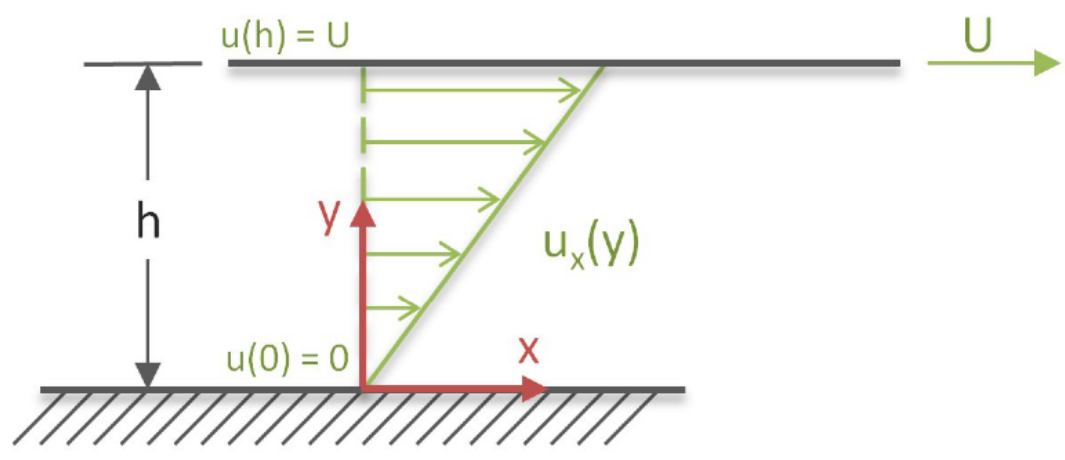

FIGURA 1. A definição do coeficiente de viscosidade.

Comecemos por considerar um gás ou vapor, o que nos permite ignorar, em primeira aproximação, as forças intermoleculares. Considerando a FIGURA 1, as moléculas, em qualquer porção do fluido, têm uma velocidade macroscópica sobreposta à sua agitação microscópica. Imaginemos um plano horizontal no seio do fluido: há moléculas, abaixo deste plano, que passam, num curto intervalo de tempo, para cima, transportando uma quantidade de movimento ligeiramente menor (porque é menor a velocidade macroscópica) que a quantidade de movimento das moléculas acima do plano; no mesmo intervalo de tempo, igual ${ }^{2}$ número de moléculas atravessa o plano de cima para baixo, transportando uma quantidade de movimento ligeiramente maior do que a quantidade de movimento das

\footnotetext{
${ }^{1}$ Ver "Fluidos".

${ }^{2} \mathrm{O}$ número de moléculas que atravessa o plano num e noutro sentido, durante o mesmo curto intervalo de tempo, é estatisticamente o mesmo porque não há transporte macroscópico de massa através do plano.
} 
moléculas abaixo do plano. Deste modo, o fluido acima do plano tende a diminuir a sua quantidade de movimento, i.e, experimenta uma força que o trava; enquanto o fluido abaixo do plano tende a aumentar a sua quantidade de movimento, i.e., experimenta uma força que o acelera. Baseando-nos nesta imagem, podemos deduzir uma expressão para o coeficiente de viscosidade. Consideremos a unidade de área num plano intermédio y qualquer da FIGURA 1.0 número de partículas que, em cada segundo, atravessa esta área, de cima para baixo, é $\frac{1}{4} n\langle v\rangle$, onde $n$ é o número de 4 partículas por unidade de volume e $\langle v\rangle$ é a média da sua velocidade microscópica. Cada uma destas partículas, de massa $m$, transporta a velocidade macroscópica $\boldsymbol{v}_{\boldsymbol{x}}$ calculada, aproximadamente, em $y+l$, onde $l$ é o livre percurso médio (distância média entre colisões sucessivas). Portanto, a quantidade de movimento transferida, por unidade de área e de tempo, de cima para baixo é $\frac{1}{4} n\langle 0\rangle m v_{x}(y+l) ;$ de modo análogo, a quantidade de movimento transferida, por unidade de área e de tempo, de baixo para cima é $\frac{1}{4} n\langle 0\rangle m_{x}(y-l)$. Então, o ganho de quantidade de movimento, por unidade de área e de tempo, da parte do fluido abaixo do plano é a diferença destas duas quantidades, i.e., a tensão tangencial exercida pela parte acima do plano sobre a parte abaixo do plano é $\tau \cong \frac{1}{2} n\langle v\rangle m l \frac{d o_{x}}{d y}$, pelo que $\eta \cong \frac{1}{2} n\langle v\rangle m l$. Assim, um aumento de pressão, que faz aumentar a densidade, ou um aumento de temperatura, que faz aumentar a velocidade microscópica e, portanto, aumenta o fluxo de partículas, levam a um aumento da viscosidade (FIGURA 2).

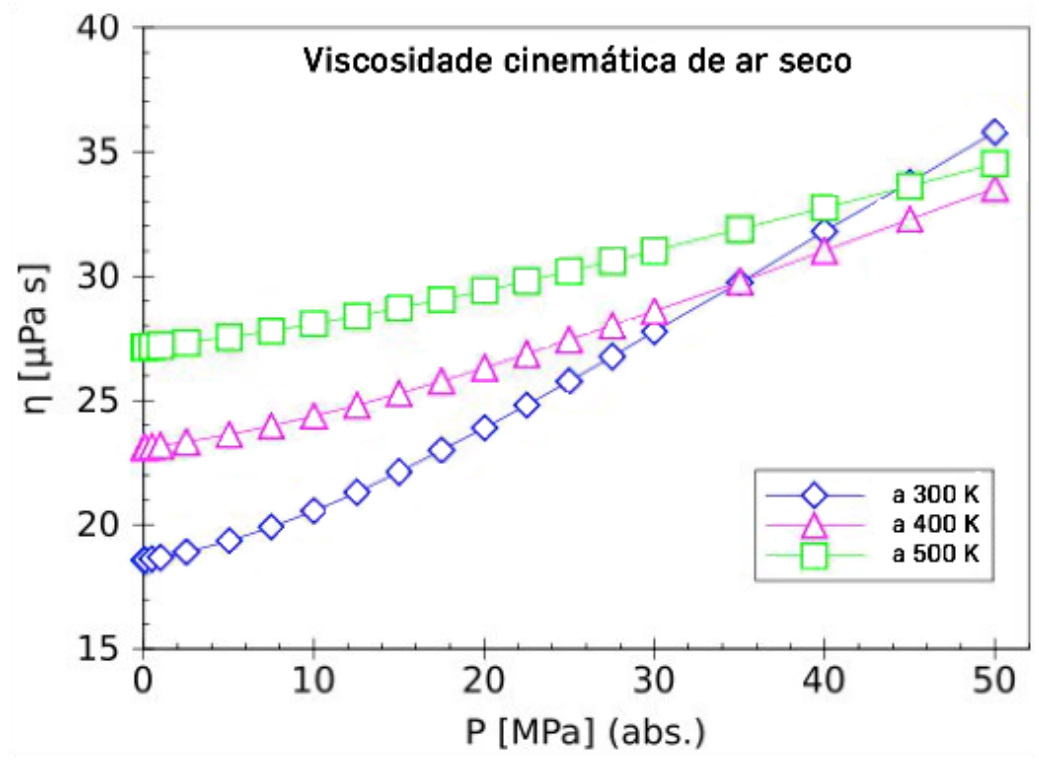

FIGURA 2. Variação do coeficiente de viscosidade num gás (ar seco)

Num liquido, a explicação anterior mantém-se, mas não podemos ignorar as forças intermoleculares: a muito maior densidade de um liquido em relação a um gás, significa, por um lado, que é muito maior o número de moléculas a atravessar o plano imaginado, pelo que é muito maior a viscosidade do líquido do que a de um gás, e, por outro lado, justifica que o efeito da pressão na viscosidade seja diminuto, porque um líquido é praticamente incompressível. Porém, um aumento de temperatura, se aumenta, como num gás, o fluxo 
de partículas, tem, como contrapartida, uma diminuição da importância do potencial intermolecular em relação à energia cinética microscópica, levando o liquido a ter um comportamento mais parecido com o de um gás, i.e., diminuindo a sua viscosidade (FIGURA 3). Note-se a diferença das escalas da viscosidade neste dois gráficos.

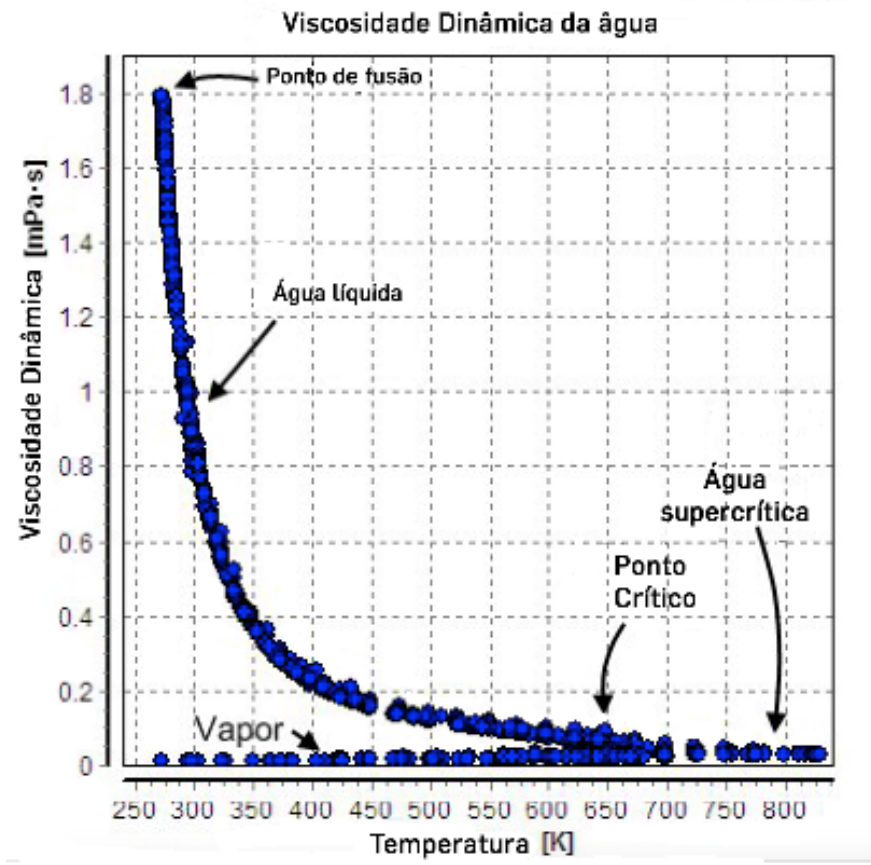

FIGURA 3. Variação o coeficiente de viscosidade com a temperatura num líquido (água) .

\section{REFERÊNCIAS}

${ }^{1}$ MASSEY, B. S., WARD-SMITH, A. J., Mechanics of Fluids (9th ed.). London \& New York: Spon Press, 2011. ISBN 978-0-415-60259-4. OCLC 690084654

2 TRITTON, D.J., Physical fluids dynamics. New York: Van Nostrand-Reinhold, 1977.

${ }^{3}$ J.F. DOUGLAS, J.M. GASIOREK, J.A. SWAFFIELD, Fluid Mechanics, Longman Scientific \& Technical, Essex, 1995.

${ }^{4}$ LAMB, W. Hydrodynamics.

${ }^{5}$ LAI, W. M. et al., Introduction to continuum mechanics. Butterworth-Heinemann, 2009.

${ }^{6}$ PRANDTL, L., \& TIETJENS, O. G., Applied Hydrodynamics.

${ }^{7}$ CURLE, N., DAVIES, H. J., Modern fluid dynamics, 1968.

${ }^{8}$ FETTER, A. L., \& WALECKA, J. D., Theoretical mechanics of particles and continua. Courier Corporation, 2003. 


\section{REFERÊNCIAS}

${ }^{1}$ HOLLIDAY, R., Epigenetics: a historical overview. Epigenetics, 1:76-80, 2006. 


\footnotetext{
2 JABLONKA, E. \& LAMB, M. J., The changing concept of epigenetics. Annals of the New York Academy of Science, 981:82-96, 2002.

${ }^{3}$ RAKYAN, V.K., et al., The marks, mechanisms and memory of epigenetic states in mammals. Biochemical Journal, 356:1-10, 2001.

${ }^{4}$ PRAY, L., Epigenetics: genome, meet your environment. Scientist, 18:14-20, 2004.

${ }^{5}$ WATTERLAND, R.A. \& JIRTLE, R.L., Transposable elements: targets for early nutritional effects on epigenetic gene regulation. Molecular and Cellular Biology, 23:5293-5300, 2003.

${ }^{6}$ JABLONKA, E. \& LAMB, M.J., Trangenerational epigenetic inheritance. In: Evolution, The Extended Synthesis. Pigliucii, M. \& Müller, G.B. (eds.). MIT Press, Cambridge, pp. 137-174, 2010.

${ }^{7}$ HAIG, D., Weismann rules! OK? Epigenetics and the Lamarckian temptation. Biology and Philosophy 22:415-428, 2007.

${ }^{8}$ BURGGREN, W.W., Epigenetics as a source of variation in comparative animal physiology - or - Lamarck is lookin' pretty good these days. Journal of Experimental Biology, 217:682-689, 2014.

${ }^{9}$ MAYR, E., Lamarck revisited. Journal of the History of Biology, 5:55-94, 1972.

10 JABLONKA, E. \& LAMB, M.J., Epigenetic Inheritance and Evolution: The lamarckian inheritance. Oxford University Press, Oxford \& New York, 1995.

${ }^{11}$ RODRIGUES, R.F.C. \& SILVA, E.P., Lamarck: fatos e boatos. Ciência Hoje, 48:68-70, 2011.
} 


\section{CITAÇÃO}

Lage, E. (2018)

Do pêndulo simples ao pêndulo de

Foucault

Rev. Ciência Elem., V6(03):054.

doi.org/10.24927/rce2018.054

\section{EDITOR}

José Ferreira Gomes,

Universidade do Porto

\section{EDITOR CONVIDADO}

Jorge Manuel Canhoto,

Universidade de Coimbra

\section{RECEBIDO EM}

24 de abril de 2018

\section{ACEITE EM}

22 de setembro de 2018

\section{PUBLICADO EM}

04 de outubro de 2018

\section{COPYRIGHT}

(C) Casa das Ciências 2018.

Este artigo é de acesso livre, distribuído sob licença Creative Commons com a designação CC-BY-NC-SA 4.0, que permite a utilização e a partilha para fins não comerciais, desde que citado o autor e a fonte original do artigo.

rce.casadasciencias.org

\section{Do pêndulo simples ao pêndulo de Foucault}

\section{Eduardo Lage}

Universidade do Porto ejslage@gmail.com

$\mathrm{O}$ pêndulo simples é um dos instrumentos mais antigos para medir o ritmo do tempo. $\mathrm{Na}$ sua forma mais primitiva, trata-se de uma pequena massa presa na extremidade de um fio, considerado inextensível e sem peso, o qual tem a outra extremidade fixa num ponto. Fazendo-o oscilar num campo gravítico uniforme, o pêndulo apresenta oscilações isócronas, para pequenas amplitudes, o que o torna num precioso relógio que também pode ser usado para medir indiretamente a longitude, fundamental para a navegação até ao sec. XVIII, ou para medir a intensidade do campo gravítico local, com importantes aplicações em Geofísica. Mas o pêndulo também pode ser posto a rodar em torno da vertical, um movimento que tantas vezes observamos quando, distraidamente, fazemos girar as chaves de casa ou do automóvel suspensas por uma fina corrente. Estes dois tipos de movimento - oscilação e rotação correspondem aos dois graus de liberdade que o pêndulo apresenta, por exemplo, o ângulo $\theta$ que o fio faz com a vertical e o ângulo $\phi$ que o plano do pêndulo, definido pelo fio e pela vertical passando pelo ponto de sustentação, faz com um outro plano vertical fixo. Estes dois movimentos só em situações simples se apresentam separados no caso geral, eles interferem mutuamente originando uma riqueza de comportamentos que nos surpreende.

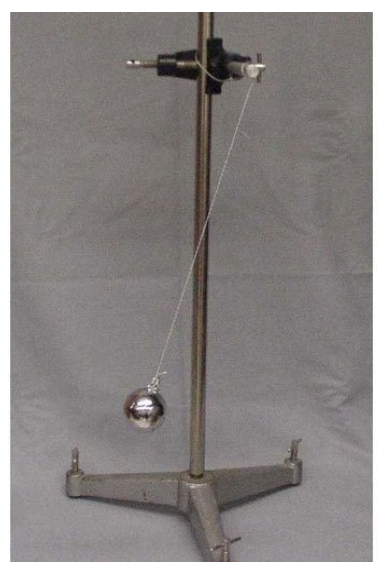

FIGURA 1. 0 pêndulo simples, 
Se a Terra não rodasse, um pêndulo manteria invariante (i.e., imóvel) o seu plano de oscilação. Mas a Terra roda, o que torna o movimento do pêndulo ainda mais interessante porque somos obrigados a considerar a força de Coriolis originada por a Terra não ser um referencial inercial. Uma imediata consequência deste facto é a rotação do plano do pêndulo. Este pêndulo de Foucault, como passou a ser conhecido, permite-nos determinar a latitude do lugar onde o pêndulo se situa.

É interessante observar que o movimento do pêndulo é inteiramente equivalente ao movimento de uma pequena esfera rígida na superfície interior de uma esfera oca, de raio igual ao comprimento do fio.

Neste artigo, é apresentada a análise genérica, mas detalhada, do movimento do pêndulo simples, ignorando, primeiro, a rotação da Terra, para, depois, se estudar o pêndulo de Foucault.

\section{0 pêndulo simples}

A FIGURA 2 mostra a caracterização dos dois graus de liberdade do pêndulo e as forças que sobre ele atuam. Consideramos um sistema tri-rectangular de eixos $O x y z$ com origem no ponto de suspensão, eixo $z$ vertical. Este eixo e o fio, de comprimento $\ell$, definem o plano do pêndulo e permitem a sua caracterização mecânica através dos ângulos $\theta$ que o fio faz com a vertical e $\phi$ que o plano do pêndulo faz com um outro plano vertical fixo, contendo a origem (na figura, o plano $x, z$ ). Indicamos, também, as forças que se fazem sentir sobre a massa $m$ presa na extremidade livre do fio: o seu peso, $m g$, vertical e a tensão $\tau$ exercida pelo fio. Daqui resulta uma imediata e importante consequência: o fio pode puxar a massa, mas não a pode empurrar, pelo que:

$$
\tau \geq 0
$$

Se esta condição não se verificar, o fio deixa de estar esticado e o movimento tem que passar a incluir a distância à origem como uma nova variável dinâmica, i.e., o sistema terá três graus de liberdade.

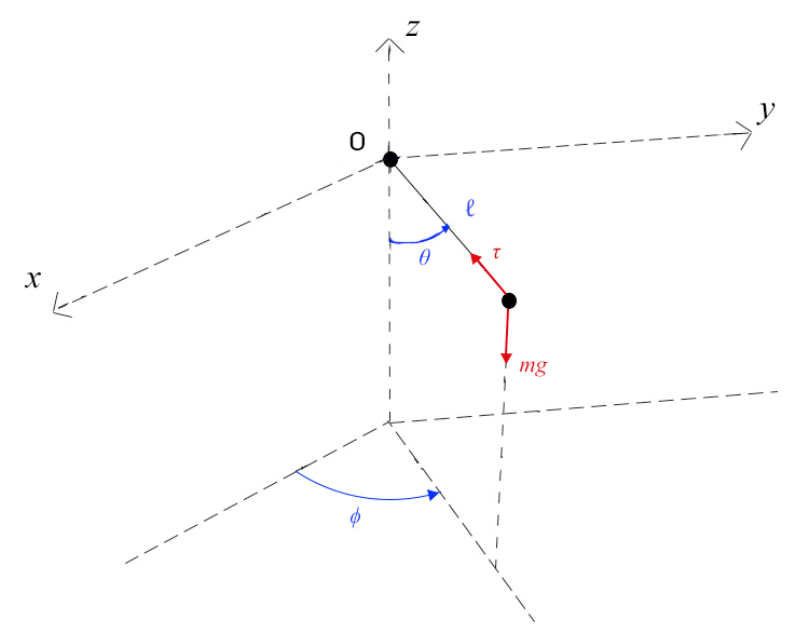

FIGURA 2.

Posto isto, a lei fundamental da dinâmica escreve-se: 
Note-se que a energia mecânica conserva-se: o peso deriva de um potencial e a tensão não realiza trabalho, com o fio esticado, e desaparece se ele deixar de estar esticado. Há três incógnitas no problema: os dois ângulos $\theta$ e $\phi$ e a tensão $\tau$. É conveniente usarmos uma base local definida por três versares ortonormados (FIGURA 3):

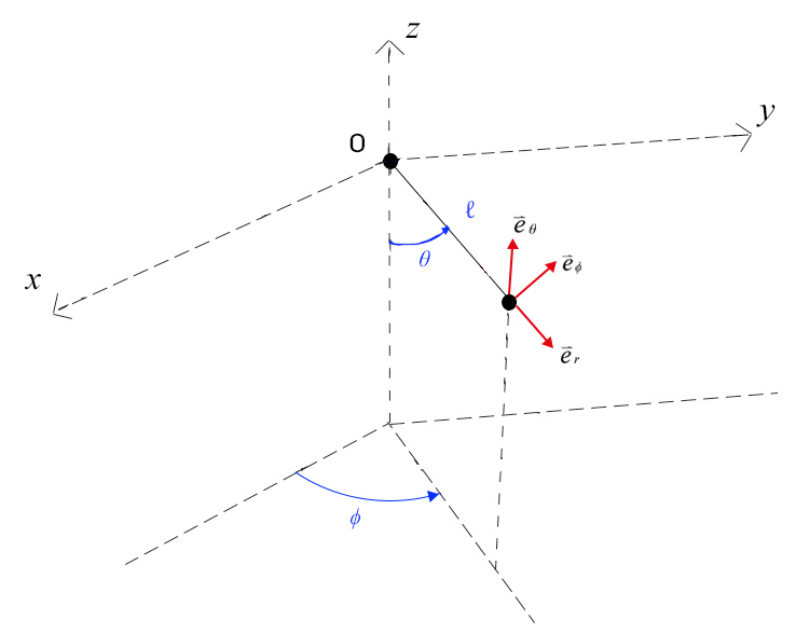

FIGURA 3.

: aponta da origem para a massa

$\vec{e}_{\phi}$ : perpendicular ao plano do pêndulo, com o sentido em que $\phi$ cresce

: no plano do pêndulo, perpendicular ao eixo, com o sentido em que $\theta$ cresce

$\mathrm{O}$ conjunto $\left({ }^{-}, \vec{e}_{\phi},{ }^{n-\ldots}\right)$, nesta ordem, forma um referencial

direto:

$$
\vec{e}_{r} \times \vec{e}_{\phi}=\vec{e}_{\theta}
$$

Da figura, obtém-se facilmente as componentes cartesianas destes versares:

$$
\begin{gathered}
=(\operatorname{sen} \theta \cos \phi, \operatorname{sen} \theta \operatorname{sen} \phi,-\cos \theta) \\
=(\cos \theta \cos \phi, \cos \theta \operatorname{sen} \phi, \operatorname{sen} \theta)=\frac{\partial \vec{e}_{r}}{\partial \theta} \\
\vec{e}_{\phi}=(-\operatorname{sen} \phi, \cos \phi, 0)
\end{gathered}
$$

Posto isto, partindo do vector de posição da massa:

$$
R \frac{d \ln p(T)}{d T}=\frac{s_{i} H_{i}}{T^{T}}
$$

obtemos a expressão da velocidade derivando em ordem ao tempo ${ }^{1}$ :

$$
\vec{v}=\ell \frac{d \vec{e}_{r}}{d t}=\ell\left[\frac{\partial \vec{e}_{r}}{\partial \theta} \theta^{\cdot}+\frac{\partial \vec{e}_{r}}{\partial \theta} \phi \cdot\right]=\ell\left[\theta \cdot \vec{e}_{\theta}+\phi \operatorname{sen} \theta \vec{e}_{\phi}\right]
$$

e, com um pouco mais de trabalho, a sua aceleração:

$$
(\pi) \quad A g \quad T T O
$$


(2) sob a forma das três seguintes equações para as suas componentes na base local:

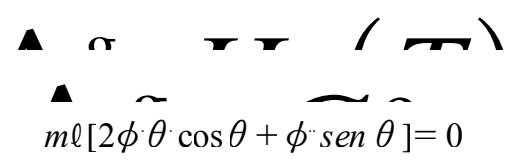

Esta última equação reescreve-se como:

$$
\frac{1}{\operatorname{sen} \theta} \frac{d}{d t}\left(\phi \operatorname{sen}^{2} \theta\right)=0
$$

Encontramos, assim, um integral primeiro:

$$
\left.\phi \operatorname{sen}^{2} \theta\right)=0=\text { constante }
$$

Qual a origem física deste resultado? Observando a FIGURA 1, vemos que, se se considerar o momento das forças com pólo na origem, apenas o peso contribui, sendo, pois nula, a sua projeção vertical. Então, pelo teorema dos momentos cinéticas, deverá ser constante a componente $L_{z}$. Ora:

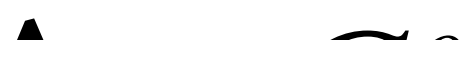

Assim,

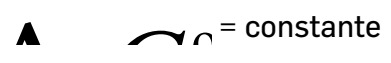

o que justifica a eq. (8).

Este sistema também conserva a energia mecânica: a tensão do fio não realiza trabalho e o peso deriva de uma energia potencial. Ora, a energia mecânica é:

$$
\frac{d E}{d t}=0 \rightarrow m \ell^{2} \theta\left(\theta+\phi^{2} \operatorname{sen} \theta \cos \theta\right)+m \ell^{2} \phi \phi \operatorname{sen}^{2} \theta+\operatorname{mg} \ell \theta \operatorname{sen} \theta=0
$$

Eliminando $\phi^{\prime \prime}$ pela eq. (7c), e simplificando o resultado, obtemos a eq. (7b).

Estes dois resultados mostram que as equações do movimento (7b) e (7c) são equivalentes, respetivamente, às conservações da energia mecânica e da componente vertical do momento cinético. Poderiamos, até, partir destas leis de conservação para deduzir rapidamente as equações do movimento. Não obteríamos, contudo, a eq. (7a) que fornece a tensão do fio, submetida à desigualdade expressa na eq. (1). É precisamente daqui que decorre uma grande riqueza de comportamentos do pêndulo como, a seguir, se analisa com alguns casos particulares.

a) Solução $\theta \equiv \theta_{0}=$ constante $\neq 0\left(\theta_{0}=0\right.$ não corresponde a qualquer movimento!)

A eq. (7c) dá: 


$$
\phi \operatorname{sen} \theta_{0}=0 \rightarrow \phi "=0
$$

0 pêndulo executa uma rotação circular em torno da vertical. Mas nem todas as configurações para tais rotações são possíveis; de facto, a eq. (7a) mostra que:

$$
\frac{\tau}{m}=g \cos \theta_{0}+\ell \phi^{2} \operatorname{sen}^{2} \theta_{0}=g\left(\cos \theta_{0}+\frac{\operatorname{sen}^{2} \theta_{0}}{\cos \theta_{0}}\right)=\frac{g}{\cos \theta_{0}}
$$

onde se usou a eq. (7b) para eliminar $\phi^{2}$. Assim, a condição (1) exige:

$$
\tau \geq 0 \rightarrow \theta_{0} \leq \frac{\pi}{2}
$$

A FIGURA 4 exibe este movimento para o qual $\phi^{2}=\frac{g}{l \cos \theta_{0}}$

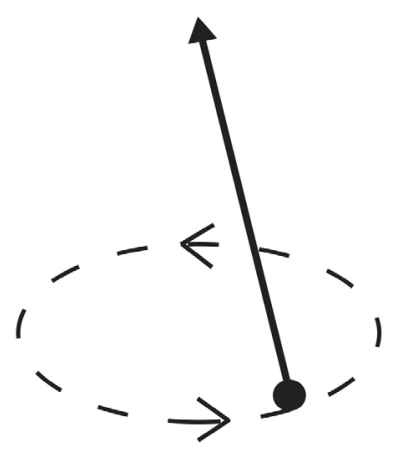

FIGURA 4.

Que aconteceria se tentássemos fazer rodar o pêndulo acima do plano horizontal passando pelo ponto de suspensão, i.e., $\theta_{0} \leq \frac{\pi}{2}$ ? A eq. (1) seria vilolada: o fio não permaneceria esticado e a massa "cairia" para o interior da esfera imaginária, de centro naquele ponto e raio $l$, o que nos obrigaria a discutir o movimento subsequente com mais um grau de liberdade (a distância à origem).

b) Solução $\phi \equiv \phi_{0}=$ constante $\rightarrow L_{\mathrm{z}}=0$

Agora, o plano do pêndulo é invariante, mas diversos comportamentos dinâmicos são possíveis, dependendo das condições iniciais. Reescrevamos as equações básicas sob a forma:

$$
\begin{gathered}
\frac{\tau}{m l}=\omega_{0}^{2} \cos \theta+\theta^{.2} \geq 0 \\
\theta+\omega_{0}^{2} \operatorname{sen} \theta=0 \rightarrow E=m \ell^{2}\left(\frac{\theta^{2}}{2}-\omega_{0}^{2} \cos \theta\right)
\end{gathered}
$$

onde:

$$
\omega_{0}^{2} \equiv \frac{g}{l}
$$


(i) Para oscilações de pequena amplitude $(\theta<<1)$, é sempre $\tau>0$ e a equação de movimento reduz-se à equação de um oscilador harmónico de frequência natural $\omega_{0}$ :

$$
\theta+\omega_{0}^{2} \theta=0
$$

Trata-se de um movimento oscilatório com aquela frequência.

(ii) Consideremos, agora as seguintes condições iniciais:

$$
\theta(0)=0 \quad \theta(0)=\theta_{0} \neq 0
$$

0 pêndulo é largado com velocidade nula na posição $\theta_{0}$, mas esta não pode ser qualquer porque o valor inicial da tensão, $\tau(0)=m l \omega_{0}^{2} \cos \theta_{0}$, exige $\theta_{0} \leq \frac{\pi}{2}$ o pêndulo não pode ser largado acima do plano horizontal passando pela origem. Uma vez assegurada esta condição, a conservação da energia mecânica dá, imediatamente, a velocidade:

$$
\frac{\theta^{2}}{2}=2 \omega_{0}^{2}\left(\cos \theta-\cos \theta_{0}\right)
$$

Assim, a oscilação dá-se no intervalo $-\theta_{0} \leq \theta \leq \theta_{0}$, como se representa na FIGURA 5.

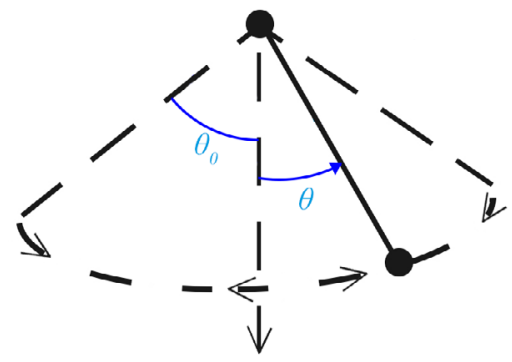

FIGURA 5.

(ii) Analisemos, agora, o que se passa com as condições iniciais:

$$
\theta(0)=\theta_{0} \neq 0 \quad \theta(0)=0
$$

Tal corresponde a dar um impulso ao pêndulo quando este se encontra na posição de equilíbrio. Da conservação da energia mecânica resulta:

$$
\theta^{2}=\theta_{0}^{2}-2 \omega_{0}^{2}(1-\cos \theta)
$$

Há várias hipóteses a considerar devido à condição sobre a tensão do fio:

$$
\frac{\tau}{m l}=\theta^{2}-\omega_{0}^{2}(2-3 \cos \theta)
$$

1 à $\operatorname{Se} \theta_{0}^{2} \geq 5 \omega_{0}^{2}$ o pêndulo gira no plano vertical, efetuando um movimento circular (FIGU- 
RA 6). Com efeito, mesmo para $\theta=\pi$, é $\tau \geq 0$, tendo o pêndulo velocidade no seu ponto mais alto: $\theta^{2}=\theta_{0}^{2}-4 \omega_{0}^{2}$ para $\theta=\pi$. Trata-se, pois, de um rotação do pêndulo.

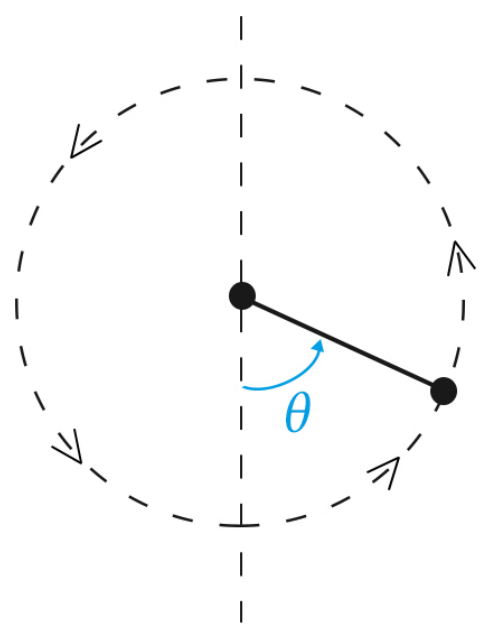

FIGURA 6 .

2a Se $2 \omega_{0}^{2}<\theta_{0}^{2}<5 \omega_{0}^{2}$, o movimento pendular não é possível porque a tensão anula-se numa posição $\theta^{\star}$ na qual o pêndulo ainda se move.

Com efeito, $\theta^{*}$, para o qual é $\tau=0$, é determinado por $\cos \theta^{*}=\frac{1}{3}\left(2-\frac{\theta_{0}^{2}}{\omega_{0}^{2}}\right)$, vindo $\theta^{*}$ real para $\theta_{0}^{2}$ no intervalo considerado. Mas, nesse ponto, é: $\theta^{2}=\frac{1}{3}\left(\theta_{0}^{2}-2 \omega_{0}^{2}\right)>0$.

3a Se $0 \leq \theta_{0}^{2} \leq 2 \omega_{0}^{2}$, o pêndulo executa um moimento oscilatório situado no intervalo - $\theta_{M} \leq \theta \leq \theta_{M}$, onde $\theta_{M}$ é o ponto onde se anula a velocidade, i.e.,

$$
\cos \theta_{M}=1-\frac{\theta_{0}^{2}}{2 \omega_{0}^{2}} \geq 0 \rightarrow 0<\theta_{M} \leq \frac{\pi}{2}
$$

Nesse ponto, a tensão é não negativa:

$$
\frac{\tau}{m l}=\omega_{0}^{2} \cos \theta_{M} \geq 0
$$

Este caso contem, evidentemente, as pequenas oscilações atrás tratadas.

\section{0 pêndulo de Foucault}

Qual o efeito da rotação da Terra no movimento de um pêndulo? Para um observador terrestre, somos obrigados a considerar as forças inerciais ${ }^{2}$, destas, a única que importa é a força de Coriolis ${ }^{3}$ :

$$
\vec{F}_{c}=-2 m \vec{\omega}_{T} \times \vec{v}
$$

\footnotetext{
${ }^{2}$ Ver «Força».

${ }^{3}$ Com efeito, a rotação da Terra pode ser considerada uniforme e com eixo fixo em escalas de tempo da ordem de milhares de anos; os outros termos das forças inerciais, exceto Coriolis) adicionam a força centrífuga à força da gravidade, originando a definição de $\vec{g}$ e a sua dependência na latitude.
} 
onde $\vec{\omega}_{T}$ é o vector rotação instantânea da Terra. Vemos já, embora qualitativamente, que o plano de oscilação de um pêndulo não é mais invariante: a força de Coriolis, perpendicular à velocidade, obriga este plano a rodar. Procedamos à análise quantitativa considerando o caso habitual de pequenas oscilações, o que nos irá garantir que o fio permanece tenso. Para isso, é conveniente considerar, agora, um referencial cartesiano com origem no ponto de suspenção do pêndulo e com os eixos assim definidos (FIGURA 7):

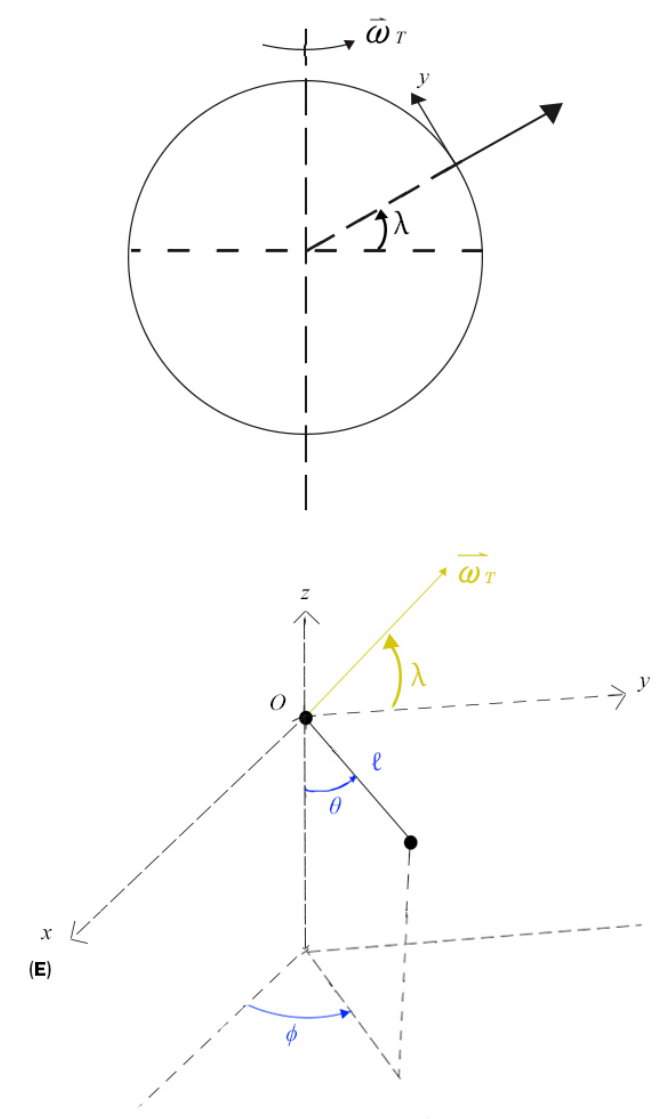

FIGURA 7

eixo $z$ : vertical do lugar (dirigido para cima)

eixo $y$ : tangente ao meridiano do lugar, apontando para Norte

eixo $x$ : tangente ao paralelo do lugar, apontando para Este.

Deste modo, o vector $\vec{\omega}_{T}$ situa-se no plano $(y z)$ fazendo um ângulo $\lambda$ (latitude do lugar) com o eixo $y$.

Para a análise do movimento, basta-nos estudar a evolução do momento cinético:

$$
\frac{d \vec{L}}{d t}=\vec{M}=\vec{r} \times(m \vec{g})-2 m \vec{r} \times\left(\vec{\omega}_{T} \times \vec{v}\right)=\vec{r} \times(m \vec{g})+2 m \vec{r} \cdot \vec{\omega}_{T} \vec{v}
$$

onde se atendeu a que $\vec{r} \cdot \vec{v}=0$ (fio permanece esticado). Usando a expressão do momento cinético atrás obtida, eq. 9, é imediato escrever as equações do movimento: 


$$
\begin{gathered}
\theta=\phi^{2} \operatorname{sen} \theta \cos \theta=-\omega_{0}^{2} \operatorname{sen} \theta-2\left(\vec{e}_{r} \cdot \vec{\omega}_{T}\right) \phi \operatorname{sen} \theta \\
2 \phi \theta \cos \theta+\phi^{\prime} \operatorname{sen} \theta=2\left(\vec{e}_{r} \cdot \vec{\omega}_{T}\right) \theta
\end{gathered}
$$

estas equações generalizam as eqs. (7b) e (7c) ao incluírem os efeitos da rotação da Terra.

Ora, $\vec{\omega}_{T}$ tem as componentes cartesianas $\vec{\omega}_{T}=\omega_{T} \quad(0, \cos \lambda$, sen $\lambda)$, pelo que:

$$
\vec{e}_{r} \cdot \vec{\omega}_{T}=\omega_{T}(\cos \lambda \operatorname{sen} \theta \cos \phi-\operatorname{sen} \lambda \cos \theta)
$$

Para pequenas amplitudes de oscilação do pêndulo $(\theta<<1)$, vem:

$$
\vec{e}_{r} \cdot \vec{\omega}_{T} \cong-\omega_{T} \operatorname{sen} \lambda
$$

pelo que a eq. (15b) admite a solução:

$$
\phi^{\cdot}=-\omega_{T} \operatorname{sen} \lambda
$$

Quer dizer, o plano do pêndulo roda, em torno da vertical, no sentido dos ponteiros do relógio no hemisfério Norte $(\lambda>0)$ e no sentido contrário no hemisfério Sul $(\lambda<0)$. Esta rotação é uniforme e informa diretamente sobre a latitude do lugar.

Finalmente, a eq. (15a) mostra que o período de oscilação do pêndulo é alterado:

$$
\omega_{0} \rightarrow \sqrt{\phi^{2}+\omega_{0}^{2}}
$$

Porém, esta alteração é, praticamente, impercetível para as condições experimentais habituais $\left(\omega_{0}>>\omega_{T}\right)$

Tem interesse, neste contexto, analisar o valor de $\omega_{T^{*}}$ Como a Terra efetua uma rotação completa em $24 \mathrm{~h}$, poder-se-ia pensar que $\omega_{T} \approx \frac{2 \pi}{24 \times 3600} s^{-1}$.Mas não é assim! Com efeito, um dia, i.e., $24 \mathrm{~h}$ é o tempo que decorre, para um observador na Terra, para o mesmo ponto do planeta se encontrar alinhado com o Sol. Mas, durante esse tempo, a Terra também se deslocou no seu movimento de translação em torno do Sol, que também é uma rotação. Para simplificar, aceitemos que este movimento é circular uniforme, realizando-se no mesmo sentido que a rotação da Terra (FIGURA 8). Então, ao fim de 24 h, a Terra rodou um pouco mais que $2 \pi$ e este excesso acumula-se exatamente em $2 \pi$ ao fim de um ano, quando a Terra regressa à sua posição inicial. Quer dizer, para um observador no Sol, considerado como observador inercial para quem $\omega_{T}$ é definido, a Terra rodou 366 vezes no tempo correspondente a 365 dias terrestres, i.e., $\frac{366}{365}$ vezes po dia terrestre, pelo que:

$$
\omega_{T} \approx \frac{2 \pi}{24 \times 3600} \times \frac{366}{365} s^{-1} \approx 7.3 \times 10^{-5} s^{-1}
$$




\section{REVISTA DE CIÊNCIA ELEMENTAR}

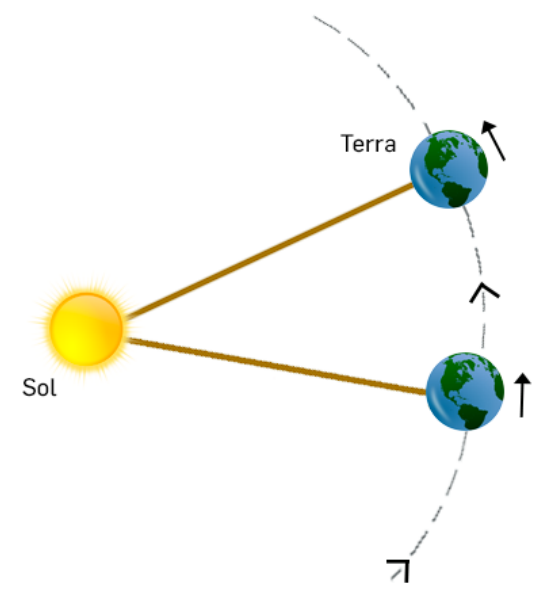

FIGURA 8.

\section{REFERÊNCIAS}

${ }^{1}$ GOLDSTEIN, H. et al., Classical Mechanics, Addison Wesley 3ạ edição, 2001.

2 FEYNMAN, R.P. et al., The Feynman Lectures on Physics. San Francisco: Pearson/Addison-Wesley ,Vol. 1, section 12-5, 2006. ISBN 0-8053-9049-9

${ }^{3}$ LANDAU, L.D. e LIFSHITZ, E.M., Mechanics. Course of Theoretical Physics. Vol. 1 (3rd ed.). ButterworthHeinenan, pp. 128-130, 1976. 


\section{CITAÇÃO}

Lage, E. (2018)

Pêndulo de Foucault,

Rev. Ciência Elem., V6(03):069.

doi.org/10.24927/rce2018.069

\section{EDITOR}

José Ferreira Gomes,

Universidade do Porto

\section{EDITOR CONVIDADO}

João Lopes dos Santos,

Universidade do Porto

\section{RECEBIDO EM}

24 de abril de 2018

\section{ACEITE EM}

22 de setembro de 2018

\section{PUBLICADO EM}

04 de outubro de 2018

\section{COPYRIGHT}

(C) Casa das Ciências 2018.

Este artigo é de acesso livre, distribuído sob licença Creative Commons com a designação CC-BY-NC-SA 4.0, que permite a utilização e a partilha para fins não comerciais, desde que citado o autor e a fonte original do artigo.

rce.casadasciencias.org

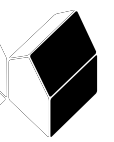

\section{Pêndulo de Foucault}

\author{
Eduardo Lage \\ Universidade do Porto \\ ejslage@gmail.com
}

Qual o efeito da rotação da Terra no movimento de um pêndulo simples ? Esta questão foi, primeiramente, considerada pelo físico francês Jean Bernard Léon Foucault (FIGURA 1A). Para isso, construiu, em 1851 , um pêndulo com fio de $67 \mathrm{~m}$ de comprimento na extremidade do qual colocou uma massa esférica de $30 \mathrm{Kg}$, assegurando, dessa forma, um grande período de oscilação (cerca de 16s) e um fraco amortecimento devido à resistência do ar (FIGURA 1B). Colocado a oscilar, com uma pequena amplitude, verifica-se que o plano de oscilação do pêndulo roda lentamente, demonstrando, dessa forma, a rotação da Terra. 0 pêndulo de Foucault, como passou a ser designado, causou, na época, enorme sensação e é hoje um instrumento obrigatório em qualquer museu de ciência.

Como se justifica esta rotação do plano do pêndulo? Para um observador terrestre, somos obrigados a considerar as forças inerciais e, destas, a única que aqui importa é a força de Coriolis:

$$
\vec{F}_{C}=-2 m \vec{\omega}_{T} \times \vec{v}
$$
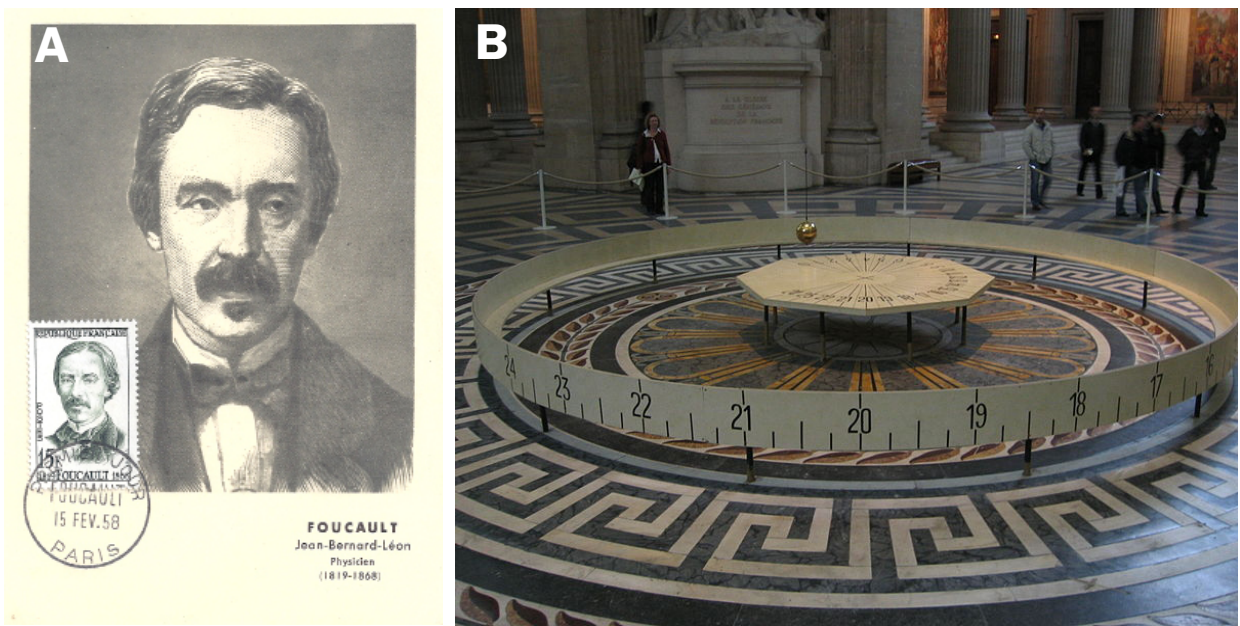

FIGURA 1. A- Léon Foucault selo comemorativo. B- Pêndulo de Foucault no Pantheón de Paris.

${ }^{1}$ Com efeito, a rotação da Terra pode ser considerada uniforme e com eixo fixo em escalas de tempo da ordem de milhares de anos; os outros termos das forças inerciais, exceto Coriolis adicionam a força centrífuga à força da gravidade, originando a definição de $\vec{g}$ e a sua dependência na latitude. 
onde $\vec{\omega}_{T}$ é o vetor rotação instantânea da Terra. Vemos já, embora qualitativamente, que o plano de oscilação de um pêndulo não é mais invariante: a força de Coriolis, perpendicular à velocidade, obriga este plano a rodar.

Procedamos à análise quantitativa, um pouco simplificada, considerando o caso habitual de pequenas oscilações, o que nos irá garantir que o fio permanece tenso. Nestas condições, o movimento do pêndulo situa-se, praticamente, no plano horizontal, onde escolhemos eixos $x$, tangente o paralelo dirigido para Este, e $y$, tangente ao meridiano dirigido para Norte (FIGURA 2). São ambos, evidentemente, perpendiculares entre si e também perpendiculares ao eixo vertical $z$. Será evidente que apenas a componente vertical de $\vec{\omega}_{T}$, é responsável pela rotação do plano de oscilação. Se não houvesse a força de Coriolis, o movimento do pêndulo seria o de um oscilador harmónico, como se viu noutra publicação, o que significa que estaria, apenas, submetido à força - $m \omega_{0}^{2} \vec{r}$, onde $\omega_{0}=\sqrt{g} / l$ sendo $l$ o comprimento do pêndulo. Pela consideração anterior, a força de Coriolis fica reduzida ao termo $-2 m \omega_{T} \operatorname{sen} \lambda \overrightarrow{e_{Z}} \times \vec{v}$, onde $\lambda$ é a latitude do lugar. Assim, as equações de movimento no plano horizontal, são:

$$
\begin{aligned}
& m \frac{d^{2} x}{d t^{2}}=-m \omega_{0}^{2} x+2 m \omega_{T} \operatorname{sen} \lambda \frac{d y}{d t} \\
& m \frac{d^{2} y}{d t^{2}}=-m \omega_{0}^{2} y+2 m \omega_{T} \operatorname{sen} \lambda \frac{d x}{d t}
\end{aligned}
$$

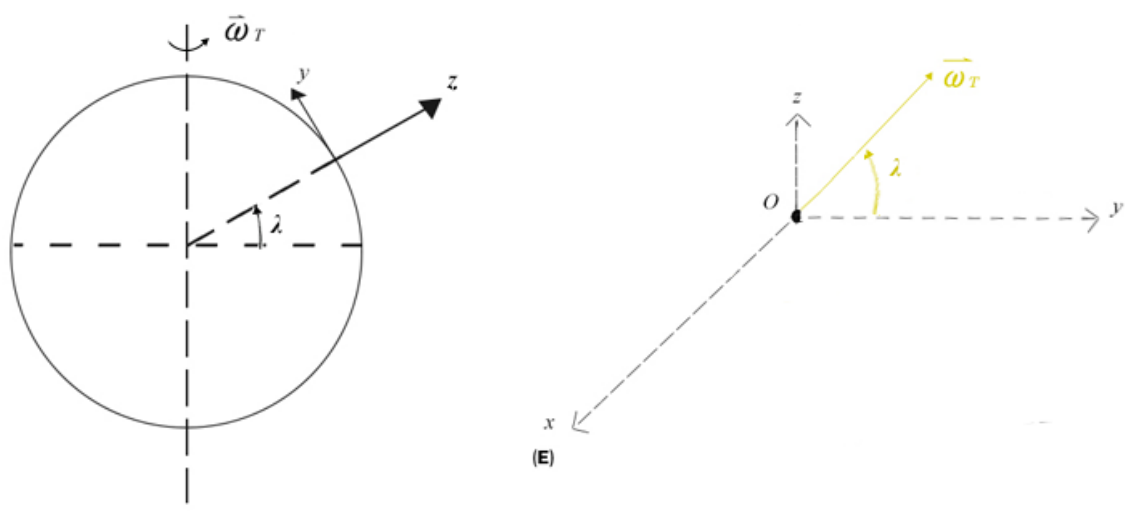

FIGURA 2. A escolha dos eixos locais na Terra (à esquerda) e a orientação do eixo da Terra nos eixos locais (à direita).

É útil, aqui, introduzir o complexo $w=x+i y$. Obtem-se:

$$
\frac{d^{2} w}{d t^{2}}+\omega_{0}^{2} w+2 i \omega_{T} \operatorname{sen} \lambda \frac{d w}{d t}=0
$$

É uma equação linear, pelo que se procuram soluções da forma $w \sim e^{i \omega t}$, vindo:

$$
-\omega^{2}+\omega_{0}^{2}-2 \omega \omega_{T} \operatorname{sen} \lambda=0
$$

Na situação habitual, é $\omega_{0}>\omega_{T}$, resultando:

$$
\omega=\mp \omega_{0}-\omega_{T} \operatorname{sen} \lambda
$$

Deste modo, a solução geral para $w(t)$ é: 


$$
w(t)=e^{-i t \omega_{T} \operatorname{sen} \lambda}\left(A e^{i t \omega_{0}}+B e^{-i t \omega_{0}}\right)
$$

onde $A$ e $B$ são constantes, complexas, determinadas pelas condições iniciais. Suponhamos, então, que estas condições são $w(0)=w_{0} \equiv a+i b$ e $w \cdot(0)=0$, isto é, o pêndulo é largado na posição genérica $x=a$ e $y=b$, com velocidade nula. Obtem-se, assim:

$$
A=\frac{\omega_{0}+\omega_{T} \operatorname{sen} \lambda}{2 \omega_{0}} \cong \frac{1}{2} \quad B=\frac{\omega_{0}-\omega_{T} \operatorname{sen} \lambda}{2 \omega_{0}} \cong \frac{1}{2}
$$

Substituindo na expressão anterior para $w(t)$, resulta:

$$
w(t)=e^{-i t \omega T \operatorname{sen} \lambda} w_{0} \cos \left(\omega_{0} t\right)
$$

Se $\omega_{T}=0$, este complexo tem sempre a direção de $w_{0}$, i.e, a trajetória seria sempre um segmento de reta, o que corresponde ao plano invariante do pêndulo. Mas $\operatorname{com} \omega_{T}>0$, a fase do complexo cresce linearmente no tempo, i.e., a trajetória roda, no sentido contrário ao dos ponteiros de um relógio, o que corresponde à rotação do plano do pêndulo, como se mostra na FIGURA 3.

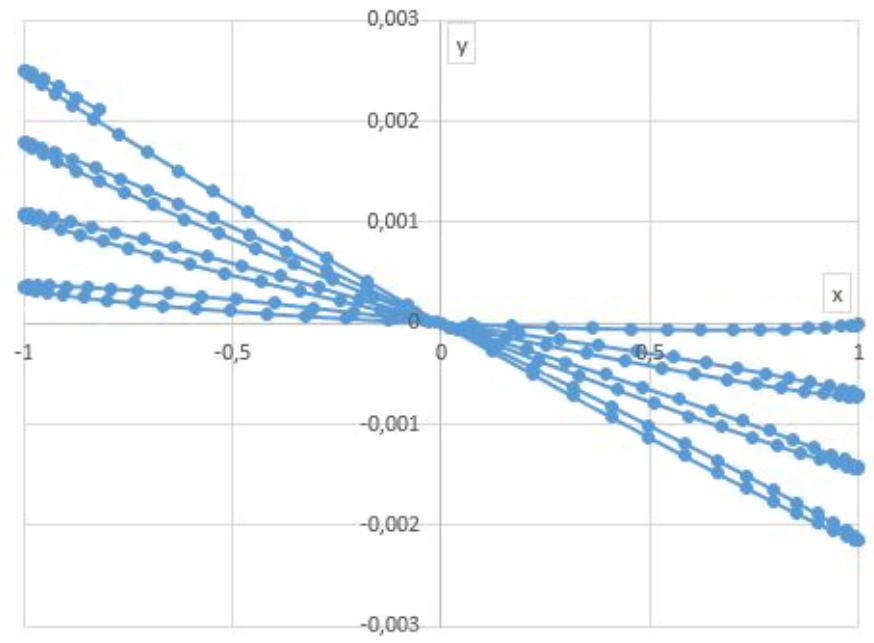

FIGURA 3. Primeiras oscilações do pêndulo, em Paris, $\lambda=49^{\circ} \mathrm{N}$; comprimento do pêndulo $67 \mathrm{~m}$, período natutal do pêndulo/período da Terra=0,002; posição inicial $x=1, y=0$.

Tem interesse, neste contexto, analisar o valor de $\omega_{T^{*}}$ Como a Terra efetua uma rotação completa em $24 \mathrm{~h}$, poder-se-ia pensar que $\omega_{T} \approx \frac{2 \pi}{24 \times 3600} s^{-1}$.Mas não é assim! Com efeito, um dia, i.e., 24 h é o tempo que decorre, para um observador na Terra, para o mesmo ponto do planeta se encontrar alinhado com o Sol. Mas, durante esse tempo, a Terra também se deslocou no seu movimento de translação em torno do Sol, que também é uma rotação. Para simplificar, aceitemos que este movimento é circular uniforme, realizando-se no mesmo sentido que a rotação da Terra (FIGURA 4). Então, ao fim de $24 \mathrm{~h}$, a Terra rodou um pouco mais que $2 \pi$ e este excesso acumula-se exatamente em $2 \pi$ ao fim de um ano, quando a Terra regressa à sua posição inicial. Quer dizer, para um observador no Sol, considerado como observador inercial para quem $\omega_{T}$ é definido, a Terra rodou 366 vezes no tempo correspondente a 365 dias terrestres, i.e., $\frac{366}{365}$ vezes po dia terrestre, pelo que:

$$
\omega_{T} \approx \frac{2 \pi}{24 \times 3600} \times \frac{366}{365} s^{-1} \approx 7.3 \times 10^{-5} s^{-1}
$$




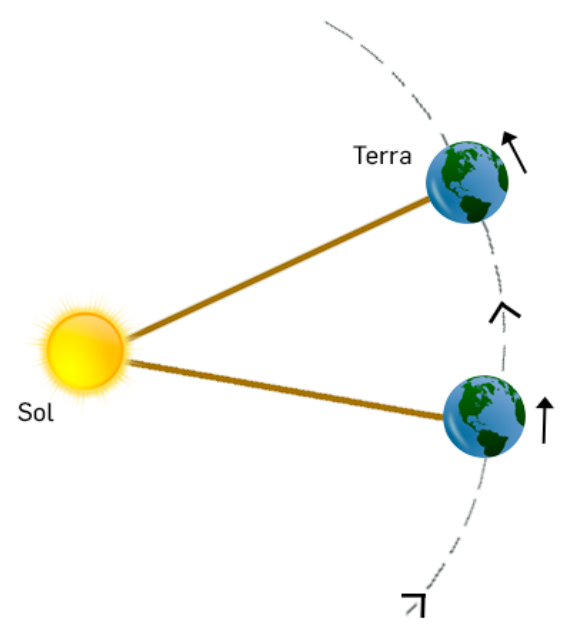

FIGURA 4. Em 24h, a Terra não só rodou em torno do seu eixo como rodou, ligeiramente, em torno do Sol.

\section{REFERÊNCIAS}

${ }^{1}$ GOLDSTEIN, H. et al., Classical Mechanics, Addison Wesley 3a edição, 2001.

${ }^{2}$ FEYNMAN, R.P. et al., The Feynman Lectures on Physics. San Francisco: Pearson/Addison-Wesley ,Vol. 1, section 12-5, 2006. ISBN 0-8053-9049-9

${ }^{3}$ LANDAU, L.D. e LIFSHITZ, E.M., Mechanics. Course of Theoretical Physics. Vol. 1 (3rd ed.). ButterworthHeinenan, pp. 128-130, 1976. 


\title{
Fluidos
}

\author{
Eduardo Lage \\ Universidade do Porto \\ ejslage@gmail.com
}

\section{CITAÇÃO \\ Lage, E. (2018) \\ Fluidos, \\ Rev. Ciência Elem., V6(03):068. \\ doi.org/10.24927/rce2018.068}

\section{EDITOR}

José Ferreira Gomes,

Universidade do Porto

\section{EDITOR CONVIDADO}

Jorge Manuel Canhoto,

Universidade de Coimbra

\section{RECEBIDO EM}

7 de fevereiro de 2018

\section{ACEITE EM}

15 de fevereiro de 2018

\section{PUBLICADO EM}

04 de outubro de 2018

\section{COPYRIGHT}

(C) Casa das Ciências 2018.

Este artigo é de acesso livre, distribuído sob licença Creative Commons com a designação CC-BY-NC-SA 4.0, que permite a utilização e a partilha para fins não comerciais, desde que citado o autor e a fonte original do artigo.

rce.casadasciencias.org

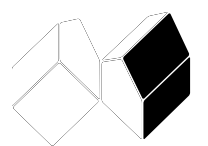

Quando pensamos em fluidos, ocorre-nos, imediatamente, a água ou o ar, os exemplos mais conhecidos de uma família vastíssima onde se incluem os óleos e as tintas, a pasta dentrífica e o champô, o magma e a lava, o mel e o chantilly, cristais líquidos e electrólitos," etc., etc.. Estes exemplos partilham a propriedade fundamental de um fluido: a sua capacidade de escoar, i.e., uma taxa de variação temporal de deformações mesmo que sejam estáticas as tensões ou forças exteriores (ao fluido) a que estejam submetidas, em óbvio contraste com um sólido onde tensões ou forças estáticas originam deformações também estáticas. Tanto um sólido como um fluido, se submetidos a pressões uniformes, alteram o seu volume; mas se aplicarmos tensões tangenciais, um sólido torce até atingir uma nova configuração de equilíbrio, enquanto que um fluido entra em escoamento. Veremos, adiante, como caracterizar esta última propriedade.

Em equilíbrio termodinâmico, qualquer substância encontra-se numa fase termodinâmica bem definida, dependente da pressão e temperatura a que esteja condicionada. Tal é representado num diagrama de fases (FIGURA 1) onde estas estão separadas por linhas limitando regiões dentro das quais a respectiva fase é estável. As fases líquida e vapor (ou gás) exibem comportamentos de fluidos. Para uma dada temperatura, por exemplo, um aumento da pressão faz condensar o vapor quando se atinge a linha que separa as fases líquido-vapor; inversamente, se se diminuir a pressão, partindo da fase liquida, ocorrerá evaporação quando a linha é cruzada. A diferença entre estas duas fases (líquido e vapor) é, essencialmente, uma diferença de densidades, maior no liquido do que no vapor. Esta diferença de densidades anula-se no ponto $C$, designado por ponto crítico: acima da temperatura crítica, as duas fases não se distinguem, não sendo, pois, possível, condensar um gás por maior que seja a pressão aplicada. Designa-se por fluido supercrítico um fluido que se encontre a temperaturas e pressões superiores à do ponto crítico - em tais condições, um fluido apresenta propriedades de solubilidade excepcionais, com imensas aplicações na indústria. Considerando, agora, a fase de sólido, a passagem à fase de liquido designa-se por fusão e a passagem à fase de vapor designa-se por sublimação. Nos sentidos inversos, as passagens de liquido ou vapor a sólido designam-se por solidificação. Cabe, aqui, referir que, no sólido podem existir várias transições entre diferentes fases sólidas, cada uma caracterizada por um diferente arranjo cristalino. 0 mesmo acontece nos cristais líquidos onde ocorrem fases esmética e nemática correspondentes a diferentes orientações dos eixos de moléculas elipsoidais, embora o sistema se comporte como um líquido. 


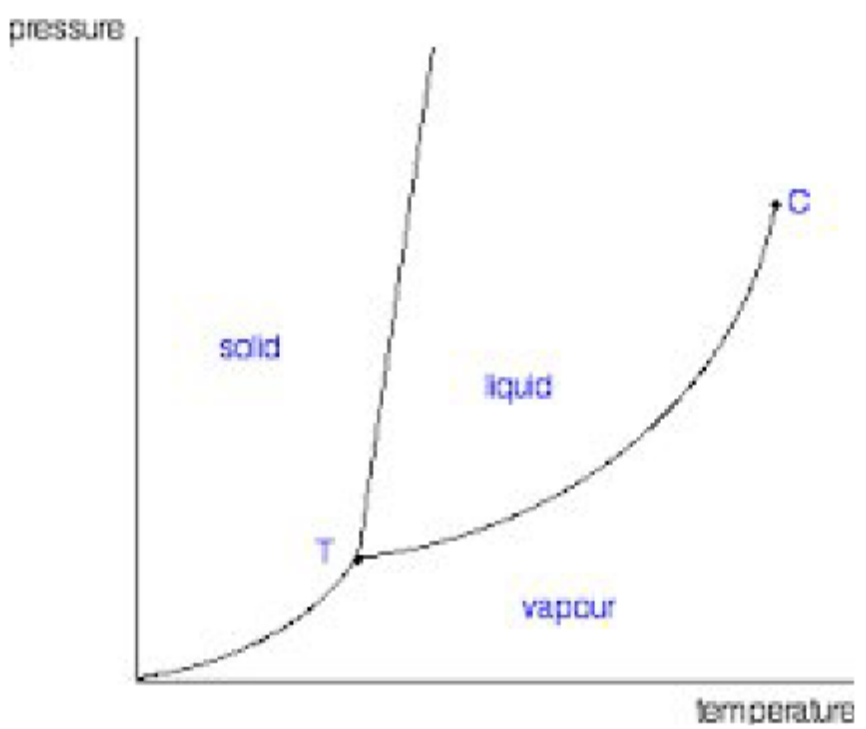

FIGURA 1.

As três linhas encontram-se num ponto $\mathrm{T}$, apropriadamente conhecido por ponto triplo. Para a água (FIGURA 2), por exemplo, o ponto triplo ocorre a $611,66 \mathrm{~Pa}^{1}$ e $0,01 \mathrm{C}$ (ou, exatamente ${ }^{2}, 273,16 \mathrm{~K}$ ), enquanto que o ponto crítico ocorre a 22,064 MPa e $374 \mathrm{C}$ (ou $647 \mathrm{~K}$ ).

Ao longo destas linhas, as transições de fase são de $1^{\text {a }}$ ordem, i.e., há descontinuidade em, pelo menos, uma das primeiras derivadas da energia livre, sendo comum uma descontinuidade da entropia bem patente no aparecimento de calores latentes (de fusão, na transição sólido-líquido; ou de vaporização, na transição líquido-vapor); estas descontinuidades estão relacionadas, pela equação de Clausius-Clapeyron, com o declive da respectiva linha ${ }^{3}$. Contudo, no ponto crítico a transição é de $2^{a}$ ordem, com divergências no calor específico ou na compressibilidade, por exemplo. Nas transições de $1^{\mathfrak{a}}$ ordem, a energia livre, considerada como uma função da densidade, apresenta, para uma dada pressão, apenas um mínimo bem dentro de qualquer das fases: a densidade, para esse mínimo, é a densidade de equilíbrio. Porém, quando o sistema, por variação de temperatura, se aproxima de uma das linhas de transição, surge um segundo mínimo que compete com o primeiro em termos de estabilidade: o mínimo absoluto define a densidade de equilíbrio, enquanto que o segundo mínimo define a densidade para um estado metastável. Esta situação inverte-se quando a linha de transição é cruzada, até que, de novo, a energia livre passa a apresentar, apenas, um mínimo definindo a densidade da outra fase. Na linha de transição, a energia livre é a mesma para os dois mínimos. Assim, junto de cada linha, existe uma região onde uma das fases é absolutamente estável e a outra é metastável, originando, desta forma, fenómenos de sub-arrefecimento ou sobre-aquecimento, bem conhecidos nas transições vapor-líquido e líquido-sólido. No ponto crítico, só há um mínimo da energia livre, em função da densidade, mas junto ao mínimo a energia livre varia muito mais lentamente que no caso das transições de $1^{\mathfrak{a}}$ ordem, originando, dessa forma, grandes flutuações da densidade que determinam grandes flutuações do índice de refração, sendo esta a causa do enorme espalhamento de luz incidente no ponto crítico, fenómeno conhecido por opalescência crítica. 


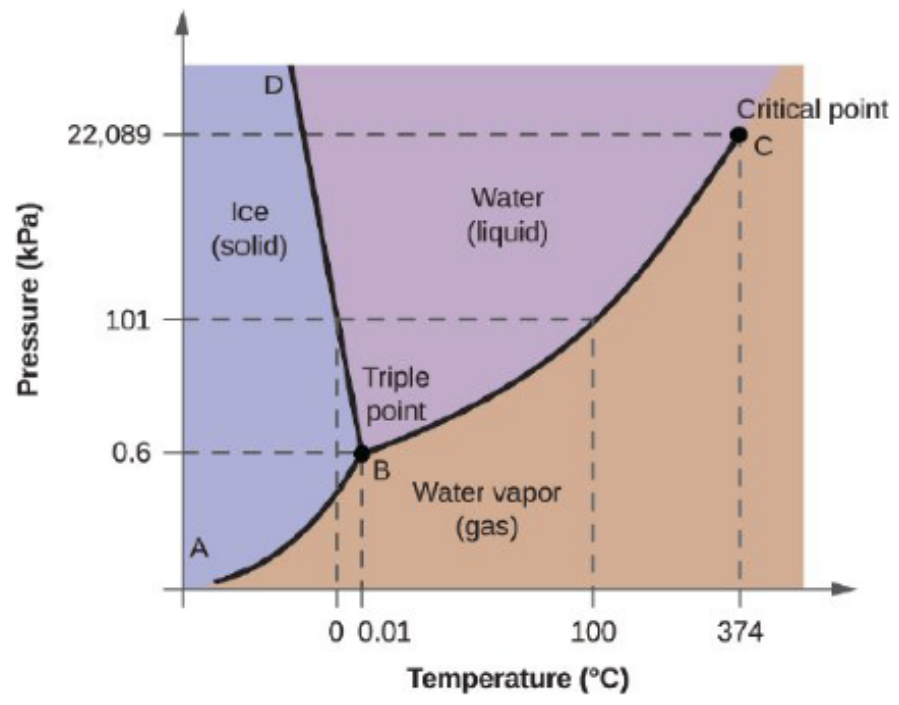

FIGURA 2.

Como se explicam estas fases na teoria atómica? Elas não resultam de qualquer propriedade de um átomo ou molécula, antes emergem de uma enorme colecção destas partículas, da ordem do número de Avogadro ou superior. São, pois, propriedades estatísticas e é assim que, em primeiro lugar, devemos considerar que a temperatura $T$ (absoluta) mede a energia cinética (de translação) média das moléculas $\left\langle E_{c}\right\rangle=\frac{3}{2} K_{B} T$, onde $K_{B}$ é a constante de Boltzmann ${ }^{4}$ ), pelo que aumentar a temperatura significa aumentar a velocidade média das moléculas; e que, em segundo lugar, a pressão resulta das colisões das partículas com as paredes do recipiente, sendo, pois, tanto maior quanto maior for a densidade (i.e., o número de partículas por unidade de volume) e a sua velocidade média. Se pudéssemos ignorar qualquer interacção entre as partículas, esta descrição estatística conduz imediatamente à equação dos gases perfeitos, sendo, assim, de esperar que esse seja o comportamento de qualquer vapor para altas temperaturas e baixas densidades. Contudo, essa interacção não pode ser ignorada se quisermos considerar as diferentes fases que um sistema apresenta. A FIGURA 3 mostra um potencial interatómico típico: existe uma forte repulsão a pequenas distâncias, originada pela repulsão electrónica) que se anula em $R_{\text {min }}$ (da ordem ${ }^{5}$ de 1 ou $2 \AA$ ), seguida por uma fraca atracção que praticamente se extingue após cerca de $5 \AA$ e que é devida a ligações electrostáticas ou covalentes. 0 potencial passa, assim, por um mínimo negativo $\left(\epsilon_{m \dot{m}}\right)$ da ordem de décimas do eV. Posto isto, imaginemos que o sistema se encontra a altas temperaturas e baixas densidades, localizado na fase de vapor (FIGURA 1). Mantendo a temperatura fixa, acima da temperatura crítica, e aumentando a pressão, aumenta a densidade do fluido e, portanto, diminui a distância intermolecular, começando, assim, a fazer-se sentir, cada vez mais, a parte atractiva do potencial, originando a formação de pequenos agregados de partículas que logo se desfazem se a energia cinética (i.e., a temperatura) for suficientemente alta. Abaixo da temperatura crítica, não só os agregados persistem durante mais tempo, porque é menor a velocidade das partículas, como um aumento de densidade, por aumento de pressão, torna estes agregados cada vez maiores e duradouros até que, ao atingir-se a linha de transição gás-líquido, acontece um fenómeno cooperativo: as moléculas estão muito próximas, atraindo-se, embora as suas velocidades sejam ainda demasiado elevadas 
para as fixarem em posições relativas estáveis. Num líquido, a distância intermolecular é da ordem da distância a que ocorre o mínimo do potencial, mas a energia cinética de cada partícula é suficientemente grande para impedir uma ligação estável: cada molécula permanece unida, durante algum tempo, com as suas vizinhas, mas logo se desfaz esta união para voltar a ser realizada com outras vizinhas. Mas se se aumentar ainda mais a pressão, o número de vizinhas começa a estabilizar, como acontece com cada um de nós no meio de uma multidão em movimento desordenado, até que, para densidades mais elevadas e menores velocidades (menor temperatura), ocorre um segundo fenómeno cooperativo: cada molécula acaba por ocupar uma posição média fixa, mantendo também fixo o número das suas vizinhas, situadas à distância média $R_{\min }$ - o sistema entrou no estado sólido que será cristalino se todo o processo, de variação de pressão ou temperatura, ocorrer com suficiente lentidão.

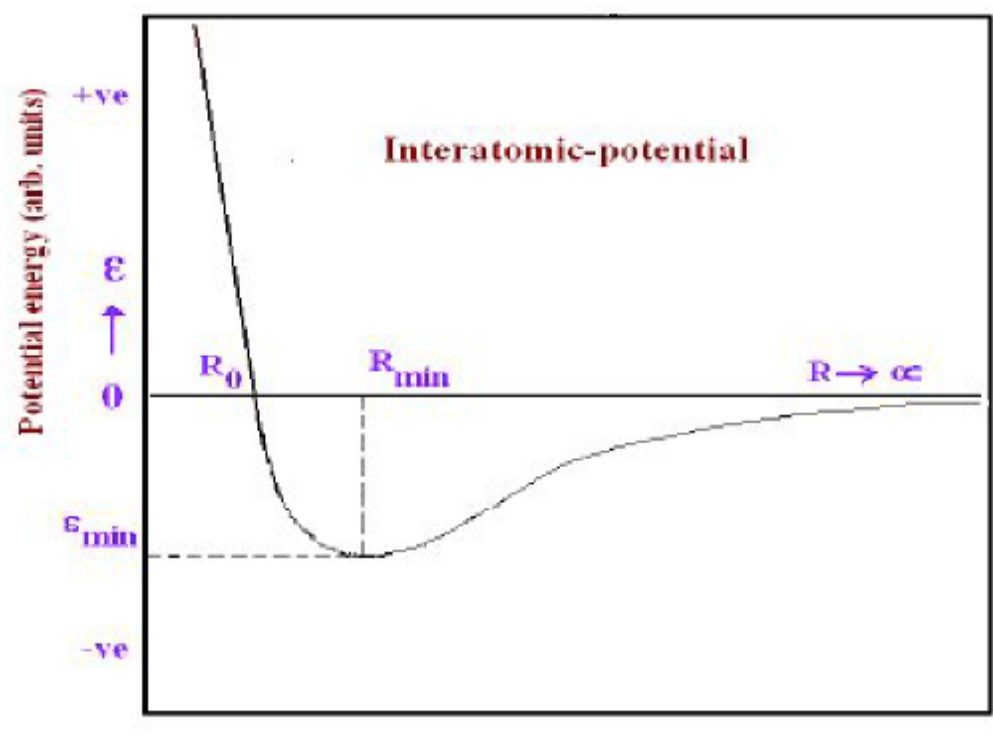

Interatomic distance (arb, units)

FIGURA 3.

O leitor poderá visualizar estas ocorrências usando um simples paliteiro, tal como o da FIGURA 4. Se o número de palitos é pequeno, agitando o paliteiro (análogo da agitação térmica), verá os poucos palitos em movimento desordenado, tal como acontece com as moléculas na fase de vapor. Se aumentar o número de palitos, observará, ainda, que cada palito, individualmente, se desloca por todo o espaço disponível, mantendo, embora, um número mais ou menos fixo de palitos vizinhos que, contudo, não são sempre os mesmos, tal como acontece na fase líquida. Se o paliteiro estiver quase cheio, a agitação pouco efeito produz: cada palito mantém os mesmos vizinhos (análogo do estado sólido) e, na verdade, com o paliteiro repleto, observará uma disposição dos palitos em rede triangular, em analogia com o estado cristalino.

As forças intermoleculares são, ainda, responsáveis pela tensão superficial, a força que se exerce na superfície livre de um fluido ou que limita dois fluidos imiscíveis e que tenta tornar a sua área tão pequena quanto possível. No seio de um fluido, as forças intermole- 
culares têm, em média, resultante nula; mas para moléculas na superfície, surge uma resultante porque as moléculas no interior do fluido puxam as da superfície. 0 mesmo se passa no contacto sólido-líquido, onde ocorre o fenómeno da capilaridade. Uma transição de fase de $2^{a}$ ordem, como a que ocorre no ponto crítico, pode ser reinterpretada como anulamento da tensão superficial.

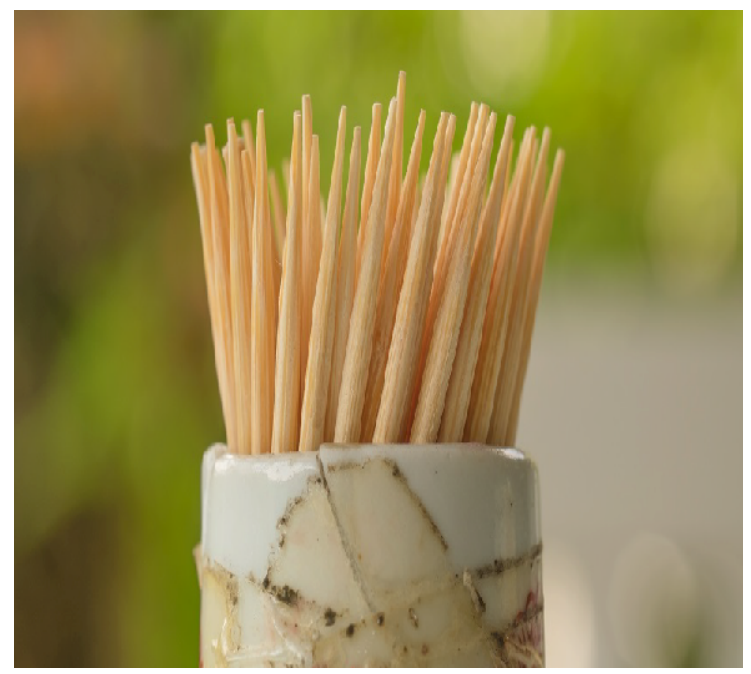

FIGURA 4

Líquidos e vapores, doravante designados por fluidos, distinguem-se, também, de sólidos pelo seu comportamento quando submetidos a tensões tangenciais. Quando a um sólido, em equilíbrio mecânico, se aplicam tais tensões, ele deforma-se até atingir um novo equilíbrio mecânico (FIGURA 5). Esta deformação pode ser caracterizada dividindo o deslocamento de um plano em relação a outro plano, paralelo ao anterior, pela distância inicial entre os planos.

É um número adimensional, em geral muito pequeno, proporcional (lei de Hooke) à tensão (força por unidade de área) tangencial aplicada.

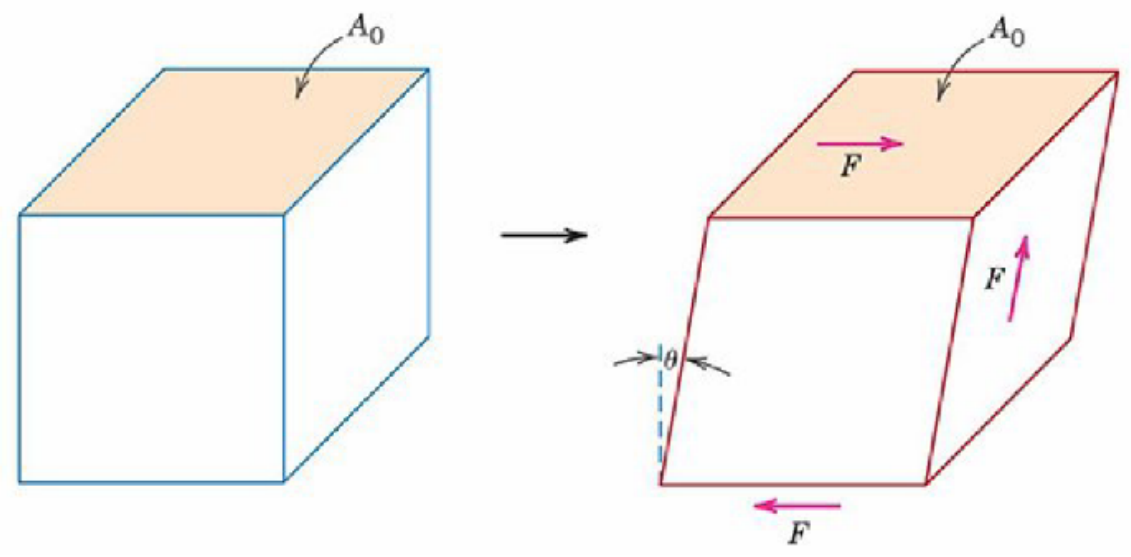

FIGURA 5. 
Um fluido, porém, apresenta um comportamento bem diferente. Se aplicarmos uma tensão tangencial ao plano horizontal que o limita superiormente, mantendo fixo o plano inferior, o fluido entra em movimento, exibindo um campo de velocidades que cresce de baixo para cima (FIGURA 6).

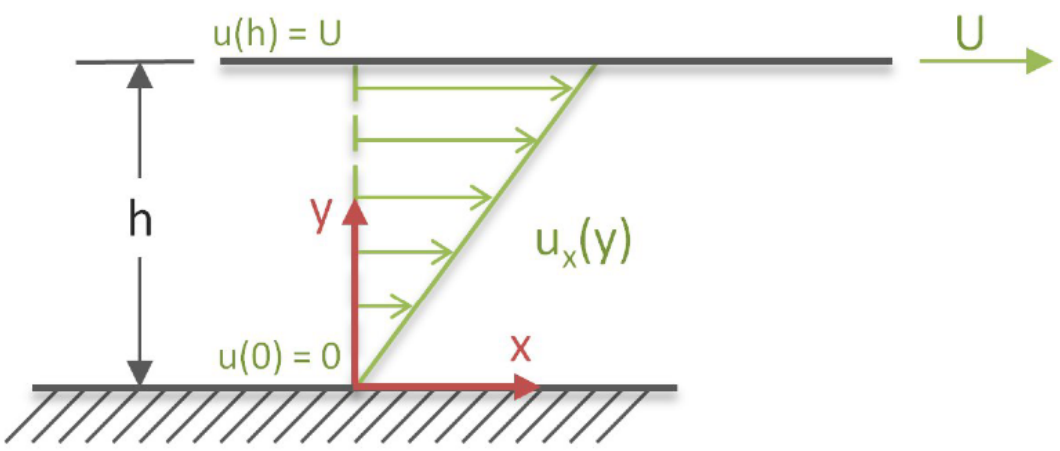

FIGURA 6. ???

Deste modo, a distância entre dois pontos situados em planos horizontais diferentes, cresce no tempo: a deformação, estática no sólido, tem de ser, agora, caracterizada pela diferença de velocidades entre os dois planos dividida pela distância entre eles, pelo que tem as dimensões do inverso do tempo. Mais precisamente, se designarmos por $\boldsymbol{v}_{x}(y)$ o campo de velocidades horizontal, sendo $y$ o eixo vertical, esta taxa de variação da deformação é $\frac{d o_{x}}{d y}$.

Qual a relação entre a tensão aplicada e esta taxa? Poderíamos pensar que seriam proporcionais, por analogia com a lei de Hooke. E, realmente, tal acontece nos fluidos newtonianos ${ }^{6}$ :

$$
\tau=\eta \frac{d b_{x}}{d y}
$$

Aqui, $\tau$ é a tensão tangencial aplicada e a constante de proporcionalidade $\eta$ é designada por coeficiente de viscosidade dinâmica, ou simplesmente viscosidade, do fluido, com unidade ${ }^{7}$ poiseuille $(\mathrm{PL})$, no $\mathrm{SI}$, ou poise $(\mathrm{P})$ no sistema CGS. Mas é, também, muito comum usar-se a viscosidade cinemática $v=\frac{\eta}{\rho}$, onde $\rho$ é a massa específica do fluido, com a unidade $\mathrm{m}^{2} / \mathrm{s}$, no SI, ou stoke (St), no sistema CGS. Qualquer destas viscosidades apresenta fortes variações com a temperatura ou pressão. Alguns exemplos ${ }^{8}$ de viscosidade dinâmica, expressos em $\mathrm{mPl}$ :

\begin{tabular}{|c|c|}
\hline Água & 1,000 \\
\hline Azeite & 84 \\
\hline Benzeno & 0,647 \\
\hline Óleo de parafina & $10^{3}$ \\
\hline Vidro fundido & $10^{15}$ \\
\hline
\end{tabular}

\begin{tabular}{|c|c|}
\hline Ar & $18,3 \times 10^{-3}$ \\
\hline Hélio & $18,6 \times 10^{-3}$ \\
\hline Metano & $10,3 \times 10^{-3}$ \\
\hline Vapor de água & $8,7 \times 10^{-3}$ \\
\hline
\end{tabular}


Note-se que a viscosidade dinâmica de gases ou vapores é cerca de mil vezes inferior à de líquidos, mas como a massa específica daqueles é, também cerca de mil vezes inferior à destes, segue-se que as viscosidades cinemáticas de uns e outros são aproximadamente iguais (excepto para vidros ou óleos). Há, porém, uma distinção importante nas viscosidades de líquidos e gases: aumentando a temperatura (ou a pressão), a viscosidade de líquidos diminui, enquanto a de gases ou vapores aumenta. Adiante, veremos a interpretação microscópica destes fenómenos.

Os exemplos anteriores são todos de fluidos newtonianos, mas há muitos outros exemplos onde a relação entre tensão aplicada e taxa de deformação não segue uma lei linear. Nestes, a tensão depende não linearmente na taxa de deformação ou mesmo na sua "história" - tal acontece com várias soluções salinas, mel, sangue, champô ou pastas dentífricas, etc., não sendo, pois, útil o conceito de coeficiente de viscosidade. A sua caracterização é feita usando outros parâmetros reológicos que não cabe, aqui, especificar. A FIGURA 7 exibe alguns destes comportamentos. No que se segue, só iremos considerar fluidos newtonianos. Mas deverá notar-se, em todos os casos, que a viscosidade é uma forma de atrito interno, gerando libertação de calor e, portanto, manifestando irreversibilidade macroscópica: qualquer fluido, abandonado a si mesmo, acabará por atingir uma situação de equilíbrio onde nenhuma das suas partes (macroscópicas) se movimenta em relação a qualquer outra.

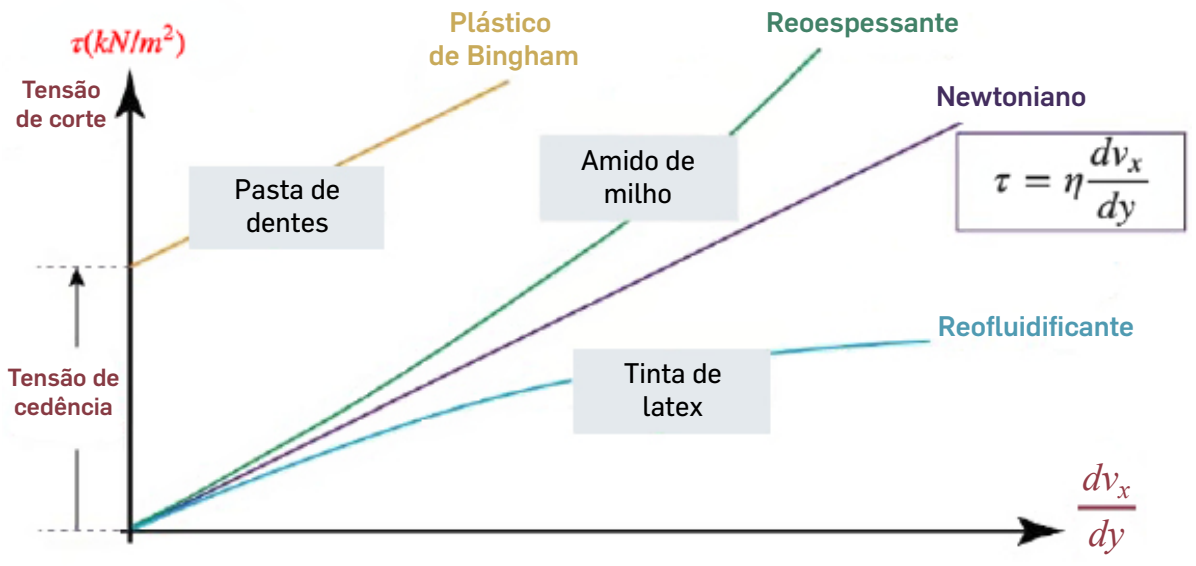

FIGURA 7. Exemplos de fluidos não newtonianos.

Qual a origem microscópica da viscosidade? Comecemos por considerar um gás ou vapor, o que nos permite ignorar, em primeira aproximação, as forças intermoleculares. Considerando a FIGURA 7, as moléculas, em qualquer porção do fluido, têm uma velocidade macroscópica sobreposta à sua agitação microscópica. Imaginemos um plano horizontal no seio do fluido: há moléculas, abaixo deste plano, que passam, num curto intervalo de tempo, para cima, transportando uma quantidade de movimento ligeiramente menor (porque é menor a velocidade macroscópica) que a quantidade de movimento das moléculas acima do plano; no mesmo intervalo de tempo, igual ${ }^{9}$ número de moléculas atravessa o plano de cima para baixo, transportando uma quantidade de movimento ligeiramente maior do que a quantidade de movimento das moléculas abaixo do plano. Deste modo, o fluido acima do plano tende a diminuir a sua quantidade de movimento,i.e, experimenta uma força que o trava; enquanto 
o fluido acima do plano tende a aumentar a sua quantidade de movimento, i.e., experimenta uma força que o acelera. Assim, um aumento de pressão, que faz aumentar a densidade, ou um aumento de temperatura, que faz aumentar a velocidade microscópica e, portanto, aumenta o fluxo de partículas, levam a um aumento da viscosidade (FIGURA 8).

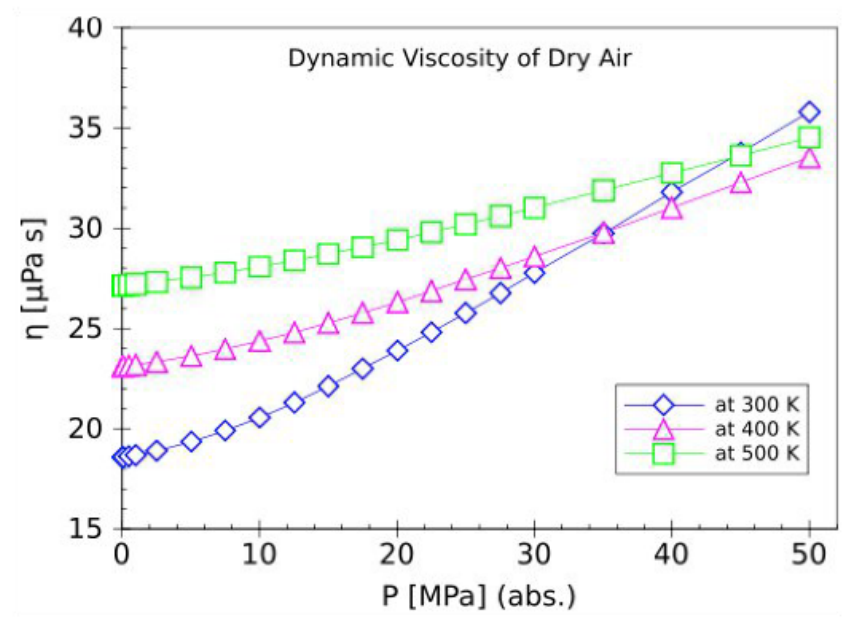

FIGURA 8. ???

Num liquido, a explicação anterior mantém-se, mas não podemos ignorar as forças intermoleculares: a muito maior densidade de um liquido em relação a um gás, significa, por um lado, que é muito maior o número de moléculas a atravessar o plano imaginado, pelo que é muito maior a viscosidade do líquido do que a de um gás, e, por outro lado, justifica que o efeito da pressão na viscosidade seja diminuto, porque um líquido é praticamente incompressível. Porém, um aumento de temperatura, se aumenta, como num gás, o fluxo de partículas, tem, como contrapartida, uma diminuição da importância do potencial intermolecular em relação à energia cinética microscópica, levando o liquido a ter um comportamento mais parecido com o de um gás, i.e., diminuindo a sua viscosidade (FIGURA 9). Note-se a diferença das escalas da viscosidade neste dois gráficos.

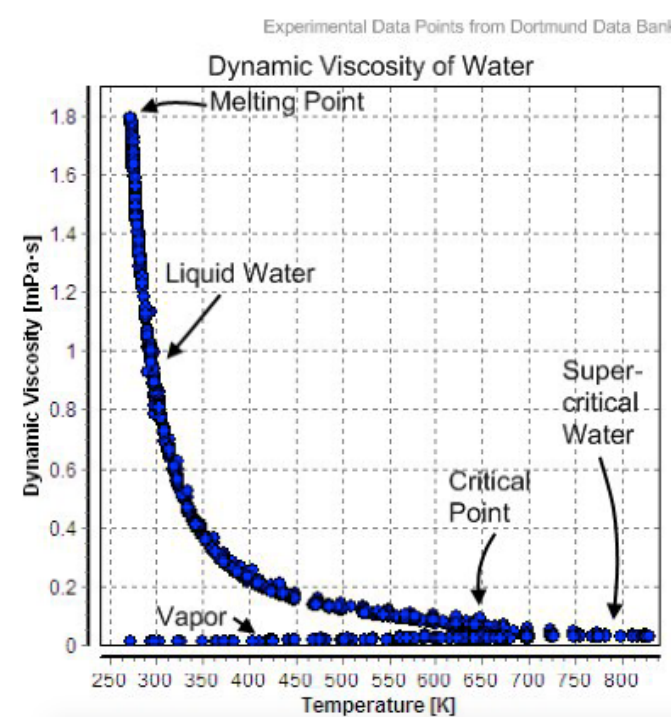


Passaremos, agora, a discutir apenas o comportamento macroscópico de fluidos.

Um fluido em movimento genérico apresenta, sempre, um campo de velocidades ${ }^{10}$, o que nos leva a atribuir uma velocidade a cada ponto do espaço: é a velocidade do fluido naquele ponto e naquele instante. Uma linha de corrente é tangente à velocidade, em cada ponto e no mesmo instante. 0 movimento diz-se permanente se o campo de velocidades não depender explicitamente do tempo: só nestas circunstâncias uma linha de corrente se confunde com a trajectória de uma pequena porção do fluido. Na superfície de contacto de um fluido viscoso com um sólido, a velocidade do fluido, nos pontos de contacto, é igual à velocidade do sólido, i.e., o fluido adere ao sólido; o mesmo se passa no contacto entre fluidos o viscosos imiscíveis: a velocidade é a mesma, em cada ponto de contacto, para os dois fluidos como acontece, por exemplo, no arrastamento de ar por água em movimento ${ }^{11}$. Poderíamos pensar que o movimento de um fluido com muito pequena viscosidade seria bem representado pelo movimento de um fluido perfeito, i.e., sem viscosidade. Contudo, a propriedade de aderência implica que os movimentos destes dois fluidos (viscoso e perfeito) diferem em regiões próximas de um corpo sólido, por exemplo, surgindo, deste modo, o conceito de camada limite no exterior da qual os dois movimentos diferem em, no máximo, $5 \%$. É um conceito muito útil porque nos permite tratar o movimento do fluido viscoso como se fosse um fluido perfeito fora desta camada limite. Voltaremos a este tópico noutra ocasião.

Posto isto, quais são as equações fundamentais que regem o comportamento de um fluido, admitindo, para simplificar, que ele é homogéneo e isotrópico? São, essencialmente, as seguintes, deixando para outras publicações a sua justificação detalhada:

1a A equação de conservação da massa ou equação da continuidade

Ela traduz, simplesmente, que a massa de um pequena porção do fluido é sempre a mesma, ainda que essa porção, no seu movimento, ocupe volumes diferentes. Esta equação escreve- se do seguinte modo ${ }^{12}$ :

$$
\frac{\partial \rho}{\partial t}+\nabla \cdot(\rho \vec{v})=0
$$

onde $\rho$ é a massa específica do fluido e $\vec{v}$ é o campo de velocidades. Se o fluido puder ser considerado incompressível, i.e., com massa específica constante em qualquer circunstância, a equação simplifica-se:

$$
\nabla \cdot \vec{v}=0 \text { (fluido incompressível) }
$$

É óbvio que tem de ser discutida a questão, nada trivial, sobre quando um fluido pode ser considerado incompressível porque alterações de pressão ou temperatura no seio do fluido deverão conduzir, certamente, a alterações da massa específica.

2a A equação fundamental da dinâmica (2ª lei de Newton)

Que forças actuam sobre uma pequena porção do fluido? À superfície da Terra, é evidente que não podemos ignorar a gravidade - ela origina uma densidade volumíca ${ }^{13}$ de força $\rho \vec{g}$, tendo, em casos importantes, que se considerar, também, os efeitos da rotação da Terra ${ }^{14}$ que fazem aparecer forças de Coriolis, como acontece, por exemplo, no estudo 
de ciclones ou tornados. Uma outra força deve-se a diferenças de pressão que, por si sós, fariam mover um fluido das altas para as baixas pressões, o que se traduz numa densidade volumíca de força $-\nabla p$, onde $p$ é o campo de pressões. Outras forças de natureza eléctrica ou magnética podem, também, intervir, mas serão aqui ignoradas, o mesmo acontecendo às forças de Coriolis. Por último, devemos considerar as forças de viscosidade, tal como foram definidas na eq. (1) - no caso de movimentos genéricos, elas conduzem ${ }^{15} \mathrm{a}$ uma densidade volumíca de força representada por $\eta[\Delta \vec{v}+\nabla(\nabla \cdot \vec{v})]$, onde admitimos que o coeficiente de viscosidade $\boxminus$ é constante, uma aproximação bastante crua dada a sua dependência na pressão e temperatura Deste modo, a equação fundamental da dinâmica escreve-se ${ }^{16}$ :

$$
\rho \vec{a}=\rho \vec{g}-\nabla p+\eta[\Delta \vec{b}+\nabla(\nabla \cdot \vec{b})]
$$

Aqui, $Đ$ representa o campo de acelerações, o qual não é simplesmente a derivada em ordem ao tempo do campo de velocidades. Com efeito, para obtermos a aceleração de uma pequena porção de fluido. é necessário seguir esta porção durante um curto intervalo de tempo, dentro do qual ela se desloca de um ponto para outro ponto do espaço nos quais estão identificadas as respectivas velocidades. Deixando a justificação detalhada para outra ocasião, o campo de acelerações deduz-se do campo de velocidades do seguinte modo:

$$
\vec{a}=\frac{\partial \vec{v}}{\partial t}+\vec{v} \cdot \nabla \vec{v} \equiv \frac{d \vec{v}}{d t}
$$

O operador $\frac{d}{d t}=\frac{\partial}{\partial t}+\vec{v} \cdot \nabla$ é a derivada material ou hidrodinâmica: ele mede a taxa de evolução temporal de qualquer grandeza definida na pequena porção de fluido.

Assim, a equação fundamental da dinâmica fica:

$$
\rho\left[\frac{\partial \vec{v}}{\partial t}+\vec{v} \cdot \nabla \vec{v}\right]=\rho \vec{g}-\nabla p+\eta[\Delta \vec{v}+\nabla(\nabla \cdot \vec{v})]
$$

De notar que, em equilíbrio, o campo de velocidades é nulo, não havendo, pois, distinção entre fluidos viscosos e perfeitos (não viscosos).

3ำ A equação de estado

Para qualquer fluido, existe uma relação termodinâmica, muitas vezes empírica, entre a massa específica, a pressão e a temperatura:

$$
\mathrm{f}(\rho, p, T)=0
$$

Por exemplo, para um gás ideal seria $p=\frac{R}{M} \rho T$, onde $M$ é a massa molecular, $R$ a constante dos gases perfeitos e $T$ é a temperatura absoluta. Invocar a equação de estado significa que localmente, i.e., em cada pequena porção do fluido, existe equilíbrio termodinâmico, embora ele possa não se verificar globalmente para todo o fluido.

As eqs. 2-4 são as equações fundamentais para um fluido viscoso. A eq. 3 é designada por equação de Navier-Stokes. Se for ignorado o termo da viscosidade, ela é conhecida 
por equação de Euler que, portanto, descreve fluidos perfeitos. São equações altamente não-lineares, com soluções simples apenas em casos bastante triviais, embora importantes, que serão analisados noutras publicações. Há, ainda, uma complicação adicional para fluidos viscosos: as forças de viscosidade geram calor, não podendo, por isso, ser ignorada a propagação de calor no seio do fluido pelo que se tem, também de considerar o campo de temperaturas. Este campo também tem de ser, em geral, incluído para um fluido perfeito porque alterações de pressão ou densidade originam, pela equação de estado, alterações de temperatura. Esta enorme complexidade matemática ${ }^{17}$ não esconde o vastíssimo leque de aplicações que vão da meteorologia à oceanografia, da acústica à turbulência, dos solitões em rios aos tsunamis, do pingo da torneira à bolha de sabão, e estende-se, mais recentemente, ao estudo de atmosferas e circulação de fluidos em exoplanetas sob condições extremas de pressões ou temperaturas. Mesmo o recurso aos mais potentes computadores para simulações numéricas é, muitas vezes, frustrado pelo fenómeno do caos caracterizado por um afastamento exponencial de soluções originadas por condições iniciais muito próximas. Compreende-se, assim, que os progressos, nos problemas mais complicados, surjam de aproximações mais ou menos justificadas pela definição de números adimensionais, como os números de Reynolds, Prandtl, Mach, Froude, Rayleigh, Taylor, etc., os quais medem a importância relativa de vários termos nas equações fundamentais, servindo, portanto, de guias para simplificações dessas mesmas equações.

\section{Exemplos}

1ํㅡㄴ Consideremos um corpo sólido mergulhado num fluido, estando ambos em repouso. 0 fluido exerce, sobre a superfície do corpo, uma força $-p \vec{n}$ em cada unidade de área, onde $\vec{n}$ é o versor exterior à superfície. Assim, a resultante destas forças de pressão é o integral (soma) sobre toda a superfície:

$$
-\oiint d S p \vec{n}=-\iiint d V \nabla p=-\iiint d V \rho \vec{g}=-M_{\text {fluido }} \vec{g}
$$

Aqui, a primeira igualdade resulta do teorema de Gauss (ou da divergência); a segunda obtém-se da eq. 3 para a situação de equilíbrio; e na última, admitiu-se que a aceleração da gravidade não varia ao longo do corpo, pelo que o integral dá $M_{\text {fluido }}$, a massa de fluido que ocuparia o domínio preenchido pelo corpo. 0 resultado obtido é o conhecido princípio de Arquimedes e aquela resultante é a impulsão que o corpo experimenta no seio do fluido, sendo de sublinhar que ela tem o sentido oposto ao do peso.

2ํㅡㄹ Regressemos a um fluído em equilíbrio: $\rho \vec{g}-\nabla p=0$. As isobáricas são as superfícies onde a pressão tem o mesmo valor. Assim, se considerarmos um pequeno passo $\delta \vec{r}$ tangente à superfície, é nula a variação de pressão, $\delta p=0$. Mas, pela definição do gradiente, é $\delta p=\nabla p \cdot \delta \vec{r}=\rho \vec{g} \cdot \delta \vec{r}=0$ - assim, as isobáricas coincidem com as isopotenciais, superfícies onde o potencial gravítico é o mesmo. Se todo o fluído estiver em equilíbrio térmico, a temperatura é a mesma em todos os pontos - então, a equação de estado impõe que nas isobáricas a massa específica é, também constante, i.e., as isodensas coincidem com as isobáricas. Como varia a pressão no interior do fluido? Comecemos por rescrever a 
equação de equilíbrio sob a forma:

$$
\frac{d p}{d z}=-\rho g
$$

onde se tomou a vertical para eixo $z$. Há dois importantes casos a considerar:

a) Num liquido, como a água, a densidade é praticamente uniforme. Então:

$$
p(0)-p(z)=\rho g z
$$

A diferença de pressões entre dois pontos é igual ao peso do cilindro vertical de liquido imaginado entre aqueles pontos, de bases com área unitária, resultado conhecido por princípio de Pascal.

b) Num gás, como o ar, a massa específica varia com a pressão. Admitamos, para simplificar, que o gás se comporta como gás ideal. $p=\frac{R}{M} \rho T$. Se o gás estiver à mesma temperatura, então a equação de equilíbrio integra-se facilmente:

$$
\frac{d p}{d z}=-\rho g=-\left(\frac{M}{R T}\right) p \quad \rightarrow \quad p(z)=p(0) e^{-\left(\frac{M}{K T}\right) z}
$$

É a lei barométrica, uma expressão aproximada da distribuição de pressões na atmosfera.

3ํㅡㄹ Consideremos o movimento horizontal e permanente de um fluido incompressível tal como representado na FIGURA 6. As linhas de corrente são horizontais, pelo que o campo de velocidades se reduz à componente $v_{x}$ que não pode depender de $x$ pela equação da continuidade: $\frac{\partial v_{x}}{\partial x}=0$. Assim: $v_{x}(y)$ - logo, mantém o seu valor ao longo da mesma linha de corrente, i.e., a aceleração é nula. 0 fluido move-se apenas porque se move o plano superior, i.e., não existe gradiente de pressão na direção horizontal. Assim, a eq. (3), projetada nos eixos $x$ e $y$ dá:

$$
\begin{gathered}
\frac{d^{2}}{d y^{2}} v_{x}=0 \quad \rightarrow \quad v_{x}=A y+B \\
-\frac{\partial p}{\partial y}-\rho g=0 \quad \rightarrow \quad p=-\rho g y+\text { constante }
\end{gathered}
$$

O campo de pressões é, portanto, hidrostático. Quanto à constantes A e B determinam-se pelas condições de aderência aos planos inferior (em repouso) e superior (em movimento uniforme com velocidade $U$ ), obtendo-se:

$$
v_{x}=\frac{U}{h} y
$$

Note-seque, paramanteromovimento do fluido, éaplicadaatensão $\tau=\eta\left(\frac{d v_{x}}{d y}\right)_{y=0}=\eta \frac{U}{h}$ que, portanto, realiza o trabalho, por unidade de tempo e unidade de área (do plano superior) $\tau U=\eta \frac{U^{2}}{h}$. Ora, cada porção do fluido move-se uniformemente, mantendo, pois, constante a sua energia cinética. Assim, aquele trabalho é integralmente convertido em 
calor no seio do fluido.

4ㅇ 0 mesmo fluido, sujeito agora, a um gradiente de pressão horizontal (originado, por exemplo, por uma bomba hidráulica) e contido na mesma geometria mas com os dois planos imóveis. 0 campo de velocidades reduz-se, como antes, à componente $\boldsymbol{v}_{x}(\boldsymbol{y})$. Assim, a eq. 3 origina:

$$
\begin{gathered}
0=-\frac{\partial p}{\partial x}+\eta \frac{d^{2}}{d y^{2}} v_{x} \\
-\frac{\partial p}{\partial y}-\rho g=0
\end{gathered}
$$

Ora, na primeira equação, se derivarmos em ordem a $x$, concluiremos que a $2^{\mathrm{a}}$ derivada da pressão em ordem a $x$, é nula, pelo que $-\frac{\partial p}{\partial x} \equiv C$ é constante, conhecida por perda de carga, que deve ser positiva, i.e., a pressão deve diminuir ao longo do movimento do fluido. Assim, aquela primeira equação integra-se facilmente, determinando-se constantes de integração pelas condições de aderência aos dois planos:

$$
v_{x}=\frac{C}{2 \eta}\left(h^{2}-y^{2}\right)
$$

O campo de pressões fica, então:

$$
p=-\rho g y-C x+\text { constante }
$$

O caudal em volume, por unidade de comprimento na direção transversal (eixo z), é:

$$
Q=\int_{0}^{k} d y v_{x}=\frac{C}{3 \eta} h^{3}
$$

Esta equação é uma forma da lei de Poiseuille adaptada à geometria aqui considerada. Imaginemos um plano vertical na posição $x$ e outro na posição $x+\delta x$. A potência da pressão atuando nestes dois planos, é:

$$
\int_{0}^{k} d y[p(x, y)-p(x, \delta x, y)] v_{x}(y)=-\delta x \int_{0}^{h} d y \frac{\partial p}{\partial x} v_{x}(y)=\delta x C Q
$$

Esta energia, fornecida pelo motor, é integralmente convertida em calor no espaço entre os dois planos.

50 Com a mesma geometria do problema anterior, estudaremos, agora, um fluido perfeito, em movimento permanente e submetido ao mesmo gradiente de pressão horizontal, ignorando-se o peso por simplicidade. Este problema serve para ilustrar a comportamento bem diferente de um fluido perfeito, comparado com o fluido viscoso, quando as condições experimentais são as mesmas. 0 campo de velocidades reduz-se à componente $\boldsymbol{v}_{\boldsymbol{x}}(\boldsymbol{x})$, mas, agora, existe aceleração, pelo que esta componente, apenas, da coordenada $x$. A equação da continuidade determina que $\boldsymbol{\rho} \boldsymbol{v}_{\mathbf{x}}$ deve ser constante, o que, pela definição de caudal, permite escrever:

$$
\rho v_{\mathbf{x}}=\frac{Q}{h}
$$


Observando, agora, a equação de movimento, vemos que ela fica:

$$
\frac{Q}{h} \frac{d v_{x}}{d x}=-\frac{d p}{d x} \quad \rightarrow \quad \frac{Q}{h}\left[v_{x}(x)-v_{x}(0)\right]=p(0)-p(x)=C x
$$

A pressão diminui linearmente para jusante, pelo que a velocidade aumenta linearmente, obrigando a massa específica a diminuir (para manter o caudal). Invocando a equação de estado, que admitiremos ser a do gás ideal, concluímos que a temperatura vai variar:

$$
\frac{R}{M} T(x)=\frac{p(x)}{\rho(x)}=\left(\frac{h}{Q}\right)^{2} p(x)\left[\frac{Q}{h} v(x)+p(0)-p(x)\right]=\left(\frac{h}{Q}\right)^{2}(p(0)-C x)\left(\frac{Q}{h} v_{x}(0)+C x\right)
$$

Assim, a temperatura passará por um máximo se $p(0)>\frac{Q}{h} b_{\mathbf{x}}(0)$, i.e., para alta pressão na origem ou baixo caudal, mas diminuirá sempre se $p(0)<\frac{Q}{h} v_{\mathbf{x}}(0)$. No primeiro caso, o trabalho realizado pelas forças de pressão aquece o fluido até que a diminuição de pressão e o acréscimo de velocidade originam o seu arrefecimento, o que acontece sempre no segundo caso. Este segundo caso é bem conhecido no esvaziamento súbito de um pequeno balão.

Há muitos outros problemas com interesse que serão considerados em futuras publicações. 


\section{CITAÇÃO}

Lage, E. (2018)

Escalares, vetores e tensores

cartesianos,

Rev. Ciência Elem., V6 (04):086.

doi.org/10.24927/rce2018.086

\section{EDITOR}

José Ferreira Gomes,

Universidade do Porto

\section{EDITOR CONVIDADO}

Jorge Manuel Canhoto,

Universidade de Coimbra

\section{RECEBIDO EM}

27 de agosto de 2018

\section{ACEITE EM}

23 de setembro de 2018

\section{PUBLICADO EM}

15 de janeiro de 2019

\section{COPYRIGHT}

(C) Casa das Ciências 2018.

Este artigo é de acesso livre, distribuído sob licença Creative Commons com a designação CC-BY-NC-SA 4.0, que permite a utilização e a partilha para fins não comerciais, desde que citado o autor e a fonte original do artigo.

rce.casadasciencias.org

\section{Escalares, vetores e tensores cartesianos}

\section{Eduardo Lage}

Universidade do Porto

ejslage@gmail.com

Em Física, deparamos muitas vezes com grandezas que, tendo uma definição precisa, são, ou podem ser, diferentemente representadas para observadores distintos. Torna-se, então, necessário estabelecer uma relação entre essas diferentes relações, surgindo assim a caracterização das grandezas como escalares, vetores ou, genericamente, tensores. São, aqui, apresentadas essas relações para observadores que se encontram imóveis (um em relação ao outro) e que cada um usa um sistema tri-rectangular ortonormado de eixos de referência (referenciais cartesianos).

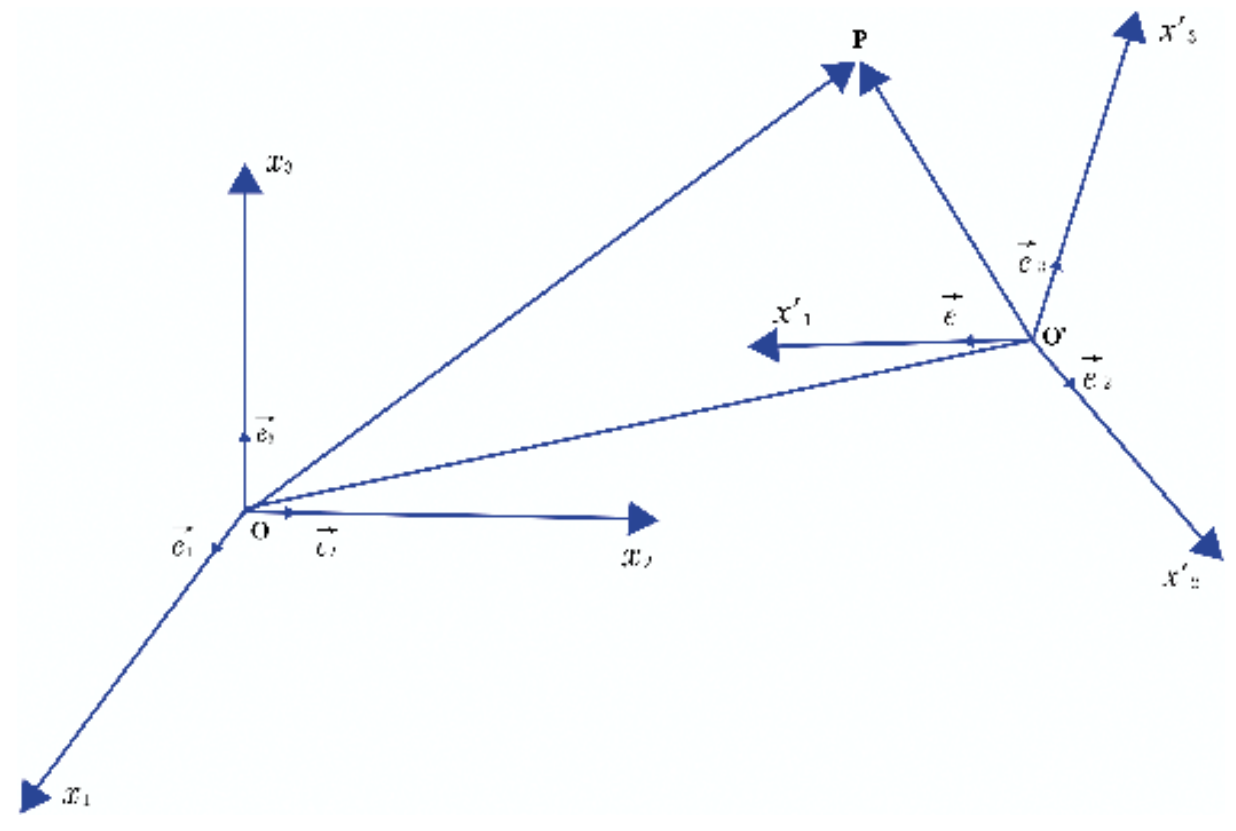

FIGURA 1. Relação entre dois referenciais cartesianos.

A figura mostra os dois sistemas de eixos: para cada observador, os três eixos são ortogonais entre si e, em cada eixo, é definida uma uma unidade de comprimento, comum não 
só aos três eixos de um observador como aos três eixos do outro observador. Tal justifica o adjectivo "ortonormado" atrás utilizado. Note-se que cada eixo se prolonga, como linha recta, indefinidamente e que, em cada um, distâncias, a partir da respetiva origem, são afetadas do sinal (+) nos sentidos indicados pelas setas e do sinal (-) nos sentidos opostos. É, assim, muito conveniente associar, com cada eixo, um vetor unitário (versor) com origem na origem do referencial, apontando no sentido positivo do eixo e de tamanho unitário. Deste modo, em cada referencial fica associada uma base $\left(\overrightarrow{e_{1}}, \overrightarrow{e_{2}}, \overrightarrow{e_{3}}\right)$ que permite univocamente definir, para cada observador, a posição de qualquer ponto no espaço.

Exigiremos, adicionalmente, que os dois sistemas de eixos tenham a mesma orientação. Isso significa o seguinte: se imaginarmos que as origens se sobrepõem ( $\left.O \equiv O^{\prime}\right)$ e alinhar$\operatorname{mos} x_{1}^{\prime} \operatorname{com} x_{1}$ e $x_{2}^{\prime} \operatorname{com} x_{2}$, fazendo coincidir as respetivas partes positivas, então não só $x{ }_{3}$ alinha com $x_{3}$ como também coincidem as respetivas partes positivas. Se, pelo contrário, a parte positiva de $x_{3}$ coincide com a parte negativa de $x_{3}$, diremos que os referenciais têm orientações inversas. Por último, designaremos um sistema de eixos por direto se um saca-rolhas progredir segundo a parte positiva de $x_{3}$ quando roda (de $90^{\circ}$ ) da parte positiva de $x_{1}$ para a parte positiva de $x_{2}$. Se aquela progressão se der para a parte negativa de $x_{3}$, diremos que o sistema de eixos é inverso. É óbvio que os dois referenciais da figura são ambos diretos, tendo, pois, a mesma orientação.

Duas notas:

$1^{\text {a }}$ - É muito comum usar-se a notação $(x, y, z)$ para os eixos, nomeadamente, $x \equiv x_{1} y \equiv x_{2_{1}} z \equiv x_{3}$. É completamente arbitrário usar uma ou outra notação mas, como veremos, há grandes vantagens em utilizar a notação mais simétrica $\left(\boldsymbol{x}_{1}, \boldsymbol{x}_{\mathbf{2}}, \boldsymbol{x}_{\mathbf{3}}\right)$ que será aqui adotada.

$2^{\text {a }}$ - É óbvio que a descrição de uma grandeza física é independente das convenções atrás utilizadas, nomeadamente, a tri-rectangularidade, normalização e orientação dos eixos. $\mathrm{E}$ é possível apresentar uma descrição mais geral, liberta destes constrangimentos e desejável para diversos fins, mas que aqui não cabe fazer.

Regressando à figura, vemos que o mesmo ponto $\mathrm{P}$ tem coordenadas $\left(\boldsymbol{x}_{1}, \boldsymbol{x}_{2}, \boldsymbol{x}_{\mathbf{3}}\right)$ para 0 observador 0 , e $\left(x_{1}^{\prime} x_{{ }_{1}}^{\prime} x_{3}^{\prime}\right)$ para o observador $0^{\prime}$. A mesma figura mostra a relação:

$$
\overrightarrow{O P}=\overrightarrow{O O^{\prime}}+\overrightarrow{O^{\prime} P}
$$

sendo, então:

$$
\begin{aligned}
& \overrightarrow{O P}=x_{1} \vec{e}_{1}+x_{2} \vec{e}_{2}+x_{3} \vec{e}_{3} \equiv x_{i} \vec{e}_{i} \\
& \overrightarrow{O P}=x_{1}^{\prime} \vec{e}_{1}^{1}+x_{2}^{\prime} \vec{e}_{2}^{1}+x_{3}^{1} \vec{e}_{3}^{\prime} \equiv x_{i}^{1} \vec{e}_{i}^{\prime}
\end{aligned}
$$

Aqui, as últimas igualdades mostram já a vantagem da notação simétrica: as duas somas são substituídas por uma notação mais compacta onde o índice repetido indica uma soma (sobre os valores desse índice). 0 índice repetido é designado por índice mudo e pode ser representado por qualquer outra letra, desde que não haja ambiguidades. 
Nas eqs.(2), os três versores são unitários e ortogonais entre si, condições que se resumem na seguinte expressão:

$$
\vec{e}_{i} \cdot \vec{e}_{j}=\delta_{i j} \quad i, j=1,2,3
$$

onde o ponto indica produto escalar e $\delta_{i j}$ é o símbolo de Kronecker:

$$
\delta_{i j}= \begin{cases}1 & \text { se } i=j \\ 0 & \text { se } i \neq j\end{cases}
$$

0 mesmo se passa, evidentemente, com os versores $x_{1_{1}}^{\prime} x_{2_{1}}^{\prime} x_{3}^{\prime}$ do outro observador:

$$
\vec{e}_{i}^{1} \cdot \vec{e}_{j}^{\prime}=\delta_{i j} \quad i, j=1,2,3
$$

Regressando a (1), designemos por $\left(\boldsymbol{x}_{1}, \boldsymbol{x}_{2}, \boldsymbol{x}_{\mathbf{3}}\right)$ as coordenadas (para o observador $\mathrm{O}$ ) do ponto O', i.e.,

$$
\overrightarrow{O O^{\prime}}=x_{i} \vec{e}_{i}
$$

Deste modo, a eq. (1) escreve-se:

$$
x_{i} \vec{e}_{i}=X_{i} \vec{e}_{i}+x_{i}^{1} \vec{e}_{i}^{\prime}
$$

Ora, sendo o espaço tridimensional, as duas bases de representação utilizadas não são independentes. Assim, por exemplo, os versores $\vec{e}_{1_{1}}^{t_{1}} \vec{e}_{{ }_{2}} \vec{e}_{3}^{1_{3}}$ devem escrever-se como combinações lineares de $\overrightarrow{e_{1}}, \overrightarrow{e_{2}}, \overrightarrow{e_{3}}$ :

$$
\vec{e}_{i}^{\prime}=M_{i \dot{v}} \vec{e}_{j}
$$

A matriz $[M]$ estabelece a relação entre as duas bases de representação e é fácil deduzir o significado dos seus elementos. Com efeito, usando as eqs. (3) e (5), obtem-se:

$$
\vec{e}_{i}^{\prime} \cdot \vec{e}_{k}=M_{i j} \vec{e}_{j} \cdot \vec{e}_{k}=M_{i j} \delta_{j k}=M_{i k}
$$

Usando a definição de produto escalar, tem-se:

$$
M_{i k}=\left|\vec{e}_{i}^{\prime} \| \vec{e}_{k}\right| \cos \left(\vec{e}_{i_{1}}^{\prime} \vec{e}_{k}\right)=\cos \left(\vec{e}_{i_{1}}^{\prime} \vec{e}_{k}\right)
$$

Isto é, $M_{i k}$ é o cosseno do ângulo formado pelas partes positivas dos eixos $\boldsymbol{x}^{\boldsymbol{1}_{i}}$ e $x_{k}$, o que justifica a designação de cossenos diretores para os elementos da matriz $[M]$. Deve notar-se que estes nove elementos não são independentes; com efeito, usando as eqs. (4) e (6), tem se:

$$
\vec{e}_{i}^{\prime} \cdot \vec{e}_{j}^{\prime}=\delta_{i j}=M_{i k} \vec{e}_{k} \cdot M_{j n} \vec{e}_{n}=M_{i k} M_{j n} \vec{e}_{k} \cdot \vec{e}_{n}=M_{i k} M_{j n} \delta_{k n}=M_{i k} M_{j k}
$$

onde se invocou a eq. (3). Assim:

$$
M_{i k} M_{j k}=\delta_{i j}
$$


ou, em termos matriciais:

$$
[M I M]^{T}=1
$$

Aqui, o sobrescrito $T$ significa matriz transporta e 1 é a matriz unidade. Estas matrizes dizem se ortogonais, sendo agora fácil obter a relação inversa da eq. (6):

$$
\left[M^{-1}\right]_{k i} \vec{e}_{i}^{\prime}=\left[M^{T}\right]_{k i} \vec{e}_{i}^{\prime}=M_{i k} \vec{e}_{i}^{\prime}=\left[M^{-1}\right]_{k i}[M]_{i j} \vec{e}_{j}=\vec{e}_{k}
$$

Como o determinante de um produto de matrizes é o produto dos respetivos determinantes, e como o determinante de qualquer matriz é igual ao determinante da sua transposta, segue-se que:

$$
\operatorname{det}[M]= \pm 1
$$

Este resultado mostra como distinguir algebricamente a orientação de dois referenciais cartesianos: se $\operatorname{det}[M]=1$, têm a mesma orientação e se $\operatorname{det}[M]=-1$, têm orientações inversas.

Exemplos (considera-se $\mathrm{O} \equiv \mathrm{O}$ ', embora seja irrelevante porque a matriz $[M]$ não depende das origens escolhidas para os eixos)

a) 0 sistema de eixos $\left(\boldsymbol{x}_{{ }_{1}}^{\prime} \boldsymbol{x}_{\mathbf{2}_{1}}^{\prime} \boldsymbol{x}_{3}^{\prime}\right)$ obtem-se de $\left(\boldsymbol{x}_{1}, \boldsymbol{x}_{\mathbf{2}}, \boldsymbol{x}_{3}\right)$ rodando, no sentido direto, de um ângulo $\phi$ em torno do eixo comum $x_{3} \equiv x_{3}^{\prime}$ :

$$
[M]=\left[\begin{array}{ccc}
\cos \phi & \operatorname{sen} \phi & 0 \\
-\operatorname{sen} \phi & \cos \phi & 0 \\
0 & 0 & 1
\end{array}\right] \rightarrow \operatorname{det}[M]=1
$$

b) 0 sistema de eixos $\left(\boldsymbol{x}_{1,}^{\prime} \boldsymbol{x}_{2_{1}}^{\prime} \boldsymbol{x}_{3}^{\prime}\right)$ obtem-se de $\left(\boldsymbol{x}_{1}, \boldsymbol{x}_{2}, \boldsymbol{x}_{3}\right)$ por reflexão especular no plano $\left(\boldsymbol{x}_{\mathbf{2}}, \boldsymbol{x}_{\mathbf{3}}\right)$ :

$$
[M]=\left[\begin{array}{ccc}
-1 & 0 & 0 \\
0 & 1 & 0 \\
0 & 0 & 1
\end{array}\right] \rightarrow \operatorname{det}[M]=-1
$$

Regressando à eq. (1), os resultados obtidos permitem escrever:

$$
x_{i} \vec{e}_{i}=X_{i} \vec{e}_{i}+x_{i}^{\prime} \vec{e}_{i}^{\prime}=X_{i} \vec{e}_{i}+x_{i}^{\prime} M_{i j} \vec{e}_{j}
$$

No último termo, podemos trocar i com j porque são ambos índices mudos (apenas indicam somas!). Com o resultado assim obtido e dada a independência linear dos vetores da base, tem-se, finalmente:

$$
x_{i}=X_{i}+M_{j i} x_{j}^{\prime}
$$




\section{Escalares}

Qualquer função que tenha o mesmo valor para os dois observadores é um escalar. São disso exemplos conhecidos a temperatura (FIGURA 2), a massa ou carga elétrica de um corpo, o volume de um domínio, a área de uma superfície ou o comprimento de uma linha.

\section{OM $36.2 C$}

FIGURA 2. Temperatura, uma grandeza escalar.

Mais geralmente, se se considerar uma função de ponto, i.e., que a cada ponto do espaço associa um número, real ou complexo, essa função (notada aqui por $\psi$ e $\psi$ ' respetivamente pelo observador O e O') é um escalar se e só se:

$$
\psi\left(x_{1}, x_{2}, x_{3}\right)=\psi^{\prime}\left(x_{1}^{\prime}, x_{2,}^{\prime} x_{3}^{\prime}\right)
$$

Deve notar-se que as formas analíticas, i.e., as expressões destas funções são, em geral, diferentes porque têm exatamente que reproduzir o mesmo valor no mesmo ponto do espaço, sendo que tal ponto apresenta coordenadas diferentes para um e outro observadores. Por exemplo, considere-se a rotação de eixos atrás definida: a distância à origem $\mathrm{O}$ de um ponto de coordenadas $\left(x_{1}, 0,0\right)$ é, evidentemente, $\left|x_{1}\right|$. Para o outro observador O' cujos eixos rodaram de $\phi$ em torno do eixo comum $\boldsymbol{x}_{\mathbf{3}} \equiv \boldsymbol{x}_{3}{ }_{3}$, essa mesma distância é expressa por $\sqrt{\left(x_{1}^{\prime} \cos \phi\right)^{2}+\left(x_{2}^{\prime} \operatorname{sen} \phi\right)^{2}}$, uma função analiticamente diferente da anterior mas que garante o mesmo valor numérico quando nelas se substituem as respetivas coordenadas do mesmo ponto do espaço.

\section{Vetores}

A eq. (10) fornece a relação entre as coordenadas do mesmo ponto $P$ para os dois observadores considerados. Imaginemos, agora, um outro ponto $Q$ cujas coordenadas são $\left(y_{1}, y_{2}, y_{3}\right)$ para $\mathrm{O}$, e $\left(y_{1_{1}}^{\prime} y_{2_{1}}^{\prime} y_{3}^{\prime}\right)$ para $\mathrm{O}^{\prime}$. A relação entre estas grandezas é dada pela mesma eq. (10):

$$
y_{i}=X_{i}+M_{j i} y_{j}^{\prime}
$$

Então o segmento orientado $\overrightarrow{P Q}$ é descrito pela diferença das coordenadas dos dois pontos, encontrando-se:

$$
y_{i}-x_{i}=M_{j i}\left(y_{j}^{\prime}-x_{j}^{\prime}\right)
$$


Esta diferença de coordenadas é, pois, independente das origens dos referenciais.

Designa-se por vetor polar, ou simplesmente vetor (FIGURA 3), uma grandeza definida por regras precisas e comuns aos dois observadores, a qual se exprime através de três números ( $\left.A_{1}, A_{2}, A_{3}\right)$ para $\mathrm{O}$ e por outros três números $\left(A_{1_{1}}^{\prime} A_{2_{1}} A_{3}^{\prime}\right)$ para $\mathrm{O}^{\prime}$, de tal forma que a relação entre estes conjuntos de números é exatamente a eq. (12):

$$
A_{i}=M_{j i} A_{j}^{\prime}
$$

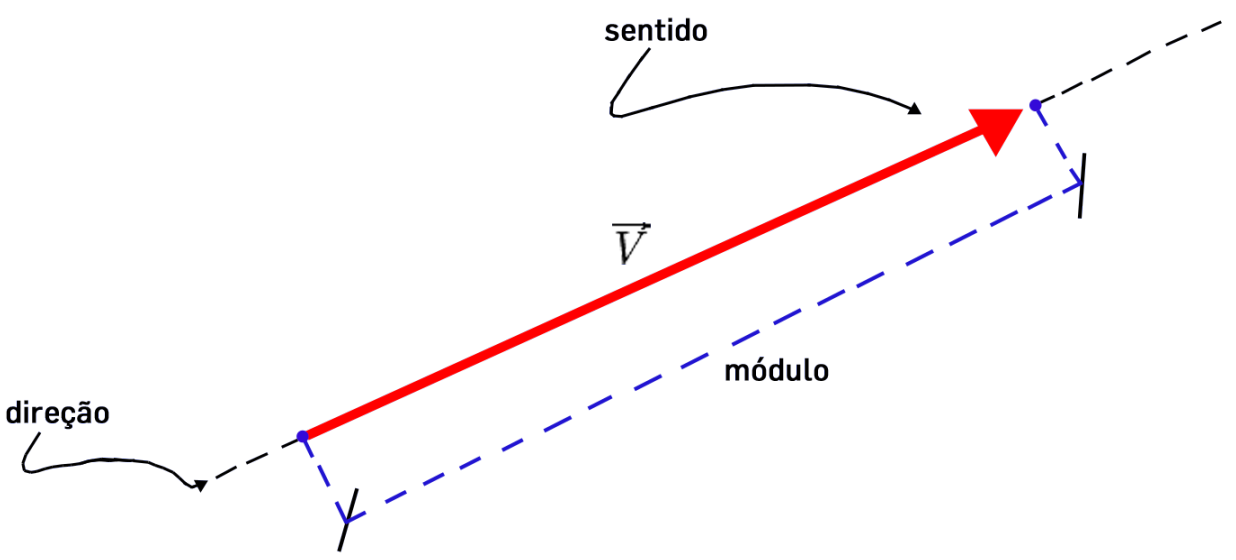

FIGURA 3. Caracterização de um vetor.

Segue-se, pois, que o segmento orientado $\overrightarrow{P Q}$ é um vetor, sendo usada a mesma notação (uma seta sobre a letra) para $\vec{A}$, um vetor de componentes $\left(A_{1}, A_{2}, A_{3}\right)$ para $O$ e ( $A^{\prime}{ }_{1}, A^{\prime}{ }_{21} A^{\prime}{ }_{3}$ ) para O'. Com a eq. (8), a relação (13) pode ser invertida:

$$
A_{i}^{\prime}=M_{\text {ik }} A_{k}
$$

Uma tal grandeza é independente dos observadores, embora, para cada um deles, ela se exprima através de componentes, em geral diferentes para os diferentes referenciais, mas relacionadas pelas eqs. (13) ou (14). São estas leis de transformação que definem um vetor e asseguram a sua independência dos observadores:

$$
\vec{A}=A_{i} \vec{e}_{i}=M_{j i} A_{j}^{\prime} \vec{e}_{i}=A_{j}^{\prime} \vec{e}_{j}
$$

A última igualdade resulta da eq. (6).

A velocidade de um ponto material é, talvez, o exemplo mais conhecido de vetor. Se tal ponto material é o ponto $P$ atrás considerado, as suas coordenadas passam a depender do tempo (um escalar!), obrigando-nos a precisar a eq. (13):

$$
x_{i}(t)=X_{i}+M_{j i} x^{\prime}{ }_{j}(t)
$$

Deve, aqui, observar-se que se admitiu que nem O' se move em relação a $\mathrm{O}$ (as coordenadas $\boldsymbol{X}_{\boldsymbol{i}}$ são fixas), nem o referencial de O’ rodou em relação ao referencial de O (a 
matriz $[M]$, dos cossenos diretores, é também independente do tempo). 0 observador $\mathrm{O}$ define a velocidade do ponto material pelo conjunto $\left(\frac{d x_{1}}{d t}, \frac{d x_{2}}{d t}, \frac{d x_{3}}{d t}\right)$ e o observador $\mathrm{O}$ 'define a velocidade do mesmo ponto por $\left(\frac{d x_{1}^{\prime}}{d t}, \frac{d x_{2}^{\prime}}{d t}, \frac{d x_{3}^{\prime}}{d t}\right)$. Ora, derivando, em ordem ao tempo, a equação anterior, obtemos:

$$
\frac{d x_{i}}{d t}=M_{j i} \frac{d x_{j}^{\prime}}{d t}
$$

Comparando com a eq. (13), estas derivadas definem um vetor, a velocidade $\vec{v}$ do ponto material cujas componentes são $\left(\frac{d x_{1}}{d t}, \frac{d x_{2}}{d t}, \frac{d x_{3}}{d t}\right)$, para o observador $\mathrm{O}, \mathrm{e}\left(\frac{d x_{1}^{\prime}}{d t}, \frac{d x_{2}^{\prime}}{d t}, \frac{d x_{3}^{\prime}}{d t}\right)$ para o observador O'. Derivando, novamente, a equação anterior, definimos um novo vetor, a aceleração $\vec{a}$ do ponto material.

Há muitos outros exemplos de vetores em Física: a intensidade do campo gravítico $\vec{G}$, a intensidade do campo elétrico $\vec{E}$, a densidade de corrente elétrica $\vec{l}$, etc.. Em todos eles, existe uma definição precisa que origina três números para um observador e outros três números para outro observador, sendo que estes conjunto de números estão relacionados pela eq. (13).

Usando a eq. (13) podemos definir duas outras importantes grandezas. Consideremos um outro vetor $\overrightarrow{\boldsymbol{B}}$, com componentes $B_{i}$, para o observador O, e $\boldsymbol{B}^{\prime}$, para o observador O'. Então:

$$
B_{i}=M_{j i}=B_{j}^{\prime}
$$

Efetuemos o produto contraído $A_{i} B_{i}$ e vejamos como ele se transforma:

$$
A_{i} B_{i}=\left(\begin{array}{lll}
M_{j i} & A_{j}^{\prime}
\end{array}\right)\left(M_{k i} B_{k}^{\prime}\right)=M_{j i} M_{k i} A_{j}^{\prime} B_{k}^{\prime}=A_{j}^{\prime} B_{j}^{\prime}
$$

Aqui, a última igualdade resultou da eq.(8). Quer dizer, o produto contraído de dois vetores é um escalar e,na verdade, reconhece-se o produto escalar dos dos vetores na eq. (15). 0 caso particular $\overrightarrow{\boldsymbol{A}}=\overrightarrow{\boldsymbol{B}}$ define um escalar importante: o quadrado da grandeza do vetor $\overrightarrow{\boldsymbol{A}}$, soma dos quadrados das suas componentes. exemplos de produtos escalares abundam em Física: o trabalho realizado por uma força ou a sua potência, o calor libertado por efeito Joule, etc..

Outro caso importante resulta de se considerar uma função escalar tal como foi definida na eq. (11). Diferenciando ambos os membros daquela equação, obtemos a seguinte igualdade escalar:

$$
\frac{\partial \psi}{\partial x_{i}} d x_{i}=\frac{\partial \psi^{\prime}}{\partial x_{j}^{\prime}} d x_{j}^{\prime}
$$

Ora, reconhecemos, em cada um dos membros, as componentes do vetor deslocamento infinitesimal $\overrightarrow{d r}$, aparecendo, então, quer o 1 을 membro quer o 20 membro como um produto escalar, o que nos faz suspeitar que $\frac{\partial \psi}{\partial x_{i}}$ e $\frac{\partial \psi^{\prime}}{\partial x_{j}^{\prime}}$ são componentes do mesmo vetor para um e outro observadores. Podemos confirmar que assim é recorrendo à lei de transformação do vetor $\overrightarrow{d r}$. Usando a eq. (14), tem-se:

$$
\frac{\partial \psi}{\partial x_{i}} d x_{i}=\frac{\partial \psi^{\prime}}{\partial x_{i}^{\prime}} M_{j i} d x_{i}
$$


Como as componentes do vetor deslocamento são arbitrárias e independentes, resulta:

$$
\frac{\partial \psi}{\partial x_{i}} d x_{i}=\frac{\partial \psi^{\prime}}{\partial x_{j}^{\prime}} M_{j i}
$$

que é a lei de transformação de um vetor (cf. eq. 13). Reconhecemos, aqui, o gradiente da função escalar:

$$
\nabla \psi=\frac{\partial \psi}{\partial x_{i}} \vec{e}_{i}=\frac{\partial \psi^{\prime}}{\partial x_{j}^{\prime}} \vec{e}_{j}^{\prime}=\nabla^{\prime} \psi^{\prime}
$$

Note-se bem o significado deste resultado: um e outro observador definem os gradientes das suas funções, analiticamente diferentes, para concluírem que os vetores assim obtidos são iguais.

Recorda-se, rapidamente, que o vetor $\nabla \psi$ é normal, em cada ponto, às superfície $\psi=c=c o n s t$ e que o seu sentido indica o sentido do crescimento da função, fornecendo, inclusivamente, a distância de um ponto destas superfícies a outra, muito próxima (onde a constante toma o valor $c+d c$ ), através de $d c /\lceil\nabla \psi\rceil$. Estes resultados obtêm-se diretamente das equações acima.

\section{Tensores}

Regressando aos vetores (arbitrários) $\vec{A}$ e $\vec{B}$ atrás considerados, iremos agora estudar como se transforma o produto $A_{i} B_{j}$, notando que aqui se definem nove termos independentes.

O segundo observador também define as nove quantidades $A_{i}^{\prime} B^{\prime}{ }_{j}$. Ora, usando a eq. (14), obtemos:

$$
A_{i} B_{j}=\left(M_{k i} A^{\prime}{ }_{k}\right)\left(M_{n j} B_{n}^{\prime}\right)=M_{k i} M_{n j} A_{k}^{\prime} B_{n}^{\prime}
$$

Definimos, agora, um tensor (cartesiano) de $2^{\text {a }}$ ordem como um conjunto de nove números, definidos por regras precisas, quer para o primeiro observador (designemo-los por $\left.T_{i j}\right)$ quer para o segundo $\left(T_{i j}^{\prime}\right)$, os quais estão relacionados como na eq. (17), i.e.,

$$
T_{i j}=M_{k i} M_{n j} T^{\prime}
$$

É esta, então, a lei de transformação de um tensor de $2^{\mathrm{a}}$ ordem. Há muitos exemplos em Física de tais tensores: o tensor de inércia, na mecânica do sólido rígido; os tensores das tensões (FIGURA 4) e das deformações, na mecânica do sólido deformável; os tensores permitividade elétrica e permeabilidade magnética, bem como o tensor de Maxwell, no eletromagnetismo; etc.. Cada uma destas grandezas tem uma definição precisa para um e outro observador, mas para todos eles a lei de transformação é a eq. (18). 


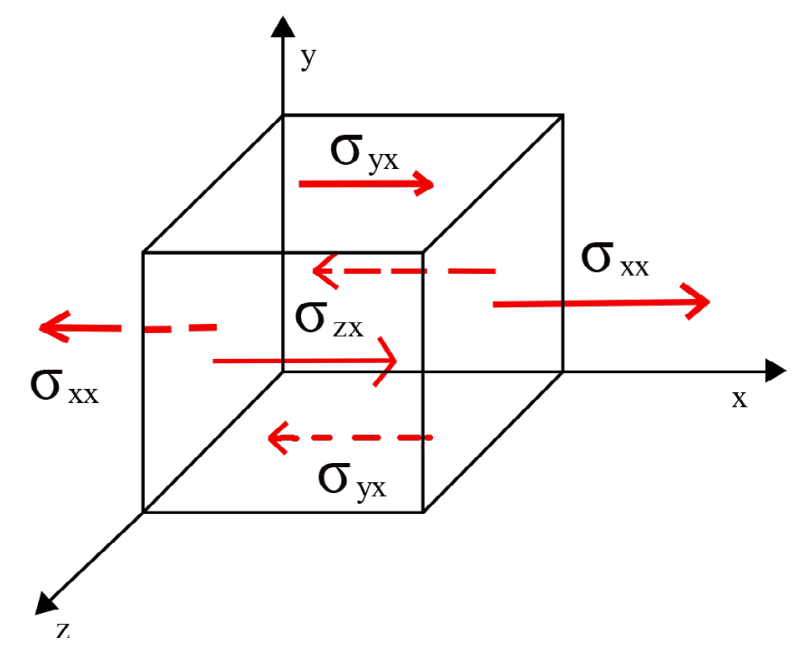

FIGURA 4. 0 tensor das tensões: $\boldsymbol{\sigma}_{\mathbf{y x}}$ é a componente, segundo x, da tensão (vetor) que atua sobre uma superfície normal a $y$.

Por esta mesma razão, a matriz [M], embora com dois índices, não é um tensor porque ela respeita à relação entre eixos de dois observadores.

Várias propriedades importantes e gerais deduzem-se facilmente a partir da eq. (18).

1a Contraíndo os índices $i$ e $j$ (i.e., igualando-os e somando sobre os seus três valores possíveis), vem:

$$
T_{i i}=M_{k i} M_{n i} T_{k n}^{\prime}=\delta_{k n} T_{k n}^{\prime}=T_{i k}^{\prime}
$$

A contração dos índices, designada por traço do tensor, define um escalar.

$2^{\text {a }}$ Multipliquemos ambos os membros da eq. (14) por um vetor $\boldsymbol{w}_{j}$, efetuando a contração deste índice:

$$
T_{i j} w_{j}=M_{k i} M_{n j} T_{k n}^{\prime} w_{j}
$$

No $2^{\circ}$ membro, reconhecemos a soma $\boldsymbol{M}_{n j} \boldsymbol{w}_{j}=\boldsymbol{w}_{n}^{\prime}$, pela eq. (14). Assim:

$$
T_{i j} w_{j}=M_{b i} T_{b}^{\prime} w_{n}^{\prime}
$$

Comparando com a eq. (13), vemos que $T_{i j} \boldsymbol{w}_{j}$ define um vetor: a contração de um tensor de $2^{\mathrm{a}}$ ordem por um vetor dá um vetor. Pode-se provar o resultado inverso: suponhamos que temos definidas 9 quantidades $T_{i j}$ para o observador $O$ e outras nove quantidades $T_{k}^{\prime}$ para o observador O'. Se a equação anterior for verificada qualquer que seja o vetor $\overrightarrow{\boldsymbol{w}}$, podemos concluír que aquelas quantidades definem um tensor de $2^{a}$ ordem. É importante, na demonstração, a arbitrariedade do vetor. Um exemplo, aparentemente inesperado, é fornecido pelo símbolo de Kronecker, atrás definido. Admitamos, então, que $T_{i j}=\delta_{i \bar{i}}$ e, também, $T_{k n}^{\prime}=\delta_{k n}$. 
Inserido na equação anterior, obtem-se:

$$
w_{i}=M_{k i} w_{k}^{\prime}
$$

Mas esta é a lei de transformação do vetor arbitrário $\vec{w}$. Então, concluímos que o símbolo de Kronecker é um tensor de $2^{\mathrm{a}}$ ordem. Vejamos como se transforma: usando a genérica eq. (18), onde se identifica $T^{\prime}{ }_{k n}=\delta_{k n}$ no $2^{\circ}$ membro, obtemos:

$$
M_{b i} M_{n j} \delta_{b j}=M_{k i} M_{k j}=\delta_{i j}
$$

onde se recordou a eq. (8). Quer dizer, o símbolo de Kronecker, como tensor de $2^{\mathrm{a}}$ ordem, tem a mesma forma para todos os observadores - diremos que é um tensor isotrópico.

3a Um tensor de $2^{\text {a }}$ ordem é simétrico ou antissimétrico se satisfizer, respetivamente, $S_{i j}=S_{j i}$ ou $A_{i j}=-A_{j i}$. É fácil ver que, no primeiro caso, o tensor tem seis elementos independentes e, no $2^{\circ}$ caso, apenas três. Como se transformam estes tensores?

Começando pelo simétrico, tem-se:

$$
M_{k i} M_{n j} S_{k t}^{\prime}=M_{k i} M_{n j} S_{n k}^{\prime}=M_{n i} M_{k j} S_{b n}^{\prime}
$$

Aqui, a $2^{\mathrm{a}}$ igualdade é obtida trocando os índices mudos $k$ e $n$. 0 resultado final mostra que a simetria de um tensor é mantida na transformação. Consideremos, agora, a transformação de um tensor antissimétrico:

$$
M_{k} M_{n j} A_{k n}^{\prime}=-M_{k i} M_{n j} A_{n k}^{\prime}=-M_{n i} M_{k j} A_{k n}^{\prime}
$$

Aqui, procedemos, como antes, na troca dos índices mudos. A conclusão é a mesma: a antisimetria de um tensor é mantida pela sua lei de transformação.

Quer isto dizer que as simetria ou anti-simetria de um tensor (de $2^{\text {a }}$ ordem) são propriedades invariantes do tensor, verificadas por qualquer observador. Um exemplo evidente é o símbolo de Kronecker, um tensor simétrico.

4a Vale a pena considerar com mais pormenor o caso de um tensor antissimétrico. Designemos as suas três entradas independentes da seguinte maneira:

$$
\begin{aligned}
& \Omega_{1} \equiv-A_{23}=A_{32} \\
& \Omega_{2} \equiv-A_{31}=A_{13} \\
& \Omega_{3} \equiv-A_{12}=A_{21}
\end{aligned}
$$

Ora, sendo $A_{i j}$ um tensor e sendo $\vec{w}$ um vetor polar qualquer, então, como vimos, $C_{i}=A_{i j} w_{j}$ é um vetor polar. Explicitando as suas componentes, encontramos:

$$
\begin{aligned}
& C_{1}=A_{12} w_{2}+A_{13} w_{3}=-\Omega_{3} w_{2}+\Omega_{2} w_{3} \\
& C_{2}=A_{21} w_{1}+A_{23} w_{3}=\Omega_{3} w_{1}-\Omega_{1} w_{3} \\
& C_{3}=A_{31} w_{1}+A_{32} w_{2}=-\Omega_{2} w_{1}+\Omega_{1} w_{2}
\end{aligned}
$$


Reconhecemos os segundos membros como as componentes de um produto vetorial o qual se escreve na sua forma habitual:

$$
\vec{C}=\vec{\Omega} \times \vec{w}
$$

como se $\left(\Omega_{1_{1}} \Omega_{2} \Omega_{3}\right)$ fossem as componentes de um vetor $\vec{\Omega}$. Contudo, $\vec{\Omega}$ não é um verdadeiro vetor (polar) porque aquelas componentes são, realmente, componentes de um tensor antissimétrico. Designa-se $\vec{\Omega}$ por vetor dual do tensor antissimétrico ou, mais habitualmente, por pseudo-vector ou vetor axial. Podemos verificar que $\vec{\Omega}$ se transforma, realmente, de maneira oposta à de um vetor polar considerando o exemplo simples da reflexão no plano $x_{2} x_{3}$ atrás considerada (FIGURA 5).
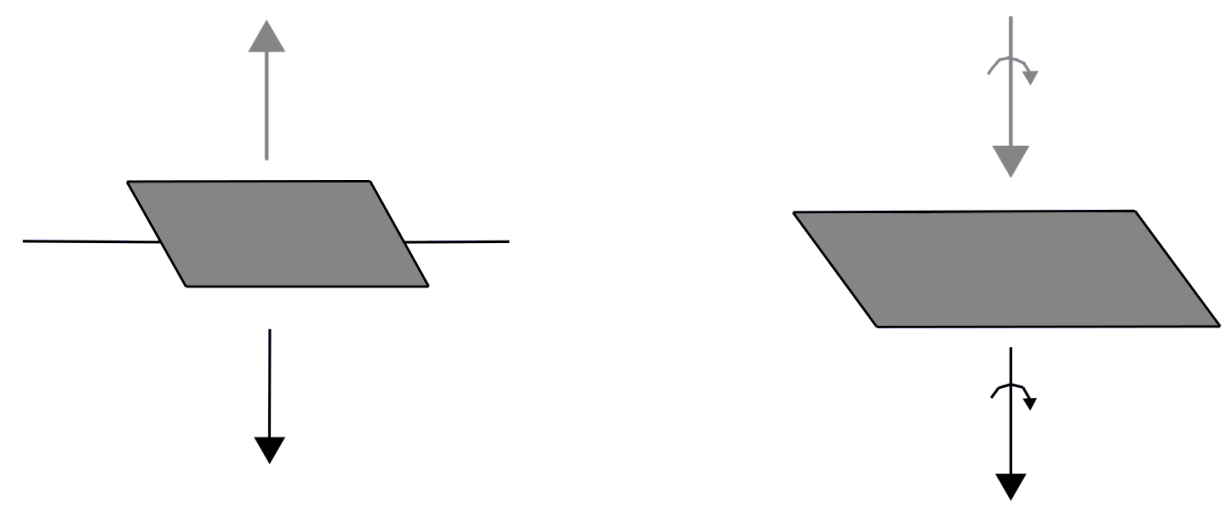

FIGURA 5. Reflexão, no plano sombreado, de um vetor polar (à esquerda) e de um vetor axial (à direita).

Usando a eq. (18) para a transformação do tensor $A_{i j}$, com a matriz [M] escrita naquele exemplo, obtemos:

$$
\begin{aligned}
& \Omega_{1} \equiv-A_{23}=-M_{22} M_{33} A_{\mathrm{m}}^{\prime}=-A_{23}^{\prime}=\Omega_{1}^{\prime} \\
& \Omega_{2} \equiv-A_{31}=-M_{k 3} M_{21} A_{\mathrm{m}}^{\prime}=-A_{31}^{\prime}=-\Omega_{2}^{\prime} \\
& \Omega_{3} \equiv-A_{12}=-M_{21} M_{22} A_{\mathrm{m}}^{\prime}=A_{12}^{\prime}=-\Omega_{1}^{\prime}
\end{aligned}
$$

Compare-se com a transformação de um vetor polar, $\overrightarrow{\boldsymbol{w}}$, por exemplo, que se obtem da eq. (13):

$$
\begin{aligned}
& w_{1}=M_{j 1} \quad w_{j}^{\prime}=-w_{1}^{\prime} \\
& w_{2}=M_{j 2} w_{j}^{\prime}=w_{2}^{\prime} \\
& w_{3}=M_{j 3} w_{j}^{\prime}=w_{3}^{\prime}
\end{aligned}
$$

Um exemplo simples: imaginemos um pião a girar, no sentido direto, com o seu eixo dirigido segundo $x_{1}$. 0 seu vetor rotação instantânea estará dirigido segundo este mesmo eixo. Veja-se a imagem no "espelho" $x_{2} x_{3}$ - é um pião a girar no mesmo sentido, pelo que é idêntico o seu vetor rotação instantânea. Mas se dermos um passo em direção ao espelho, a nossa imagem dará um passo em sentido contrário - o deslocamento definido pelo passo é um verdadeiro vetor.

No entanto, é verdade que, para transformações entre referenciais com a mesma orien- 
tação, um vetor axial se comporta como um vector polar. É fácil verificar esta afirmação, repetindo os cálculos anteriores mas usando a matriz $[M]$ definida para o outro exemplo considerado atrás (rotação de eixos).

Voltando à eq. (20), recordamos que ela apenas reescreveu uma relação tensorial envolvendo o vetor $\vec{w}$ e o tensor antissimétrico $A_{i j}$, conduzindo a contração obtida, necessariamente, a um verdadeiro vetor $\vec{C}$ (ver eq. 20). Assim, nesta equação, somos obrigados a concluir que o produto vetorial de um pseudo-vetor por um vetor polar conduz a um vetor polar. Alternativamente, o produto vetorial de dois vetores polares ou de dois pseudo-vetores resulta necessàriamente num vetor axial.

São muitos os exemplos em Física onde intervêm pseudo-vetores. São assim o momento cinético de uma partícula ou o (pseudo) vetor rotação instântanea de um sólido rígido, o campo magnético ou o momento magnético em eletromagnetismo, etc.. É de salientar que tais pseudo-vectores surgem em definições apropriadas mas acabam por aparecer em novos produtos vetoriais gerando, assim, verdadeiros vetores (por exemplo, o campo magnético dado pela lei de Biot-Savart faz-se sentir pela força de Lorentz - ambas as expressões contêm produtos vetoriais).

4a Será, agora, óbvio que o produto escalar de um vetor por um pseudo-vector, por exemplo, $\vec{\Omega} \cdot \overrightarrow{\boldsymbol{w}}$ tal como referidos acima. não é um verdadeiro escalar, dada a diferente lei de transformação dos termos nele presentes: é realmente um pseudo-escalar e como tal designado. Contudo, o produto escalar de dois pseudo-vectores é um verdadeiro escalar, de que são exemplos a potência de um sólido em rotação (produto escalar do seu momento cinético pelo pseudovector rotação instantânea) ou a energia de um magneto submetido a um campo magnético (produto escalar do seu momento magnético pela intensidade do campo magnético).

\section{REFERÊNCIAS}

${ }^{1}$ SPIEGEL, M. R., et al., Vector analysis. Schaum's Outlines ( $2^{\text {a }}$ ed.). McGraw Hill, 2009. ISBN 978-0-07$161545-7$

2 JEFFREYS, H., Cartesian Tensors. The University Press, 1961.

${ }^{3}$ TEMPLE, G. F. J., Cartesian Tensors: An Introduction. Dover Books on Mathematics Series. DOVER PUBN Incorporated, 2004. ISBN 0-4864-3908-9.

${ }^{4}$ SYNGE, J. J. L. \& SCHILD, A., Tensor Calculus. Courier Dover Publications, 1978. ISBN 0-4861-4139-X 